\title{
AN ANALYSIS OF FRESH, MECHANICAL AND DURABILITY PROPERTIES OF LIGHTWEIGHT SELF- CONSOLIDATING FIBER REINFORCED CONCRETE
}

\author{
By \\ Imge Nicole Celasun \\ BEng, Ryerson University, 2015
}

\author{
A MRP \\ presented to Ryerson University \\ In partial fulfillment of the \\ requirements for the degree of \\ Master of Engineering \\ In the Program of Civil Engineering
}

Toronto, Ontario, Canada, 2017

(C) Imge Nicole Celasun 2017 


\section{Author's Declaration}

AUTHOR'S DECLARATION FOR ELECTRONIC SUBMISSION OF A MRP

I hereby declare that I am the sole author of this MRP. This is a true copy of this MRP, including any required final revisions.

I authorize Ryerson University to lend this MRP to other institutions or individuals for the purpose of scholarly research

I further authorize Ryerson University to reproduce this MRP by photocopying or by other means, in total or in part, at the request of other institutions or individuals for the purpose of scholarly research.

I understand that my MRP may be made electronically available to the public. 


\section{Abstract \\ An Analysis of Fresh, Mechanical and Durability Properties of Lightweight Self-Consolidating Fiber Reinforced Concrete Imge Nicole Celasun}

\section{7, Master of Engineering, Department of Civil Engineering, Ryerson University}

This research investigated the fresh, mechanical and durability behavior of lightweight selfconsolidating fiber reinforced concrete (LWSCFRC) with four different fibers (Polyethylene, Polyvinyl Alcohol, High-Density Polyethylene and Crumb Rubber). Two LWSCFRC mixtures were created for each fiber to analyze the effects of increasing fiber content on fresh state properties: slump flow and density. Mechanical and durability tests included compressive/ flexural strength, rapid chloride permeability and resistance to acid attack. The increase in fiber content decreased the workability of LWSCFRC mixtures except for crumb rubber. Flexural strength of all LWSCFRC specimens was similar compared to their control counterparts, while crumb rubber exhibited the highest compressive strength from all fiber specimens. Addition of fibers resulted in good resistance against chloride ion penetration but compressive strength of specimens in a $5 \%$ sulfuric acid solution decreased. Overall, 1.0\% Crumb Rubber performed better in fresh, mechanical and durability testing from all the fiber specimens. 


\section{Acknowledgements}

I would like to express my deepest gratitude to my supervisor, Dr. Khandaker. M. Anwar Hossain, for his excellent guidance, support and patience during the development of this research project. He provides me opportunities to learn while gaining experience through his effective training. Without his time and countless efforts, this work would not have been completed. A special thank you to Research Assistant Adam Culpeper for his great efforts in all aspects of this experimental project. I would also like to express my gratitude to my family and friends who supported me over the course of my study. 


\section{Table of Contents}

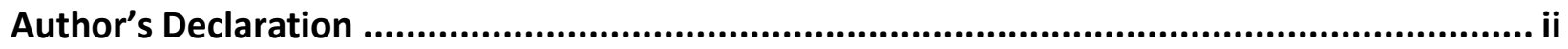

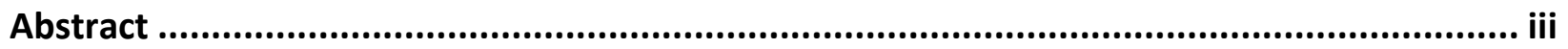

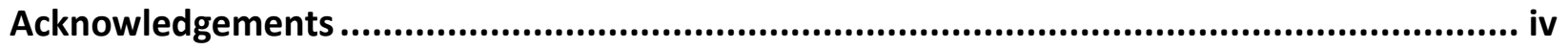

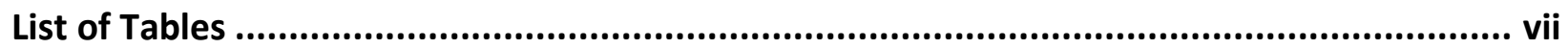

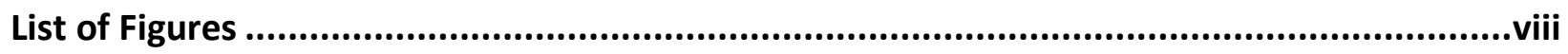

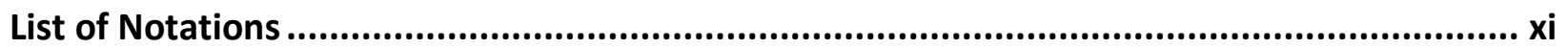

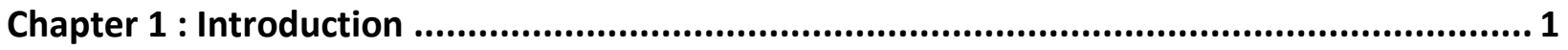

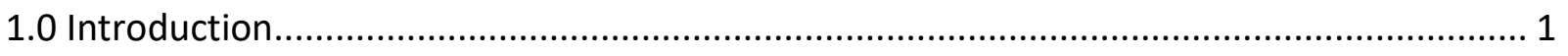

1.1 Research Significance, Objectives and Methodology .................................................... 2

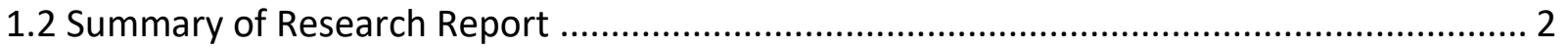

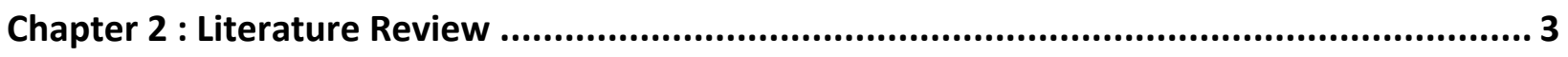

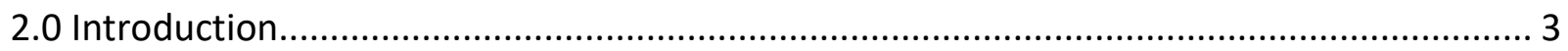

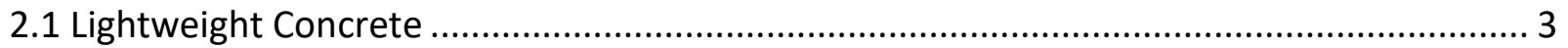

2.2 Comparison of Normal and Lightweight Aggregate .................................................. 4

2.3 Lightweight Aggregates ......................................................................................... 5

2.4 Lightweight Self - Consolidating Concrete (LWSCC) .................................................. 6

2.4.1 Fresh and Mechanical Performance ................................................................... 7

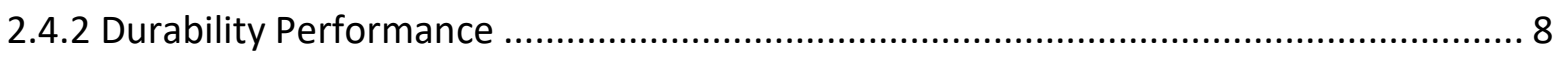

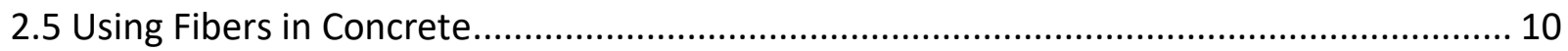

2.6 Effects of Fibers on Fresh Properties of Concrete .................................................... 10

2.7 Effects of Fibers on Mechanical Properties of Concrete............................................... 11

2.8 Effects of Fibers on Durability Properties of Concrete ............................................... 12

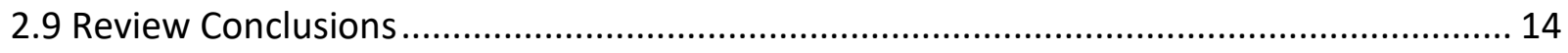

Chapter 3 : Experimental Program and Procedures ....................................................... 15

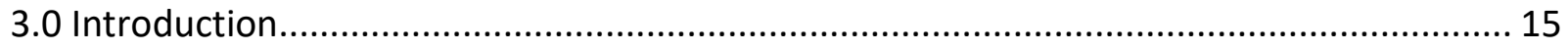

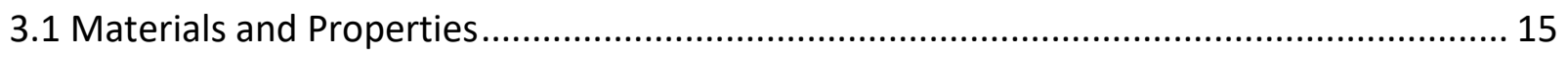

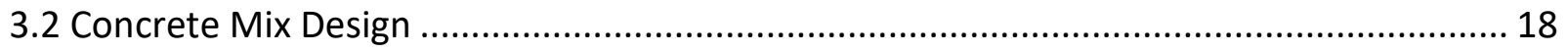




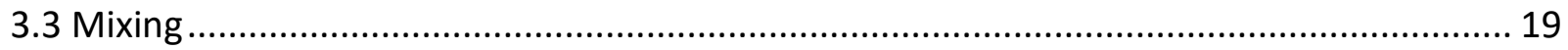

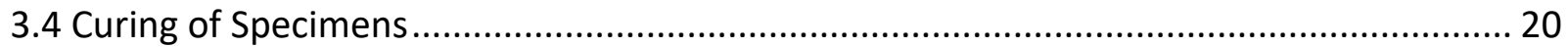

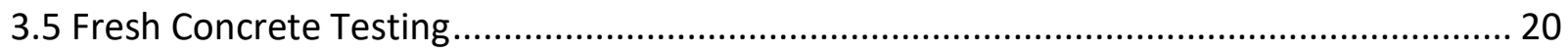

3.5.1 Slump Flow Test.......................................................................................................... 21

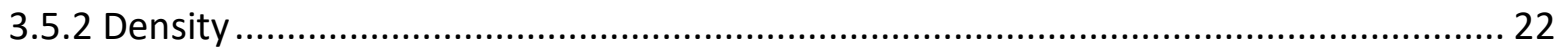

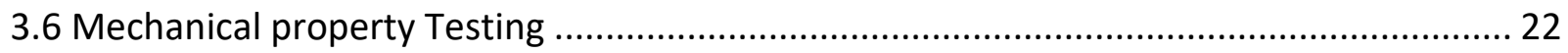

3.6.1 Compressive Strength............................................................................................... 23

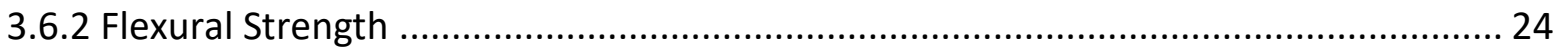

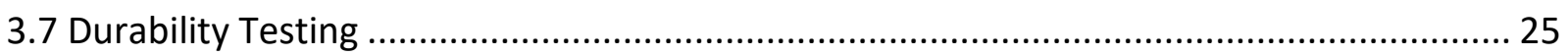

3.7.1 Rapid Chloride Penetration Test............................................................................... 25

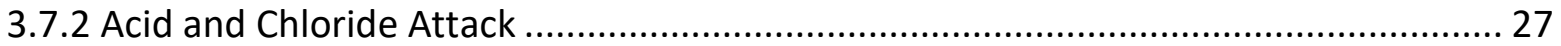

Chapter 4 : Results and Analysis ........................................................................................... 29

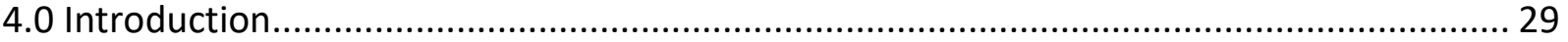

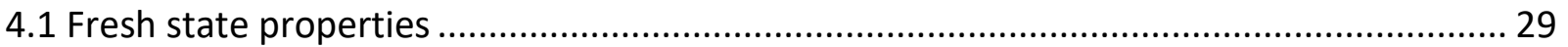

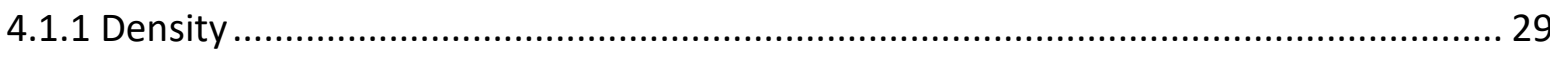

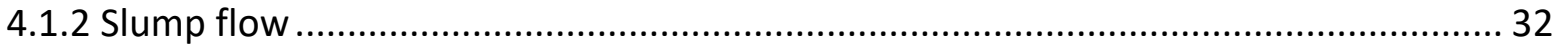

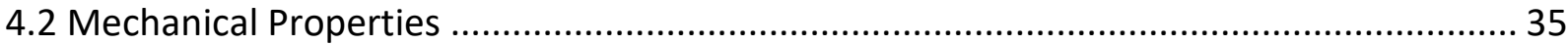

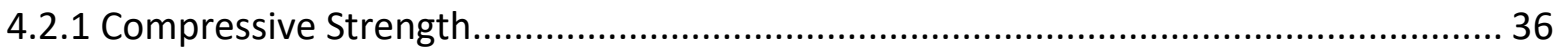

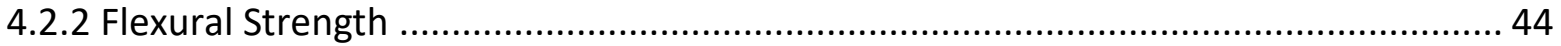

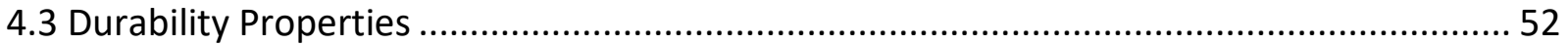

4.3.1 Rapid Chloride Permeability (RCP) Properties ..................................................... 52

4.3.2 Resistance to Acid $\left(\mathrm{H}_{2} \mathrm{SO}_{4}\right)$ and Chloride $(\mathrm{NaCl})$ Attack ............................................... 54

Chapter 5: Conclusion and Recommendations for Future Research Studies .......................... 73

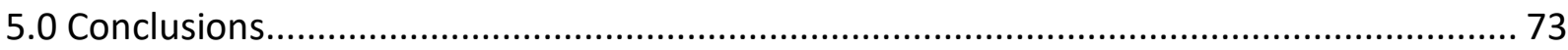

5.1 Recommendations for Future Research …………...................................................... 75

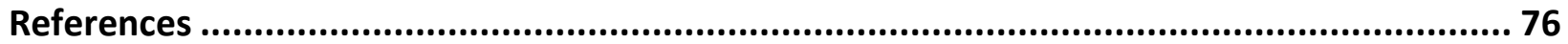




\section{List of Tables}

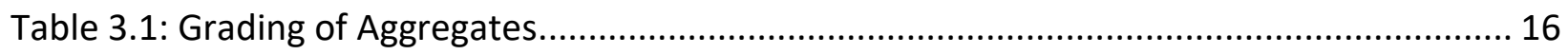

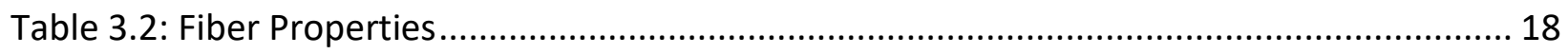

Table 3.3: Concrete Mixtures Proportion Ratios per Type 10 Cement ..................................... 19

Table 3.4: Visual Stability Index (ASTM C1611/ C1611M (2014)) ............................................. 22

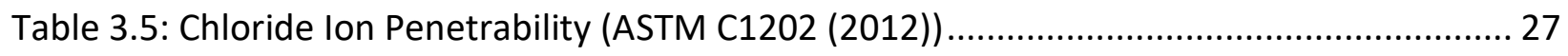

Table 4.1: Fresh, Air Dry and Oven Dry Densities of Specimens ............................................. 30

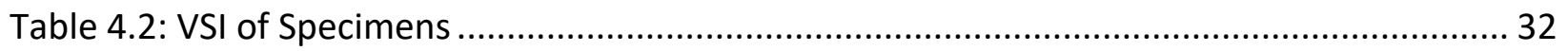

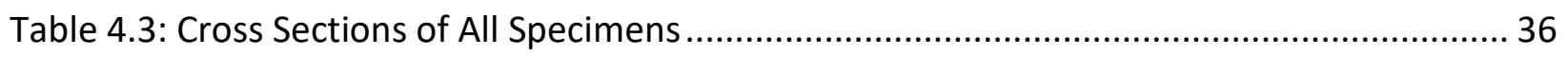

Table 4.4: Failure Loading and Corresponding Compressive Strength at Seven Days ................ 40

Table 4.5: Failure Loading and Corresponding Compressive Strength at Twenty - Eight Days.... 40

Table 4.6: Crack Pattern for Each Specimen at Twenty - Eight Days...................................... 41

Table 4.7: Failure of Specimens under Maximum Compressive Loading .................................. 42

Table 4.8: Number of Cracks and Range of Crack Widths ................................................. 48

Table 4.9: Peak Load, Displacement and Modulus of Rupture............................................. 48

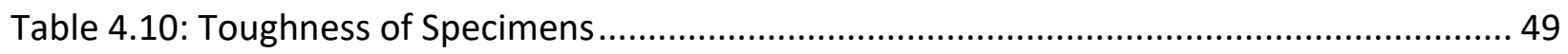

Table 4.11: Chloride Ion Penetrability of Specimens........................................................... 53

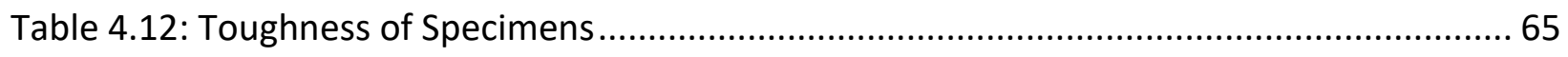

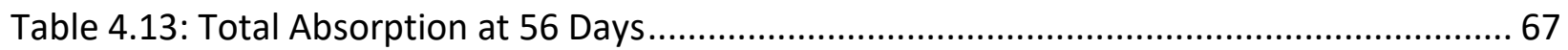

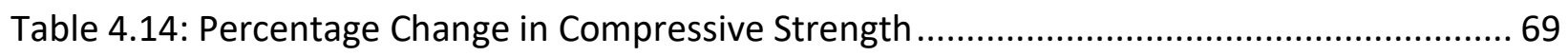




\section{List of Figures}

Figure 2.1: Bonding of LWA and Paste Under SEM (Lo \& Cui, 2004)....................................... 5

Figure 2.2: Lightweight Aggregates: a) Furnace Slag. b) Expanded Clay (Lotfy et al. 2016).......... 6

Figure 3.1: Left: Fine Aggregate - Litex. Right: Coarse Aggregate - Slag ................................ 16

Figure 3.2: Top Left: Crumb Rubber. Top Right: PVA. Bottom Left: HDPE. Bottom Right: PE...... 18

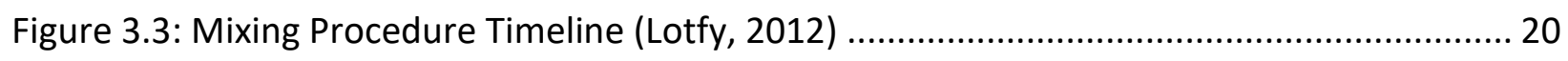

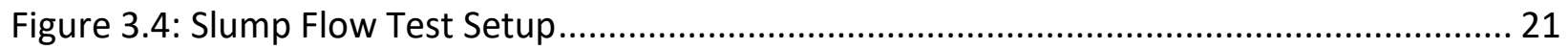

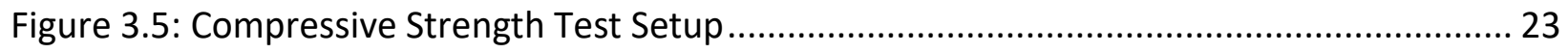

Figure 3.6: Crack Patterns for Compressive Strength Testing (ASTM C39/ C39M (2016)).......... 24

Figure 3.7: Typical Setup for Flexural Strength Test ............................................................. 25

Figure 3.8: Rapid Chloride Penetration Test Setup ................................................................ 26

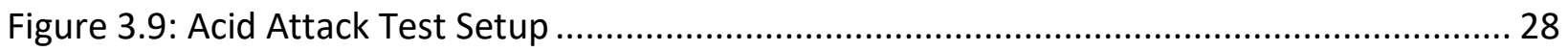

Figure 4.1: Densities of Concrete Mixtures ........................................................................... 31

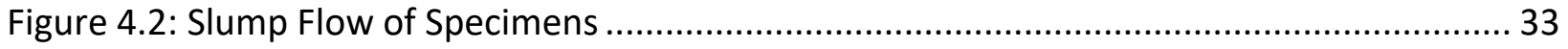

Figure 4.3: Slump Flow for 0.5\% PE Concrete Mixture ........................................................ 34

Figure 4.4: Slump Flow for 0.25\% PVA Concrete Mixture ..................................................... 34

Figure 4.5: Slump Flow for 1.0\% Crumb Rubber Concrete Mixture .......................................... 34

Figure 4.6: Slump Flow for 1.0\% HDPE Concrete Mixture ................................................... 35

Figure 4.7: Seven and Twenty - Eight Day Compressive Strength of Specimens ...................... 39

Figure 4.8: Relationship between Compressive Strength and Density ................................. 44

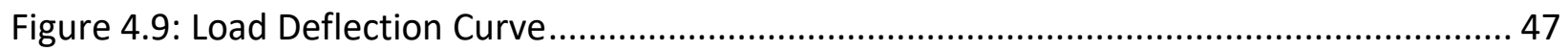

Figure 4.10: Flexural Crack Due to Maximum Load for Control Specimens .............................. 49

Figure 4.11: Flexural Crack Due to Maximum Load for 0.5\% HDPE Specimens ........................ 49

Figure 4.12: Flexural Crack due to Maximum Load for 1.0\% HDPE Specimens..........................50

Figure 4.13: Flexural Crack due to Maximum Load for 0.5\% Crumb Rubber Specimens ............. 50

Figure 4.14: Flexural Crack due to Maximum Load for 1.0\% Crumb Rubber Specimens ............ 50

Figure 4.15: Flexural Crack due to Maximum Load for 0.125\% PVA Specimens ....................... 51

Figure 4.16: Flexural Crack due to Maximum Load for 0.25\% PVA Specimens .......................... 51 
Figure 4.17: Comparison of Modulus of Rupture and Compressive Strength at Twenty - Eight Days

Figure 4.18: Coulombs Passed Through Specimens 54

Figure 4.19: Deterioration of 1.0\% HDPE (Left) and 0.5\% HDPE (Right) after 56 Days in $5 \% \mathrm{H}_{2} \mathrm{SO}_{4}$ 55

Figure 4.20: Deterioration of 1.0\% Crumb Rubber (Left) and 0.5\% Crumb Rubber (Right) after 56 Days in $5 \% \mathrm{H}_{2} \mathrm{SO}_{4}$ 55

Figure 4.21: Deterioration of 0.25\% PVA (Left) and 0.125\% PVA (Right) after 56 Days in 5\%

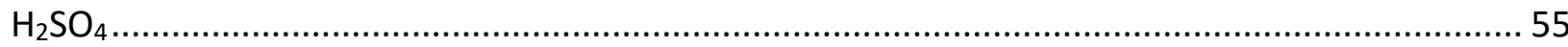

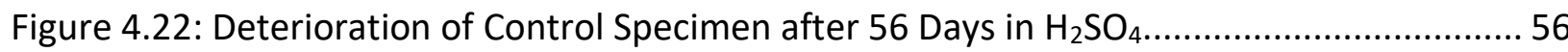

Figure 4.23: Failure of Specimens under Compression after Exposure to 5\% Sulfuric Acid Solution 58

Figure 4.24: Failure of Specimens under Compression after Exposure to Water Immersion...... 60

Figure 4.25: Load Deformation Curve for 0.25\% PVA Specimen in Water.... 61

Figure 4.26: Load Deformation Curve for 0.25\% PVA Specimens in 5\% Sulfuric Acid Solution Left:

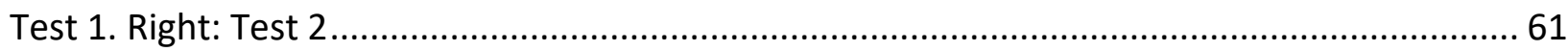

Figure 4.27: Load Deformation Curve for 1.0\% HDPE Specimen in Water................................ 61 Figure 4.28: Load Deformation Curve for 1.0\% HDPE Specimens in 5\% Sulfuric Acid Solution Left: Test 1. Right: Test 2.. 62

Figure 4.29: Load Deformation Curve for 1.0\% Crumb Rubber Specimen in Water.... 62 Figure 4.30: Load Deformation Curve for 1.0\% Crumb Rubber Specimens in 5\% Sulfuric Acid Solution Left: Test 1. Right: Test 2 62

Figure 4.31: Load Deformation Curve for Control Specimen Left: Water. Right: 5\% Sulfuric Acid Solution 63

Figure 4.32: Load Deformation Curve for 0.125\% PVA Specimen Left: Water. Right: 5\% Sulfuric Acid Solution 63 Figure 4.33: Load Deformation Curve for 0.5\% HDPE Specimen Left: Water. Right: 5\% Sulfuric Acid Solution 63 
Figure 4.34: Load Deformation Curve for 0.5\% Crumb Rubber Specimen Left: Water. Right: 5\% Sulfuric Acid Solution 64

Figure 4.35: Mass Change of Specimens Submerged in Water ................................................. 66

Figure 4.36: Mass Change of Specimens Submerged in 5\% $\mathrm{NaCl}$ Solution ................................... 66

Figure 4.37: Mass Change of Specimens Submerged in 5\% $\mathrm{H}_{2} \mathrm{SO}_{4}$ Solution ................................ 67

Figure 4.38: Comparison of Compressive Strength between 5\% Sulfuric Acid Solution and Water

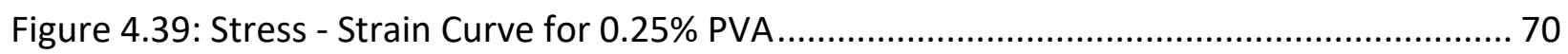

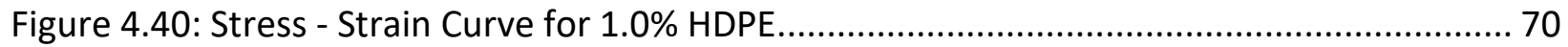

Figure 4.41: Stress - Strain Curve for 1.0\% Crumb Rubber....................................................... 71

Figure 4.42: Stress - Strain Curve for 0.125\% PVA ..................................................................... 71

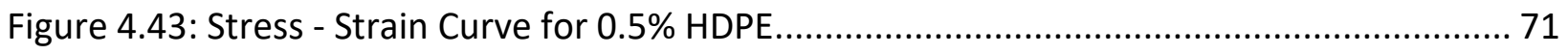

Figure 4.44: Stress - Strain Curve for 0.5\% Crumb Rubber ....................................................... 72

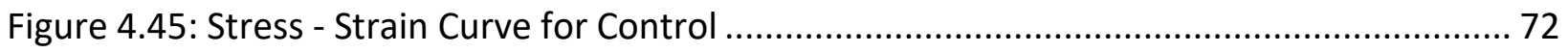




\section{List of Notations}

\begin{tabular}{|c|c|}
\hline ASTM & American Society for Testing and Materials \\
\hline C & Coulombs \\
\hline $\mathrm{C}-\mathrm{S}-\mathrm{H}$ & Calcium Silicate Hydrate \\
\hline $\mathrm{H}_{2} \mathrm{O}$ & Water \\
\hline $\mathrm{H}_{2} \mathrm{SO}_{4}$ & Sulfuric Acid \\
\hline HDPE & High Density Polyethylene Fibers \\
\hline HRWRA & High Range Water Reducing Admixture \\
\hline ITZ & Interfacial Transition Zone \\
\hline kN & Kilonewton \\
\hline $\mathrm{Kg}$ & Kilogram \\
\hline $\mathrm{lb}$ & Pound \\
\hline LWA & Lightweight Aggregate \\
\hline LWC & Lightweight Concrete \\
\hline LWSCC & Lightweight Self - Consolidating Concrete \\
\hline LWSCFRC & Lightweight Self - Consolidating Fiber Reinforced Concrete \\
\hline $\mathrm{m}$ & 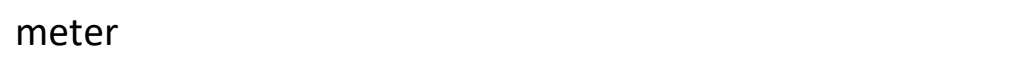 \\
\hline $\mathrm{mm}$ & millimeter \\
\hline $\mathrm{ml}$ & milliliter \\
\hline $\mathrm{MPa}$ & Mega Pascals \\
\hline $\mathrm{m} / \mathrm{s}$ & speed \\
\hline $\mathrm{NaCl}$ & Sodium Chloride \\
\hline NWC & Normal Weight Concrete \\
\hline $\mathrm{O}_{\mathrm{m}}$ & Oven - dry density \\
\hline $\mathrm{PE}$ & Polyethylene Fibers \\
\hline PP & Polypropylene Fibers \\
\hline
\end{tabular}




$\begin{array}{ll}\text { PVA } & \text { Polyvinyl Alcohol Fibers } \\ \text { RCPT } & \text { Rapid Chloride Penetration Test } \\ \text { SEM } & \text { Scanning Electron Microscope } \\ \text { SCC } & \text { Self - Consolidating Concrete } \\ T_{50} & \text { Time for the fresh concrete to spread to a diameter of } 500 \mathrm{~mm} \\ \text { V } & \text { Voltage } \\ \text { VSI } & \text { Visual Inspection Index } \\ W_{\text {initial }} & \text { Initial Weight } \\ W_{\text {final }} & \text { Final Weight } \\ w / c m & \text { Water to Cementitious Material Ratio } \\ w / b & \text { Water Binder Ratio } \\ y d & \text { yard }\end{array}$




\section{Chapter 1 : Introduction}

\subsection{Introduction}

The broad use of concrete for many years has paved the way for construction of many structures around the world. This material is mainly made of three components; aggregate, water, and cement. With the advancement of technology today, there are many types of concrete such as high strength, high performance, lightweight and self-consolidating concrete. The development of these types of concrete increased the abundance of complex structures with many advantages throughout the construction stages and service life of the structure.

Over 2000 years ago, lightweight concrete (LWC) has been used to construct famous landmarks such as the Pantheon Dome and the Coliseum ( $\mathrm{ACl}$ Committee 213, 2014). Today there are many applications of lightweight concrete which have provided many advantages to architects and engineers alike. Self-consolidating concrete (SCC) is starting to become a preferred choice of concrete since this type of material can fill in forms and gaps without the need for any mechanical vibrations (Mazaheripour et al. 2011, Lotfy et al. 2016)

Throughout the years, engineers have started to realize the potential of improvement of the concrete performance by adding fibers. Research has shown that adding fibers into concrete can prevent damaging effects such as shrinkage and micro cracks (Gonen, 2015). There are a variety of fibers available that has different properties, advantages and disadvantages. Even though there is research so far on the benefits and disadvantages of using fibers in concrete, there is not enough research conducted on the effects of fibers in lightweight self-consolidating fiber reinforced concrete (LWSCFRC). Lightweight self-consolidating fiber reinforced concrete (LWSCFRC) is a new technology that can combine benefits of LWSCC and fiber reinforced concrete (FRC) (Gonen 2015). Limited research studies have been conducted to date on the properties of LWSCFRC with different types and contents of fibers (Corinaldesi and Moriconi, 2015; Doukakis 2013) 


\subsection{Research Significance, Objectives and Methodology}

This research is a timely initiative which will definitely to contribute to the development and performance evaluation of LWSCFRC, The main objective for this reasearch is to investigate the performance of various LWSCFRC mixtures made of different types and contents of fibers based on fresh state, mechanical and durability properties. To meet the objective, eight concrete mixtures were designed and made with four different types of fibers: Polyethylene (PE), Polyvinyl Alcohol (PVA), high density polyethylene (HDPE) and crumb rubber. For each of the concrete mixtures, fresh state characteristics (in terms of density and slump flow) and mechanical properties (compressive strength and flexural strength) were investigated. In addition, durability properties based on rapid chloride permeability ' $\mathrm{RCP}$ ' and resistance to acid attack (using 5\% sulfuric acid solution) and chloride attack (using $5 \%$ sodium chloride solution) of all LWSFRC mixtures were also investigated. Results were analyzed in conjunction with the findings of previous research studies to study the influence of fiber types on LWSCFRC properties.

\subsection{Summary of Research Report}

Chapter 1 highlighted objectives and significance of the research. Chapter 2 focuses on the review of LWC and LWSCC, comparison of normal weight aggregate and lightweight aggregate, use of fibers in LWSCFRC and the effects of fibers on concrete's fresh, mechanical and durability properties. Chapters 3 is dedicated to the experimental program, concrete mix design, materials used and procedures for fresh, mechanical and durability testing of LWSCFRC mixtures. The results along with an analysis on the effects of fibers on various properties of LWSCFRC mixtures are summarized in Chapter 4. Chapter 5 presents the conclusions with recommendations for future research studies. 


\section{Chapter 2 : Literature Review}

\subsection{Introduction}

Lightweight concrete is used in many applications, but to further optimize the performance of this concrete, research is currently being conducted around the world to showcase the advantages and disadvantages of using fibers in lightweight fiber reinforced concrete mixtures. Comparison between the use of normal weight aggregate and lightweight aggregate and how the concrete's performance is affected is discussed. In addition, the vast variety of fibers available along with the overall effects of using fibers in lightweight concrete found in previous research is mentioned.

\subsection{Lightweight Concrete}

To be classified as lightweight concrete, the unit weight of the concrete mix needs to be below $2000 \mathrm{~kg} / \mathrm{m}^{3}$ (Gonen, 2015). The concrete proportions can vary between mixes, but a major difference between normal weight and lightweight concrete, is the use of lightweight aggregate (LWA). Ideal lightweight aggregate for producing LWC are natural occurring aggregate such as pumice and manufactured aggregate such as expanded shale and clay ( $\mathrm{ACl}$ Committee 213, 2014). There are many structural and economic advantages for using LWC which includes;

- Self - weight of the concrete member is significantly lighter than using normal weight concrete. As a result, the construction of structures will be cheaper than the normal weight counterparts.

- Lighter structure will result in lower seismic impacts (ACl Committee 213, 2014).

- This type of concrete can be used for many structural applications such as beams, bridge decks, and curtain walls (ACl Committee 213, 2014).

- Increased costs are associated with the production of lightweight aggregate but this cost is offset by lighter member sections that are created which reduces labor and foundation costs (Lotfy, 2012).

- An industrial bi-product, Fly Ash can be used as lightweight aggregate which can provide environmental benefits (Kayali et al. 2003). 
Some of the disadvantages of using lightweight concrete are that the compressive strength can be affected with the use of lightweight aggregate (LWA). The flexural strength decreases with increased amount of LWA (Arisoy et al. 2008). Furthermore, increasing the strength of LWC can cause an increased risk of brittleness which can decrease ductility and workability (Kayali et al. 2003).

Mix design for normal weight concrete cannot be used since it can lead to segregation of different materials in the concrete mix such as aggregates (Mazaheripour et al. 2011). Since LWA has increased porosity, this affects the absorption of concrete; therefore, caution should be taken when creating the mix design (Doukakis, 2013). Also, LWA has a lower density than the paste in the concrete mix, therefore, the aggregate can segregate to the bottom of the mix and the paste can move to the top making the mix unusable (Lotfy, 2012). Due to the lower modulus of elasticity of LWC, the flexibility is greater compared with normal weight concrete (NWC) that can lead to settlement issues in the structure's foundation (Doukakis, 2013).

\subsection{Comparison of Normal and Lightweight Aggregate}

The use of lightweight aggregate can change the concrete mixture and properties compared to using normal weight aggregate such as rocks. Due to the difference in physical properties between normal and lightweight aggregate, the overall state of the concrete mixture, as well as the performance of concrete can change. To manufacture LWC there are many types of LWA that can be used such as pumice, expanded shale, and clay. Depending on the use of the concrete, LWA should be chosen with close consideration of how the concrete mixture will be used. For example, for structural elements such as load bearing members; expanded shale, clay or slate should be used since this will result in a concrete mix with a higher strength (Lotfy,2012).

One of the important factors of designing a lightweight concrete mix is the absorption properties of LWA. Absorption differs between LWA, such as pumice compared with normally used aggregate, such as rock. As a comparison, these types of aggregates can absorb from $5 \%$ to $25 \%$, while normal aggregate can absorb to a maximum of 2\% (Lotfy, 2012). The high absorption in LWA is due to high porosity, which allows for more absorption of water. Even though high absorption can seem as a negative aspect of LWA, on the contrary, this provides decreased plastic 
shrinkage during concrete mixing and provides better internal curing since water is more evenly distributed throughout the concrete matrix (Lotfy 2012).

Another difference between the uses of NWA and LWA is the effect it has on the interfacial transition zone (ITZ) in the concrete. Concrete with normal weight aggregate has a visible ITZ layer on the aggregate surface when analyzed under a Scanning Electron Microscope (SEM) (Lo \& Cui, 2004). This is not the case for concrete made with LWA because of the rough surface texture and high porosity of the lightweight aggregate. As a result, there is better bonding between the aggregate and the paste as shown in the figure below (Topcu \& Uygunoglu, 2010). Figure 2.1 represents a magnification of the lightweight aggregate and cement paste interaction under a SEM, the black line that divides the aggregate and the paste is called the ITZ. This bonding provides a denser matrix which overall can enhance different properties of concrete (Lo \& Cui, 2004). Although this is the trend, it should be noted that there are many factors that can affect the ITZ, such as the type of aggregate and porosity just to name a few (Lo \& Cui, 2004).

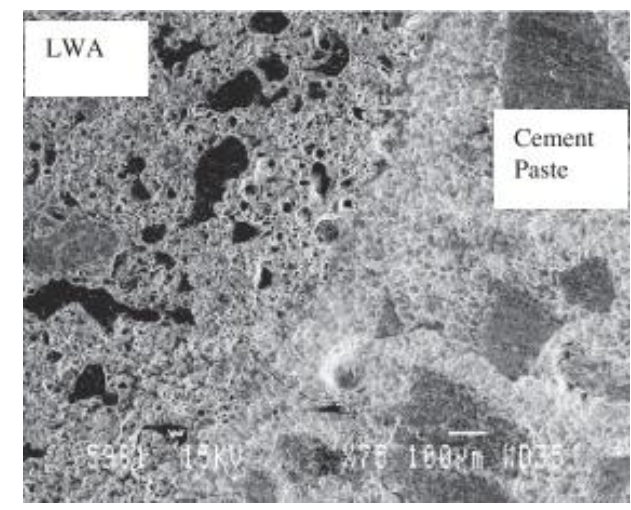

Figure 2.1: Bonding of LWA and Paste Under SEM (Lo \& Cui, 2004)

\subsection{Lightweight Aggregates}

A vast variety of lightweight aggregate is available to use for concrete mixes. LWA can be manmade or natural (ACl Committee 213, 2014). Figure 2.2 shows furnace slag and expanded clay, which are two types of LWA. Depending on the purpose of the concrete and the location of the project, certain considerations are considered when selecting the type of the LWA to be used. All types of aggregates have their own advantages and disadvantages, but LWA can present more problems and challenges to the concrete's fresh, mechanical and durability properties. For 
instance, the lightweight concrete mixture should be made properly to ensure that there is low permeability of water, therefore providing higher durability $(\mathrm{ACl}$ Committee 213, 2014). This reveals that the nature of lightweight aggregate such as absorption and density can affect the durability capacity of lightweight concrete (Yehia et al. 2014). Further discussion into how lightweight aggregate affects the behavior of lightweight concrete is further discussed in the next section.
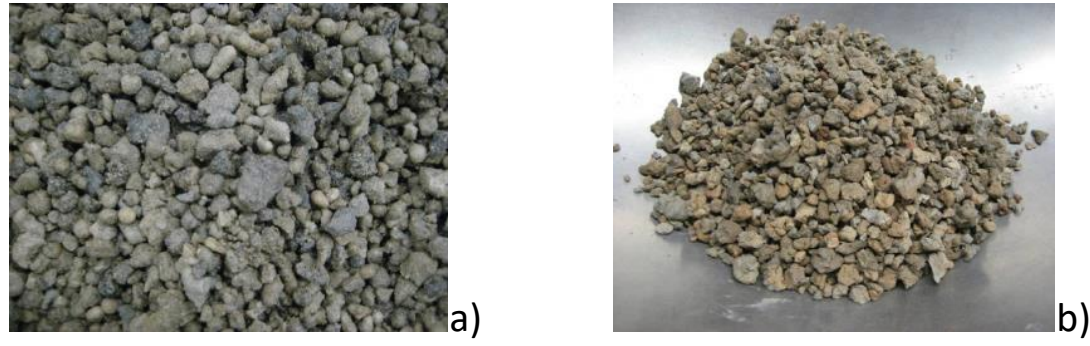

Figure 2.2: Lightweight Aggregates: a) Furnace Slag. b) Expanded Clay (Lotfy et al. 2016)

Some of the different type of LWA includes expanded clay, expanded shale, volcanic pumice, furnace slag, limestone and diatomite. All these types of aggregate have their unique properties that can affect the concrete mix positively or negatively. Many contributing factors affect the properties of concrete; type of aggregate, water-binder ratio and amount of cementitious material. For example, the porous nature of volcanic pumice aggregate used in lightweight concrete resulted in increased permeability of the mix, which can lead to lower durability during freeze and thaw cycles (Hossain 2004). Therefore, using this type of aggregate is not recommended for coastal regions or areas prone to harsh freeze and thaw cycles since the porous material will result in higher water penetration and corrode the structure faster. Overall, how the concrete will be used in a project and the environment that it will be in during the service life will help engineers establish which type of aggregate is to be use to meet their needs.

\subsection{Lightweight Self - Consolidating Concrete (LWSCC)}

Originating in Japan, engineers have been using self-consolidating concrete (SCC) since the 1990's for many different structural applications such as; precast sections and concrete form wall systems ( $\mathrm{ACl}$ Committee 213, 2014). Even though the components to make this type of concrete is the same as normal weight concrete (NWC), the addition of other materials such as viscosity 
modifying admixtures (VMA) is required to ensure that segregation between the cement paste and aggregates does not occur. For a concrete mixture to be classified as LWSCC, according to standards (ACl Committee 213, 2014; ACI Committee 318, 2014), concrete needs to obtain a dry unit weight of approximately $1840 \mathrm{~kg} / \mathrm{m}^{3}$ and achieve a compressive strength of $17.2 \mathrm{MPa}$ or more at or after 28 days of curing. The proportioning of this type of concrete mix is crucial in maintaining high workability and allowing easy flow ability of the concrete (Lotfy, 2012). Some advantages of using SCC are the ability to easily flow into densely reinforced or tight areas without the need for mechanical vibrations ( $\mathrm{ACl}$ Committee 213, 2014). Also, member sections are lighter therefore; they are easier to put together on site ( $\mathrm{ACl}$ Committee 213, 2014).

Although, LWSCC is proving to be a good alternative for normal weight concrete, there are some negative aspects associated with using or manufacturing this type of concrete. Some of the disadvantages are the increased material cost since more powder material such as fly ash is needed (Mazaheripour et al. 2011). The mix design used for normal weight concrete cannot be used since this method can result in material segregation in self - consolidating concrete (Mazaheripour et al. 2011). Furthermore, it was sometimes evident that the concrete mix can result in producing a higher strength than the desired strength (Gonen, 2015).

\subsubsection{Fresh and Mechanical Performance}

Creating a concrete mix that is classified as LWSCC is known to provide many benefits during construction and economically, but this type of concrete can also have negative effects on the fresh and mechanical properties of concrete.

A lightweight concrete mixture can provide many benefits when used in structures, but if it is produced in the same way that normal weight concrete is produced then segregation can occur between the aggregate and the cement paste because of the density decrease in LWA compared with normal weight aggregate (Kim et al. 2010). Therefore, flow ability of LWSCC and creating a homogenous mixture are important properties to ensure that once the concrete is hardened it will perform at the intended specifications. Depending on what type of LWA is being used, slump flow values can vary even if other concrete material proportions are kept the same. For example, the slump flow of a lightweight self-consolidating concrete mixture made with diatomite had a 
slump flow of $840 \mathrm{~mm}$ and when compared to other lightweight aggregates such as pumice and tuff; it had the highest slump flow (Topcu \& Uygunoglu, 2010). It can be concluded that the lighter the mixture, the lower the slump values since the high porosity of the aggregate will absorb more water, therefore creating a lower slump flow compared with normal weight concrete (Hossain et al. 2011).

Depending on what type of lightweight aggregate is in the concrete mixture, concrete performance can change. It is common that as the concrete cures and hardens the compressive strength properties increase. Another factor that affects the strength of concrete is the waterbinder $(w-b)$ ratio because as the $w-b$ ratio increases the strength of the concrete specimen decreases, which is resulted from a non-homogenous mixture (Topcu \& Uygunoglu, 2010). For example, a LWSCC specimen with pumice aggregate had a maximum compressive strength of 27 MPa, while another LWSCC specimen with diatomite aggregate had only $22 \mathrm{MPa}$ (Topcu \& Uygunoglu, 2010). This reveals that the increased porosity and weaker structure of the diatomite aggregate compared to the pumice aggregate resulted in a lower compressive strength. In addition, to the structure of the aggregate, the amount of LWA used can also affect the compressive strength. For example, a lightweight volcanic pumice concrete mixture with a varying amount of volcanic pumice aggregate from $0 \%$ to $100 \%$ revealed a decrease in compressive strength from $40 \mathrm{MPa}$ to $27 \mathrm{MPa}$, respectively (Hossain et al. 2011). The ITZ also positively affects the compressive strength of concrete because as previously mentioned the bonding of the LWA and cement is higher, which in return creates a denser matrix that allows the mixture to develop a higher compressive strength compared with NWC. One experiment that was conducted on LWC revealed a higher strength in the early curing stages compared with twenty-eight-day compressive strength which was attributed to good bonding performance between the aggregate and cement in the ITZ (Lo \& Cui, 2004).

\subsubsection{Durability Performance}

The optimal performance of structural concrete members is crucial throughout the service life of the structure. An increase in load or chloride penetration can cause risk of severe deterioration and reduce the lifespan of the concrete member. Therefore, to decrease these risks, optimization 
of durability properties should be considered. To produce good durability against acid attack and freeze and thaw the concrete mixture needs to be created with reduced permeability and absorption capabilities. If the concrete mix has good durability against freeze and thaw, chloride penetration and sulfate resistance, then these concrete members can last a long time in their surrounding environments. There are many factors to take into consideration when evaluating the durability of the lightweight concrete, such as; chloride penetration, freeze and thaw, sulfate resistance, abrasion resistance and permeability. Overall, LWA is known to have an increased porosity when compared with NWA. Different researchers have concluded that the increased porosity either has positive or negative effects on the durability of the concrete. For example, the LWA used in lightweight concrete has shown to have more resistance to higher temperatures and have lower thermal conductivity which aids in better insulation for reinforcement (Lotfy et al. 2016). Another advantage to using LWA is improved freeze and thaw resistance due to the increased porosity of the aggregate which reduces the expansion of water during the freezing stages, therefore, decreasing the physical damages on the concrete (Yehia et al. 2014). Lightweight concrete that has been created with furnace slag exhibited an increased resistance to scaling, which in return was due to the lower porosity of the aggregate with respect to other LWA such as expanded clay which has a high porosity and absorption capacity (Lotfy et al. 2016). A negative effect of using LWA to produce lightweight concrete is the increase in porosity reduces the compressive strength and increases creep strain due to lower modulus of elasticity (Yehia et al. 2014) It is known that as the concrete ages the compressive strength increases. Although this is the case generally, the use of lightweight aggregate can negatively affect the concrete's ability to reach a higher compressive strength. This is due to the aggregate's properties since a more porous aggregate will result in a weaker concrete mixture (Topcu et al. 2010). Another LWA used in lightweight concrete that exhibits lower compressive strength is diatomite. The lower compressive strength is due to the increased weakness of the aggregate which also causes lower bond strength in the interfacial transition zone (ITZ) (Topcu et al. 2010). Furthermore, the increasing porosity of the aggregate in the concrete mix can affect a variety of mechanical characteristics of the concrete such as decreasing abrasion resistance and modulus of elasticity. Overall there are both advantages and disadvantages of using LWA, but the correct aggregate 
should be chosen based on the purpose of the concrete member and the surrounding environment to ensure longer durability throughout its service life.

\subsection{Using Fibers in Concrete}

The variety of fibers that are available to add to the concrete mix is vast. There are many different categories of fibers such as; naturally occurring, synthetics, glass and steel. Some popular types of synthetic fibers include; polyethylene, polyester and polypropylene (Doukakis, 2013). Currently, society is trying to become more sustainable to increase the longevity and availability of natural occurring materials. To aid in this sustainability and protect the environment, researchers have started to test the effects of using recycled fibers such as waste pet bottles, plastic, glass and, old tires in concrete mixes. By using these types of fibers, the concrete mix would be more economical and less waste would be produced (Foti, 2013). Each type of fibers has their own unique properties and characteristics, and they come in various sizes and compositions. The purpose of using fibers in concrete is to enhance different concrete properties and try to decrease the use of structural reinforcement, which as a result decreases construction costs, increases speed of production and reduces noise and disruption in the surrounding areas of the construction site (Park et al. 2007). Depending on which types of fibers are used, some may be more beneficial depending on how the concrete will be used and the properties of that particular fiber. For example, the use of steel fibers provides good crack propagation, while glass fibers provide a lower permeability (Manjunatha et al. 2015). Overall, research being conducted into how concrete performance can be improved, will provide more advantages during construction ( $\mathrm{ACl}$ Committee 544, 2001 ).

\subsection{Effects of Fibers on Fresh Properties of Concrete}

As previously stated LWSCC is beneficial in the construction of structural members because it is lightweight and can fill in the formwork on its own. To ensure that these benefits are kept when adding in fiber, workability of the concrete mixture should be closely observed to ensure the mixture can still be classified as LWSCC. The overall trend of workability for LWSCFRC shows that increasing the fiber content in the concrete mixture will decrease the workability. To support this statement, lqbal et al. (2015) have concluded from their experiment that slump flow varied from 
$790 \mathrm{~mm}$ to $630 \mathrm{~mm}$ for five different high strength LWSCC concrete specimens having $0 \%$ to $1.25 \%$ steel fibers respectively. The difference in the type of fibers used also plays a vital role in the difference of slump flow. For example, polypropylene fibers (PP) ranging from $0 \%$ to $0.3 \%$ volume used in LWSCC, resulted in a slump flow difference ranging from $720 \mathrm{~mm}$ to $410 \mathrm{~mm}$ (Mazaheripour et al. 2011). PP fibers exhibit significantly lower slump flow values at lower volumes as compared with steel fibers. This can be a result of the fiber properties. For example, fibers that tend to clump together during the mixing phase will result in a lower slump flow because the paste will surround the clumps more, compared to a homogenous mixture.

To provide an optimum level of workability, an addition to the water content can be made, but this can lead to segregation between the fibers and the paste. It is important to consider the viscosity of the mixture, since decreased viscosity will result in a flowable mixture that can cause for the fibers to sink to the bottom of specimen and increase segregation (Park et al. 2007). Therefore, this will not provide a homogenous concrete mixture and will not accurately represent the behavior of the specimens under a variety of mechanical and durability tests.

\subsection{Effects of Fibers on Mechanical Properties of Concrete}

From the previous section, it was noted that fresh concrete properties such a slump flow changed not only with the amount of fibers used but also the type. This statement is also true for mechanical properties such as compressive strength, flexural strength and, modulus of elasticity. These advantages can include increased flexural and compressive strengths, as well as enhancing fatigue and shrinkage resistance (Doukakis, 2013). Other mechanical properties that can be improved are toughness, ductility, tensile strength, and crack control (Gencel et al. 2011). Depending on the use of the concrete mix, certain fibers provide better performance, such as using steel fibers for load bearing structural members (Ali et al. 2016). PP fibers show that it can provide better resistance against cracks due to improved ductility (Gencel et al. 2011).

It is known that lightweight concrete is more brittle in nature than its normal weight counterpart. To decrease the brittleness of the lightweight concrete, researchers have concluded that adding fibers into the concrete mix can reduce this effect (Corinaldesi \& Moriconi, 2015). 
From different experiments conducted by researchers, there are varying advantages and disadvantages with the use of fibers in LWSCC. Researchers, Arisoy and Wu (2008) stated that adding fibers to concrete mixes increased the concrete's ductility and flexural strength (Arisoy \& $\mathrm{Wu}, 2008)$. For example, comparing a LWSCC specimen without any fibers and another with $0.3 \%$ polypropylene fibers resulted in an increased flexural strength of 5.83 MPa (Mazaheripour et al. 2011). Furthermore, other researchers have showcased from their experiments that failure cracks occurred at lower loads and there was an increased resistance in crack propagation in lightweight reinforced concrete than the same type of concrete without fibers (Ali et al. 2016).

\subsection{Effects of Fibers on Durability Properties of Concrete}

There are a variety of ways for testing the durability of concrete, such as using rapid chloride penetration and freeze and thaw testing. The ability for concrete to resist chemical attacks and water penetration reveals that the permeability is decreased, which overall ensures that the mechanical properties are not affected and the physical properties are not damaged. There are many factors that affect the durability properties of concrete such as admixtures, amount and type of fine and coarse aggregates used and, the amount of cement etc. With the addition of fibers, it was revealed in previous sections that the fresh and mechanical properties were changed depending on the type and amount of fibers used in the concrete mix. In this case, the addition of fibers also plays a part in determining how durable the concrete is. In a RCPT analysis for fiber reinforced self-consolidating concrete, it was revealed that the use of synthetic or steel fibers resulted in a low number of coulombs passing the sample (Yehia et al. 2016). This was due to the increased density of the concrete with the addition of fibers, therefore, increasing the durability of the sample by decreasing the permeability. In addition to steel fibers, researchers are considering more sustainable fibers such as rubber from recycled tires. It was concluded from another research that the increase in rubber content for rubberized self-consolidating concrete from $28 \mathrm{~kg} / \mathrm{m}^{3}$ to $84 \mathrm{~kg} / \mathrm{m}^{3}$, increased rapid chloride permeability and mass loss after freeze and thaw testing due to the higher porosity and increased water absorption (Karahan et al. 2012). For SCC mixtures, low amount of coulombs passed through a concrete sample with steel and polypropylene fibers under rapid chloride penetration test which therefore yielded a rating of "very low" (Yehia et al. 2016). In addition to the effects of fibers under RCPT, the effect of w/cm 
ratio and aggregate type also affects the resistance capacity of concrete for chloride ions. For example, chloride penetration decreased from a rating of 'high' to 'moderate' with the use of a lower $\mathrm{w} / \mathrm{cm}$ ratio in LWC, but penetration increased with the use of lightweight aggregate (Chia et al. 2002). Another factor that is considered when evaluating durability performance is the amount of fiber that is in the mixture because this can affect the ITZ and the bonding between the fiber and cement. It was found that the increase in rubber content increased the chloride ion penetration under RCPT and caused the rating to change from "very low" to "low" chloride ion penetrability (Karahan et al. 2012). In addition to using one kind of fiber, some researchers have tried to find an optimal concrete mix design by using a combination of fibers. For example, a high performance concrete mix with $0.7 \%$ steel fibers and $0.3 \%$ polypropylene fibers had water

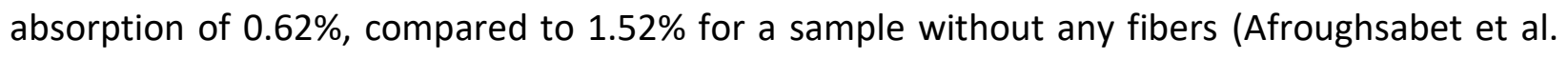
2015). Therefore, it can be said that certain types of fibers in a concrete mixture can increase the porosity of the specimen, which therefore can negatively affect the durability of the concrete.

The performance of concrete is especially important during exposure to acid attack because the penetration of acid can cause physical damage, which as a result can affect the performance and strength capacity of the concrete. As with any other testing performed on LWSCC, the composition of the concrete mixture is important in ensuring that the mixture performs as intended under acid attack. It was concluded by researchers that the addition of fly ash and silica fume also aided in the improvement of durability against acid attack exposure (Lotfy, 2016). For a $1 \%$ sulfuric acid solution, LWSCC with silica fume would have a better resistance against sulfuric acid because of the reduced formation of $\mathrm{Ca}(\mathrm{OH})_{2}$ (Lotfy, 2012). Furthermore, the distribution of fibers in fiber reinforced self-compacting concrete is especially important, since it can help with crack bridging and reduction in permeability (Yehia et al. 2016). Lastly, the duration the concrete specimens are exposed to the acid is another important factor to consider, since a shorter duration will not accurately depict deterioration. This is because the shorter exposure does not allow for proper penetration of acid into the concrete specimen to cause damage in the ITZ (Lotfy, 2016). 


\subsection{Review Conclusions}

Literature review suggests the beneficial effects of fibers in concretes. However, very limited research studies have been conducted on the effect of different types of fibers and dosages on the properties of LWSCFRC. There is need to do research on the development of LWSCFRC mixtures with different types of fibers based on comprehensive investigations on fresh state, mechanical and durability properties. The current research addresses this need and its findings will aid in developing a better understanding of how the inclusion of different types of fibers affects fresh state, mechanical and durability properties of LWSCFRC mixtures. 


\section{Chapter 3 : Experimental Program and Procedures}

\subsection{Introduction}

Experimental investigations were conducted to demonstrate the effect of four different fibers (PE, PVA, crumb rubber and HDPE) on fresh, mechanical and durability properties of eight lightweight self-consolidating fiber reinforced concrete (LWSCFRC) mixtures. The fresh state properties of all concrete mixtures were analyzed by conducting slump flow, and density tests to ensure that they are workable, have a homogenous mixture and are able to be categorized as lightweight concrete. The mechanical properties were tested by conducting compressive strength and flexural strength testing. The durability properties of LWSCFRC specimens compared to control (without fibers) specimens were analyzed from rapid chloride penetration test (RCPT), freeze-thaw resistance and resistance to sulfuric acid and sodium chloride attack.

For the concrete mix to be considered lightweight, a challenge was presented when developing LWSCFRC mix designs with four types of fibers. The correct proportions of water, aggregate, cement, admixture and fiber was found by trial and error until the proper consistency and workability of the concrete was found. Since maximum volume of fibers in a concrete mix is $1.5 \%$, the chosen percentages (contents) of fiber for the mix designs varied between the type of fibers used. Each concrete batch went through fresh property tests: slump flow and density. Cylinders and beam specimens were casted and cured for different ages to determine compressive and flexural strengths. Besides rapid chloride penetration test and freeze-thaw test as well as tests on sulfuric acid and sodium chloride attack were conducted. All tests on the specimens have been conducted according to relevant ASTM standards except for the acid attack.

\subsection{Materials and Properties}

The following materials were used to produce the lightweight self -consolidating concrete: ASTM Type 1 Portland cement with a specific gravity of 3.17, Class F fly ash with a specific gravity of 2.6, Litex blast furnace slag fine aggregate, blast furnace slag coarse aggregate, dry densified silica fume and high-range water-reducing admixture (HRWRA). The fine and coarse aggregates have been obtained from Lafarge in Ontario, while the silica fume and the HRWRA have been obtained 
from BASF. Figure 3.1 shows the fine and coarse aggregate used in the creating of the concrete mixtures. A gradation analysis of fine and coarse aggregates shown in Table 3.1 was completed following the procedure put forth in ASTM C330/C330M (2014).

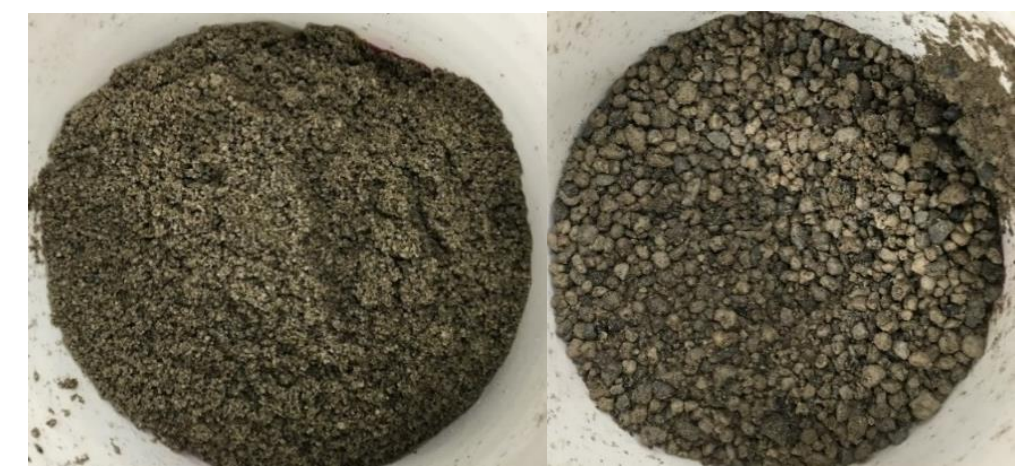

Figure 3.1: Left: Fine Aggregate - Litex. Right: Coarse Aggregate - Slag

Table 3.1: Grading of Aggregates

\begin{tabular}{ccccc}
\hline & \multicolumn{3}{c}{ Percentage Passing } \\
\cline { 2 - 4 } Sieve Size (mm) & \multicolumn{2}{c}{$\begin{array}{c}\text { ASTM C330 } \\
\text { Guidelines }\end{array}$} & Fine Aggregate & Coarse Aggregate \\
& Fine & Coarse & & \\
\hline 25 & - & - & - & 100 \\
\hline 12.5 & - & $90-100$ & - & 98.6 \\
\hline 9.5 & - & $40-80$ & - & 78.9 \\
\hline 4.75 & $85-100$ & $0-20$ & 100 & 23.5 \\
\hline 2.36 & - & $0-10$ & 66.9 & - \\
\hline 1.18 & $40-80$ & - & 32 & 10.6 \\
\hline 0.3 & $10-35$ & - & 3.2 & 3.4 \\
\hline 0.15 & $5-25$ & - & 2.2 & 1.2 \\
\hline 0.075 & - & $0-10$ & 0.3 & 0.5 \\
\hline Absorption $(\%)$ & - & - & 6.5 & 8 \\
\hline Dry Loose Bulk & 1120 & 880 & 2250 & 1750 \\
\hline Density $\left(\mathrm{kg} / \mathrm{m}^{3}\right)$ & & & &
\end{tabular}


Supplementary cementitious materials - dry-densified silica fume and Class F fly ash have been used to assist in obtaining a workable and uniform concrete mixture. The silica fume used in all the concrete batches provides many benefits such as reducing bleeding, increasing strength and durability (BASF, 2016). Fly ash is known to provide many benefits to concrete mixtures such as providing better workability and increased resistance to sulfate (Gencel et al. 2011). In addition, reduced segregation of fresh concrete has been noticed with the use of Class F fly ash (Lotfy 2012). Overall these two cementitious materials will provide enhanced mechanical and durability properties for the lightweight concrete. Glenium, which is a high-range water-reducing admixture (HRWRA) has been used because it is beneficial when producing self-consolidating concrete. Some of these benefits include early strength development, slump retention and increased compressive strength development (BASF, 2015).

To provide a range of results in concrete performance under fresh, mechanical and durability testing, the four fibers were chosen with different physical properties such as length and size. PVA, PE and HDPE which are white in color had different lengths and diameters. Crumb rubber was black with a sand like texture and has been made from recycled tires by grinding and has a specific gravity is 0.9 (Karahan et al. 2012). The source and summary of the characteristics of the fibers used in this research have been summarized in the Table 3.2. Figure 3.2 shows PE, PVA, HDPE fibers as well as crumbed rubber used in this study. 

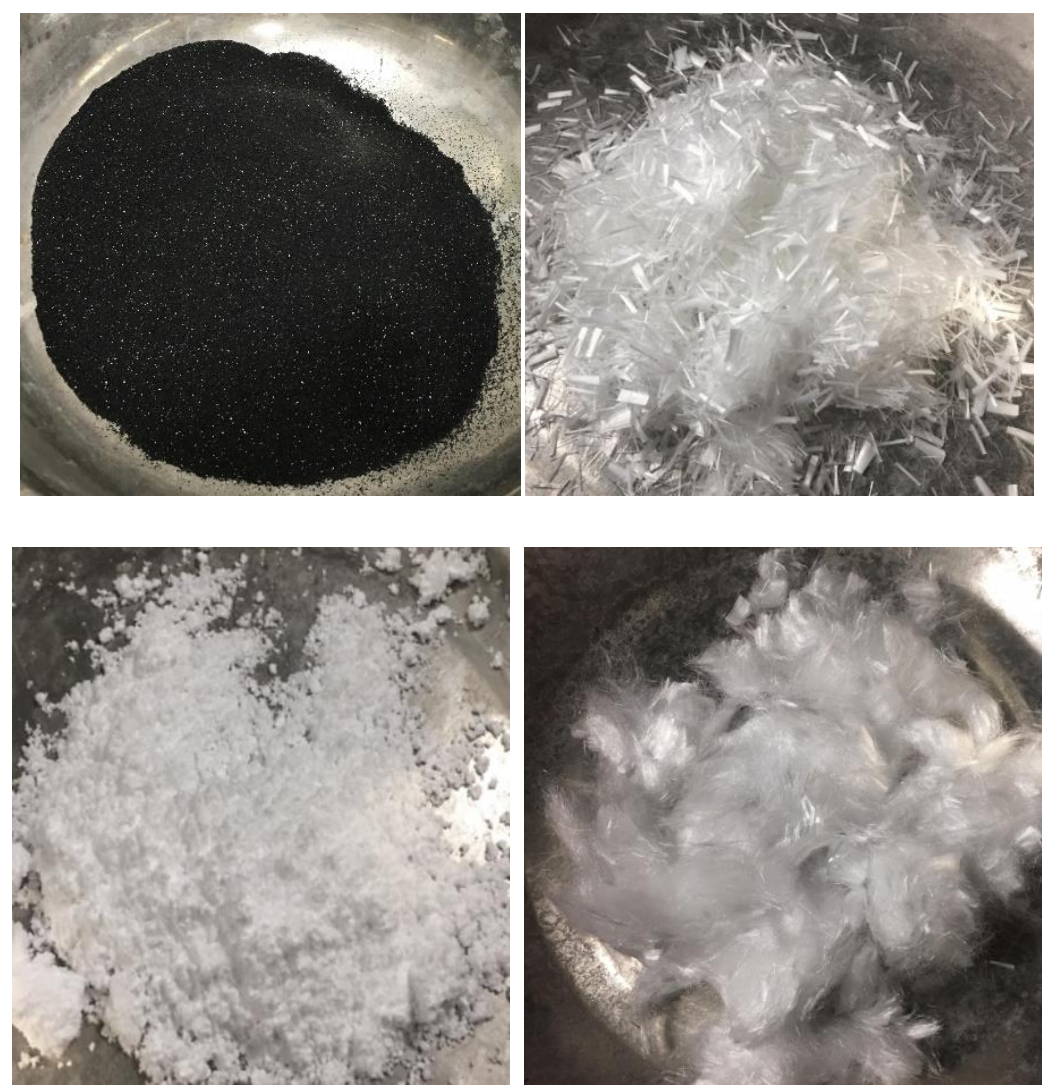

Figure 3.2: Top Left: Crumb Rubber. Top Right: PVA. Bottom Left: HDPE. Bottom Right: PE

Table 3.2: Fiber Properties

\begin{tabular}{ccccccc}
\hline $\begin{array}{c}\text { Fiber } \\
\text { Type }\end{array}$ & $\begin{array}{c}\text { Source } \\
\text { (Manufacturer) }\end{array}$ & $\begin{array}{c}\text { Product } \\
\text { Specification }\end{array}$ & $\begin{array}{c}\text { Length } \\
(\mathbf{m m})\end{array}$ & $\begin{array}{c}\text { Specific } \\
\text { Gravity } \\
\left(\mathbf{g} / \mathbf{c m}^{\mathbf{3}}\right)\end{array}$ & $\begin{array}{c}\text { Melting } \\
\text { Point }\left({ }^{\circ} \mathrm{C}\right)\end{array}$ & $\begin{array}{c}\text { Diameter } \\
\text { (Microns) }\end{array}$ \\
\hline PVA & Nycon & PVA RECS15 & 8 & 1.3 & 225 & 38 \\
\hline PE & MiniFibers INC & UHMW & 13 & 0.93 & 123 & 2.2 \\
\hline HDPE & MiniFibers INC & $\begin{array}{c}\text { (ShortStuff) } \\
\text { ESS5F }\end{array}$ & 0.1 & 0.96 & 135 & 5 \\
\hline
\end{tabular}

PVA: Polyvinyl alcohol, PE: Polyethylene; HDPE: High density polyethylene

\subsection{Concrete Mix Design}

The eight concrete mixtures presented in Table 3.3 were developed using large number of trial mixes using the control mix without fiber. The objective was to have homogenous mixtures with good slump flow and workability when fibers were incorporated. Therefore, the ratio of water to 
cement and fine aggregate to coarse aggregate varied slightly between the fiber types. The control concrete specimens without fibers underwent the same tests as to compare the results with that of the specimens with fibers. It has been previously stated that the maximum amount of fibers in a concrete mix is $1.5 \%$. The selection of the amount of fiber for each concrete was mostly based on trial and error and selected a lower value which allowed better workability and less clumping of the fibers. During mixing it was noticed that the control batch was rather watery, therefore, to counteract this more silica fume was added to reduce the bleeding and make the mixture more workable. Thus, the $\mathrm{w} / \mathrm{cm}$ ratio was decreased to 0.33 . In addition to the control batch, the 0.5\% HDPE batch had an increase of HRWRA (Glenium) to decrease the water and ensure that the concrete mix was workable and uniform.

Table 3.3: Concrete Mixtures Proportion Ratios per Type 10 Cement

\begin{tabular}{cccccccccc}
\hline $\begin{array}{c}\text { Concrete } \\
\text { Mix ID }\end{array}$ & w/cm & $\begin{array}{c}\text { Type 10 } \\
\text { Cement }\end{array}$ & $\begin{array}{c}\text { Fly } \\
\text { Ash }\end{array}$ & $\begin{array}{c}\text { Silica } \\
\text { Fume }\end{array}$ & Water & Coarse & Fine & $\begin{array}{c}\text { HRWRA } \\
\left(\mathbf{k g} / \mathrm{m}^{3}\right)\end{array}$ & $\begin{array}{c}\text { Fibers } \\
\left(\mathbf{k g} / \mathrm{m}^{3}\right)\end{array}$ \\
\hline Control & 0.33 & 1 & 0.156 & 0.137 & 0.431 & 1.179 & 1.667 & 3.876 & - \\
\hline $0.5 \%$ PE & 0.35 & 1 & 0.156 & 0.094 & 0.437 & 1.179 & 1.667 & 4.750 & 4.85 \\
\hline $1.0 \%$ PE & 0.35 & 1 & 0.156 & 0.094 & 0.437 & 1.179 & 1.667 & 4.750 & 9.70 \\
\hline $\begin{array}{c}0.5 \% \\
\text { HDPE }\end{array}$ & 0.4 & 1 & 0.156 & 0.094 & 0.506 & 1.179 & 1.640 & 7.50 & 4.80 \\
\hline $\begin{array}{c}1.0 \% \\
\text { HDPE }\end{array}$ & 0.35 & 1 & 0.156 & 0.094 & 0.437 & 1.179 & 1.614 & 4.750 & 9.60 \\
\hline $\begin{array}{c}0.5 \% \\
\text { Crumb }\end{array}$ & 0.35 & 1 & 0.156 & 0.094 & 0.437 & 1.179 & 1.640 & 4.750 & 4.50 \\
Rubber & & 1 & 0.156 & 0.094 & 0.437 & 1.179 & 1.614 & 4.750 & 9.00 \\
\hline $\begin{array}{c}1.0 \% \\
\text { Crumb }\end{array}$ & 0.35 & 1 & 0.156 & 0.094 & 185.50 & 500 & 707 & 3.876 & 1.625 \\
\hline $\begin{array}{l}\text { Rubber } \\
0.125 \% \\
\text { PVA }\end{array}$ & 0.35 & 1 & 0.156 & 0.094 & 185.50 & 500 & 701 & 4.750 & 3.25 \\
\hline $\begin{array}{c}0.25 \% \\
\text { PVA }\end{array}$ & 0.35 & 1 & & & & & & & \\
\hline
\end{tabular}

$\mathrm{cm}=$ summation of cement, fly ash and silica fume; numeric in Mix ID represents $\%$ of fiber

\subsection{Mixing}

Before the materials were mixed in the drum, the coarse aggregate and fine aggregate were presoaked in water for approximately two days. This allowed for the aggregates to be saturated, 
therefore when the water was added to the concrete mix, the mixture would not be dry causing low workability. The day of the mixing, the aggregates were dried and the depending on which batch was being made, some materials such as water and silica fume were adjusted to consider the extra water in the aggregates, which would have made the mixture very watery if the water was not adjusted in the mixture beforehand.

The mixing process as shown in Figure 3.3 was used to create the nine concrete mixtures. All the concrete batches were mixed in this time frame. This procedure allowed for proper and sufficient mixing of the materials and allowed for the fibers to be fully dispersed and mixed uniformly within the concrete mixture.

\begin{tabular}{|l|l|l|r|r|}
\hline $\begin{array}{l}\text { Sand + Coarse } \\
\text { LW aggregate }\end{array}$ & $3 / 4$ water & Binder & $\begin{array}{c}1 / 4 \text { water }+ \\
\text { HRWRA }\end{array}$ & Mixing \\
\hline
\end{tabular}

Figure 3.3: Mixing Procedure Timeline (Lotfy, 2012)

Each concrete batch was used to cast $100 \times 200 \mathrm{~mm}$ cylinders and $150 \times 75 \times 360 \mathrm{~mm}$ beams to be used for mechanical and durability testing.

\subsection{Curing of Specimens}

After casting, cylinders and cube specimens, the specimens were placed in a curing room with a temperature of 23 degrees Celsius and a relative humidity of $90 \%$. The specimens were then demolded after 24 hours and kept in the curing room until it was time to use the specimens for testing. The process of curing of these specimens was followed by using ASTM C192/C192M (2016).

\subsection{Fresh Concrete Testing}

The main purpose of the slump flow test was to conclude if the concrete mixture was workable and the LWA was uniformly distributed. Furthermore, checking the density of the fresh concrete 
also allowed for classification of the mixture as lightweight according to $\mathrm{ACl}$ specifications $(\mathrm{ACl}$ Committee 213, 2014).

\subsubsection{Slump Flow Test}

The slump flow test for all the concrete mixtures were conducted using standards and procedure of ASTM C1611/C1611M (2014). This test determines the flow of the concrete mixture after it has been mixed and the rate of viscosity. This is an important test to conduct due to the fact that there is a higher risk of segregation of lightweight aggregate and bleeding of the mix.

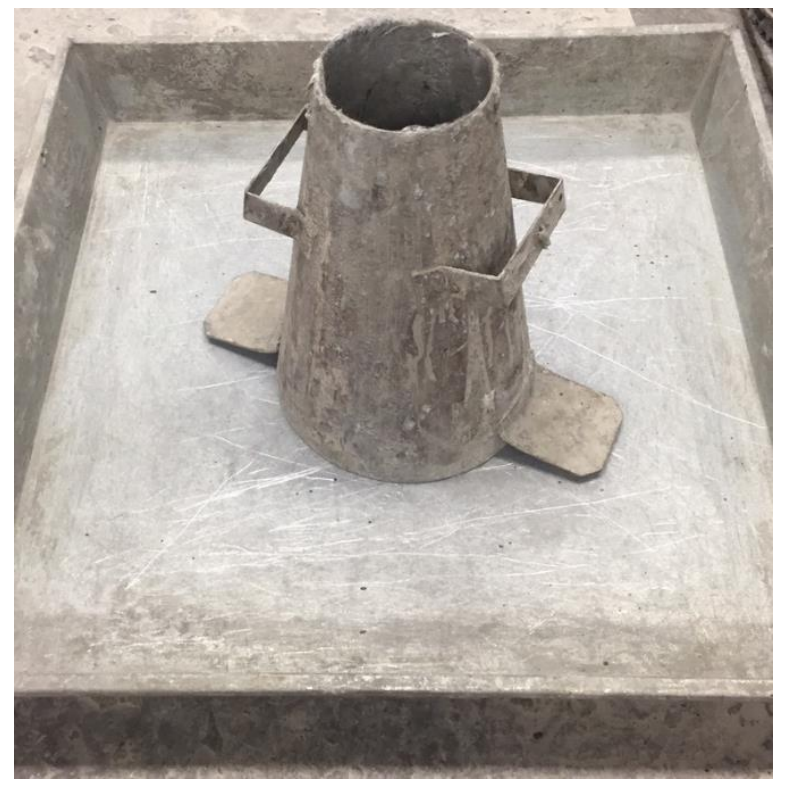

Figure 3.4: Slump Flow Test Setup

The set up for this test is shown in Figure 3.4 and a summary of the procedure of this test is as follows; a reference diameter of $500 \mathrm{~mm}$ has been drawn out on the flat surface. Then the slump cone which was placed on a flat surface in the center of the reference diameter had been filled with the concrete mix till it reached the top of the cone. After the excess concrete at the top of the cone had been removed using a bar. The mold was then removed and once the cone was lifted off the surface a timer had started to measure the time it took for the concrete mix to reach $500 \mathrm{~mm}$. This time is known as the variable $\mathrm{T}_{50}$. Once the mix had stop spreading, a visual inspection was made to see that no segregation or bleeding around the diameter was present. Two diameter measurements were taken and the slump flow was calculated by taking the 
average of the two measurements. The visual inspection of the fresh concrete for each mix has been classified into a Visual Stability Index value. Table 3.4 is a summary of the VSI values.

Table 3.4: Visual Stability Index (ASTM C1611/C1611M (2014))

\begin{tabular}{cc}
\hline VSI Value & Criteria \\
\hline (0) Highly Stable & No evidence of segregation or bleeding \\
\hline (1) Stable & No segregation and slight bleeding as a sheen \\
\hline (2) Unstable & $\begin{array}{c}\text { Slight mortar halo } \leq 10 \mathrm{~mm} \text { and/or aggregate } \\
\text { piled in the center of the concrete mass }\end{array}$ \\
\hline (3) Highly Unstable & $\begin{array}{c}\text { Segregated, large mortar halo }>10 \mathrm{~mm} \text { and/ } \\
\text { or large aggregate pile in the center of the } \\
\text { concrete mass }\end{array}$ \\
\hline
\end{tabular}

\subsubsection{Density}

For this experiment, it is crucial to obtain the fresh density, air dry density and oven dry density of the concrete batch once it had been made, because one way to classify the specimens as LSWCC is to make sure that it meets the density criteria put forth in $\mathrm{ACl} 318$. There are a variety of factors that affect the fresh density of concrete such as; air content, water demand, moisture content of the aggregate and proportioning of the concrete materials (ACI Committee 213, 2014). It is commonly known that fresh density of concrete will be higher than oven dry density because of the moisture and water absorbed by the specimen creates more weight. Besides fresh density, the air dry and oven dry densities will be found at twenty - eight days of curing to see how the density of the specimen changes as the water inside is drawn out. To find the oven dry density, procedure put forth by ASTM C567/ C567M (2014) has been followed.

\subsection{Mechanical property Testing}

Due to time constraints of the experiment, only the seven-day and twenty-eight-day compressive strength of the concrete specimens were determined. The flexural strength of all the specimens was determined at twenty-eight days. 


\subsubsection{Compressive Strength}

One of the main tasks of this research was to distinguish how fibers affect the compressive strength of lightweight self-consolidating fiber reinforced concrete (LWSCFRC). To test the compressive strength, the procedure outlined in ASTM C39/ C39M (2016) had been used. It is known that concretes strength improves with age. The difference between seven days and twenty-eight days' compressive strength difference can be entirely different, which is the reason why the specimens had been tested at these two ages. A set up of the experiment using one of the specimens can be seen in the Figure 3.5. The testing machine was calibrated and the specimen was aligned correctly, the loading was applied to the specimen continuously until the specimen had failed.

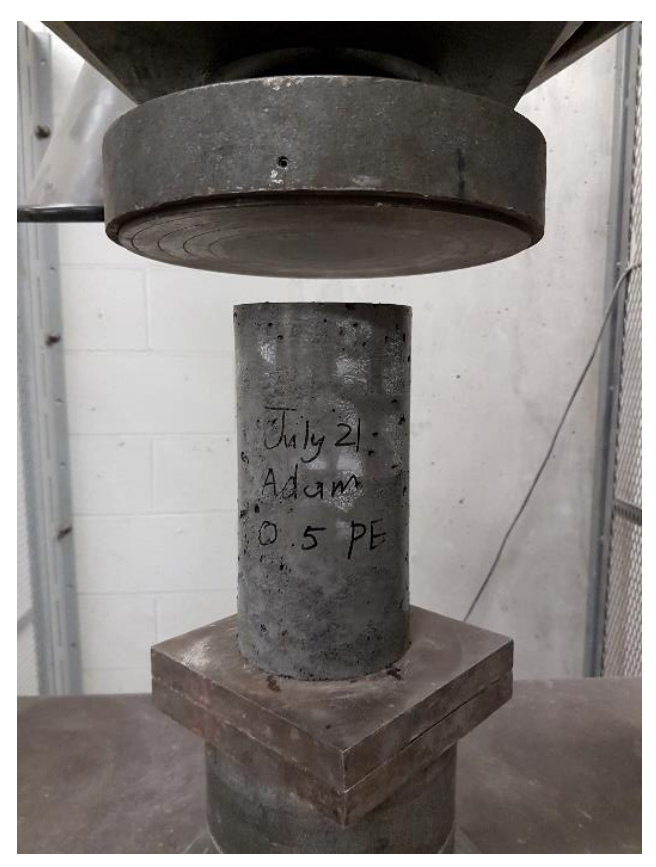

Figure 3.5: Compressive Strength Test Setup

After the specimen failed, the pattern of cracks was noted and compared with those specified in the ASTM C39/ C39M (2016) as shown in Figure 3.6. The maximum load applied to the specimen when it failed, along with the compressive strength were noted. Three cylinders have been allocated to this experiment and mean values were taken. 


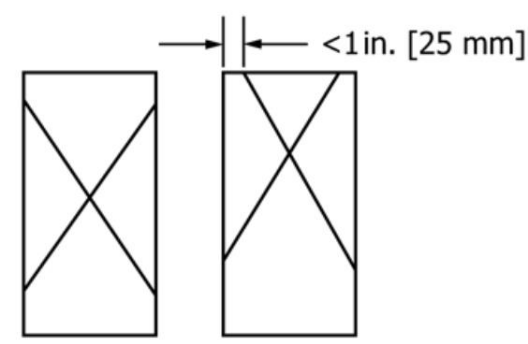

Type 1

Reasonably well-formed cones on both ends, less than 1 in. [25 mm] of cracking through caps

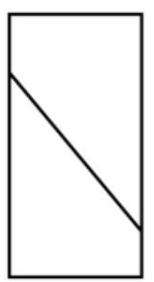

Type 4

Diagonal fracture with no cracking through ends; tap with hammer to distinguish from Type 1

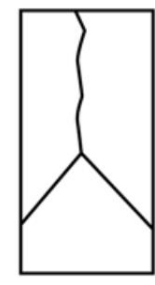

Type 2

Well-formed cone on one end, vertical cracks running through caps, no welldefined cone on other end
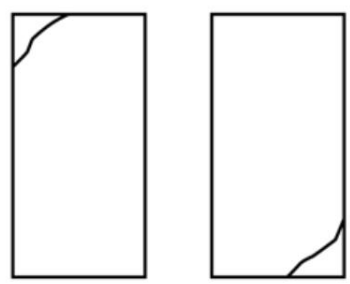

Type 5

Side fractures at top or bottom (occur commonly with unbonded caps)

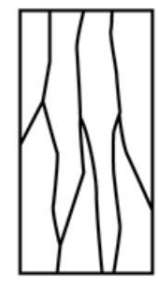

Type 3 Columnar vertical cracking through both ends, no wellformed cones

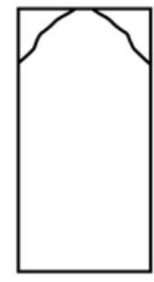

Type 6

Similar to Type 5 but end of cylinder is pointed

Figure 3.6: Crack Patterns for Compressive Strength Testing (ASTM C39/ C39M (2016))

\subsubsection{Flexural Strength}

This test had been completed using ASTM C1609/ C1609M (2012) on beams that were cast for each of the nine concrete mixes. The results of this test using third point loading will provide an insight into the flexural behavior of the concrete specimen by using the various data collected such as: peak loads and the corresponding peak strengths. A load deflection curve was made for all the specimens and the area beneath the curve was calculated as the toughness of the specimen. Furthermore, the modulus of rupture was also calculated. 


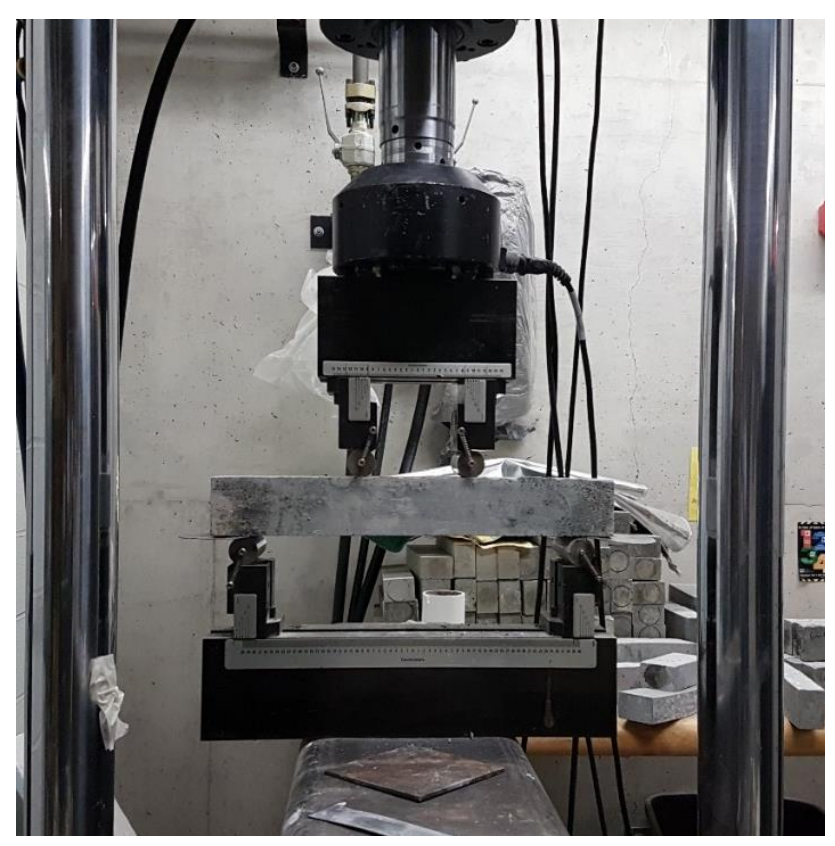

Figure 3.7: Typical Setup for Flexural Strength Test

A typical set up is shown in Figure 3.7. The simply supported (75 mm by $100 \mathrm{~mm}$ by $350 \mathrm{~mm}$ ) beam specimens subjected to third-point loading. Since this was not a standard dimension given in the standard, the rate of loading was changed to $0.005 \mathrm{~mm} / \mathrm{sec}$. The beam was loaded until failure, and the maximum loading that the specimen could take was recorded as the peak load.

\subsection{Durability Testing}

The durability of a concrete specimen is crucial, especially in corrosive and extreme environments, where the specimen can be affected negatively. Even though durability testing was performed in a controlled environment, the parameters used in the test mimics approximately realistic conditions to provide accurate results. The durability testing that were performed on the concrete specimens were rapid chloride testing (RCPT), and resistance to sulfuric acid and sodium chloride attack.

\subsubsection{Rapid Chloride Penetration Test}

The purpose of this test is to show how the concrete specimens are resistant to chloride ions being penetrated into the specimen by means of using an electric current. Chloride ions can be detrimental to the performance of concrete specimens, especially if the concrete is used in 
structures in coastal lines and environments with increased chemical exposure. ASTM C1202 12 (2012) was used to set up and perform this test. To test the durability of concrete mixtures, cylindrical specimens for each concrete batch was used and cut into disks (100 $\mathrm{mm}$ diameter and $50 \mathrm{~mm}$ thick) and a $60 \mathrm{~V}$ current was applied for the duration of the test according to the aforementioned ASTM standard. A set up of the experiment is shown in Figure 3.8. The specimens that were tested were cured till twenty - eight days. From the data that was received from the gauges, the charge that could penetrate into the specimen was recorded for the sixhour duration of the test. The negative and positive terminals were connected to the specimens to a machine that provided readings for voltage and current. Depending on the amount of coulombs that were passed across the specimen, the chloride ion penetrability varied. Table 3.5 was used to identify the level of chloride ion penetrability for each specimen. There are many factors that affect the penetrability such as w/c ratio, age and aggregate type ASTM C1202 (2012). Therefore, the $\mathrm{w} / \mathrm{c}$ ratios across the specimens are similar to allow for proper comparisons.

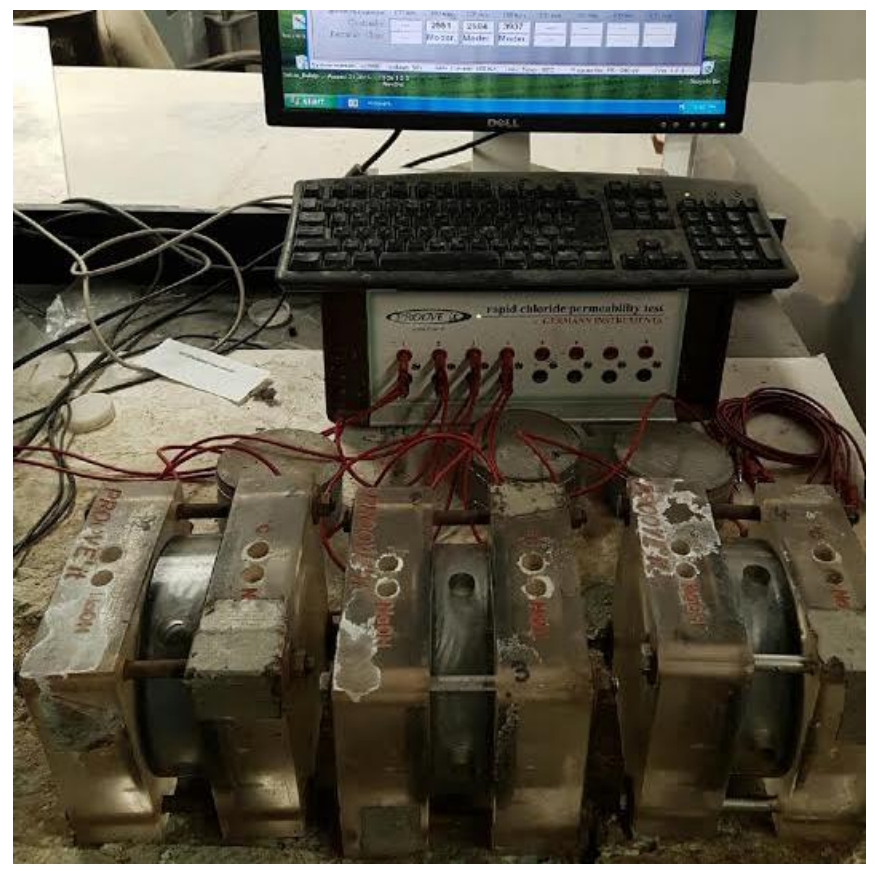

Figure 3.8: Rapid Chloride Penetration Test Setup 
Table 3.5: Chloride Ion Penetrability (ASTM C1202 (2012))

\begin{tabular}{cc}
\hline Charge Passed (Coulombs) & Chloride lon Penetrability \\
\hline$>4000$ & High \\
\hline $2000-4000$ & Moderate \\
\hline $1000-2000$ & Low \\
\hline $100-1000$ & Very Low \\
\hline$<100$ & Negligible \\
\hline
\end{tabular}

\subsubsection{Acid and Chloride Attack}

To test durability under aggressive environment, two solutions had been created; $5 \%$ Sodium Chloride $(\mathrm{NaCl})$ solution and $5 \%$ Sulfuric Acid $\left(\mathrm{H}_{2} \mathrm{SO}_{4}\right)$ solution. These solutions have been created in a bin as shown in Figure 3.9 using the respective acid and water to dilute the solution to 5\%. $5 \%$ solutions have been chosen to allow for the specimens to exhibit an accelerated deterioration in a shorter period of time. To compare, cylindrical concrete specimens were also immersed in water for the same duration as the ones in the acid/chloride solutions. To set up the experiment, each cylindrical specimen was cut in half to produce more samples for each solution. The size of the specimens had a cross section and a height of $100 \mathrm{~mm}$. Each solution was placed in their respective bin and the solutions were diluted using water. The specimens were then placed in the bins and the tops were covered to ensure that the solution would not evaporate. Every couple of days the solutions were mixed to ensure that the acid would not sink to the bottom and cause an inaccurate mass loss in the specimens. The duration for this test was eight weeks and the change in mass was recorded throughout the duration of the test. Once the specimens stayed in the solution for the eight-week period, the samples were then crushed to test the change in compressive strength. The crushing of the specimens was performed in the same manner as the testing for twenty-eight day compressive strength. The loading rate used for the testing was 1 $\mathrm{mm} / \mathrm{min}$. 


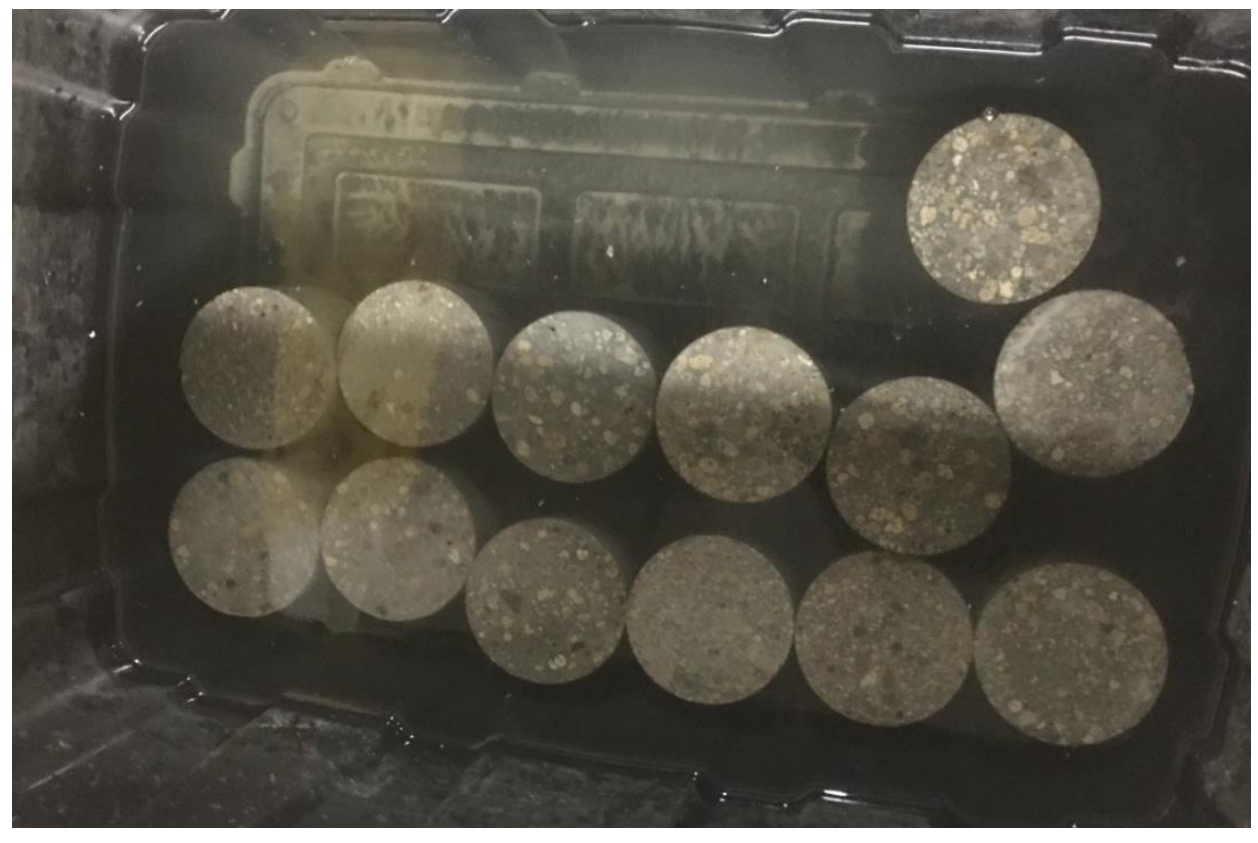

Figure 3.9: Acid Attack Test Setup 


\section{Chapter 4 : Results and Analysis}

\subsection{Introduction}

Experimental results on fresh state, mechanical and durability tests are presented and analyzed in this Chapter. An analysis of the effects of fibers on the properties of LWSCFRC mixtures compared to control mixture (without fiber) is provided along with the findings from previous research studies.

\subsection{Fresh state properties}

The density or unit weight of fresh concrete, as well as the slump flow, have been calculated after the concrete batches had been mixed. During the mixing of the concrete batches, some problems arose with the addition of fibers. Even though best efforts were taken to create a homogenous mixture, clumping occurred for PVA and HDPE mixtures. This clumping was more noticeable in these two concrete mixtures because of the short length of fibers. Therefore, this negatively affected the workability and the self-compacting ability of the concrete mixtures. Thus, some improvements were made with the addition of water and HRWRA. It was also imperative that water was added in small quantities while mixing because a suitable viscosity was to be maintained to ensure that the fibers did not segregate when the mixing stopped. This was also mentioned by researchers, where they made a note stating the increase in the viscosity of mixture would reduce the risk of segregation of the fibers and aggregates (Park et al. 2007).

\subsubsection{Density}

The fresh unit weight, air dry density, and oven dry density have been measured for the mixtures, and a comparison of densities is shown in Figure 4.1. The twenty - eight day oven dry and air dry density criteria are less than or equal to $1840 \mathrm{~kg} / \mathrm{m}^{3}$ as per $\mathrm{ACl} 213 \mathrm{R}$, and this is also represented in Figure 4.1. Numerical comparisons of these densities are also summarized in Table 4.1. From all the specimens that were tested, $0.5 \%$ and $1.0 \%$ PE fiber specimens have achieved an oven dry density of $1537 \mathrm{~kg} / \mathrm{m}^{3}$ and $1465 \mathrm{~kg} / \mathrm{m}^{3}$ respectively. Compared to the control mixture, this is a decrease of $14.3 \%$ and $18.4 \%$, respectively which can be due to the dense concrete mixture which allowed for more water evaporation when the mixture was placed in the oven. Furthermore, 
1.0\% Crumb Rubber and 0.25\% PVA specimens have only achieved oven dry densities of 1810 $\mathrm{kg} / \mathrm{m}^{3}$ and $1830 \mathrm{~kg} / \mathrm{m}^{3}$, respectively. Therefore, since these specimens have not reached the maximum density limit according to $\mathrm{ACl} 213 \mathrm{R}$. Thus, it has been decided to remove the PE specimens from further testing and analysis. Although very close to the target density HDPE along with Crumb rubber and PVA specimens have been kept for further mechanical analysis.

It is common for oven dry density to be lower than air dry density because of water evaporation during the time that the mixture is being dried in the oven. The comparison of oven dry densities of all the specimens shows a range between $1465 \mathrm{~kg} / \mathrm{m}^{3}$ to $1875 \mathrm{~kg} / \mathrm{m}^{3}$. Comparing all three densities for each specimen type, the decrease in density from fresh to oven dry is due to the water evaporation and the increase of water absorption of the porous lightweight aggregates. Another factor that affects the density of the concrete is the expanded slag that is used to create the mixtures. The increased porosity of the LWA soaks in more water creating a heavier mixture; hence the fresh density of each specimen is higher.

Table 4.1: Fresh, Air Dry and Oven Dry Densities of Specimens

\begin{tabular}{cccc}
\hline Specimen Type & $\begin{array}{c}\text { Fresh Density } \\
\left(\mathbf{k g} / \mathbf{m}^{3}\right)\end{array}$ & $\begin{array}{c}\text { Air Dry Density } \\
\left(\mathbf{k g} / \mathbf{m}^{3}\right)\end{array}$ & $\begin{array}{c}\text { Oven Dry } \\
\text { Density }\left(\mathbf{k g} / \mathbf{m}^{3}\right)\end{array}$ \\
\hline Control & 1976 & 2048 & 1795 \\
\hline $0.5 \%$ PE & 1900 & 1746 & 1537 \\
\hline $0.5 \%$ HDPE & 2065 & 2057 & 1853 \\
\hline $0.5 \%$ Crumb Rubber & 1975 & 2065 & 1875 \\
\hline $0.125 \%$ PVA & 2000 & 1925 & 1840 \\
\hline $1.0 \%$ PE & 1720 & 1615 & 1465 \\
\hline $1.0 \%$ HDPE & 2162 & 1942 & 1840 \\
\hline $1.0 \%$ Crumb Rubber & 2067 & 1870 & 1830 \\
\hline $0.25 \%$ PVA & 1950 & 1930 & \\
\hline
\end{tabular}

From these results, comparisons were made with previous research on different fibers and their effects on the concrete's density. It was found that the addition of $17.8 \mathrm{~kg} / \mathrm{m}^{3}$ of steel fibers with 
a length of $50 \mathrm{~mm}$ obtained an oven dry density of approximately $1560 \mathrm{~kg} / \mathrm{m}^{3}$ (Doukakis, 2013). This is very similar to the $0.5 \%$ PE fiber specimen which obtained an oven dry density of 1537 $\mathrm{kg} / \mathrm{m}^{3}$. Even though steel fibers are known to be heavier than synthetic fibers, a factor that caused the specimen to have a lower value is the air voids that were created once the concrete batch was mixed. The increased length of the fibers could have caused the fibers and paste not to mix well, therefore not creating a dense concrete matrix. Thus, this could have caused larger air avoids to occur which reduced the density of the mixture (Doukakis, 2013). The highest oven dry density was found in the $0.5 \%$ Crumb Rubber specimen with $1875 \mathrm{~kg} / \mathrm{m}^{3}$. This higher density can be due to the behavior of the fibers and the paste. Since the rubber is plastic, it does not absorb as much water as the other fibers used in this experiment the bonding between the fibers and paste is poor. As a result, the repelled water increases the density of the specimen. Overall, the addition of fibers in a concrete mixture increased the density of the mixture compared to the control mixture.

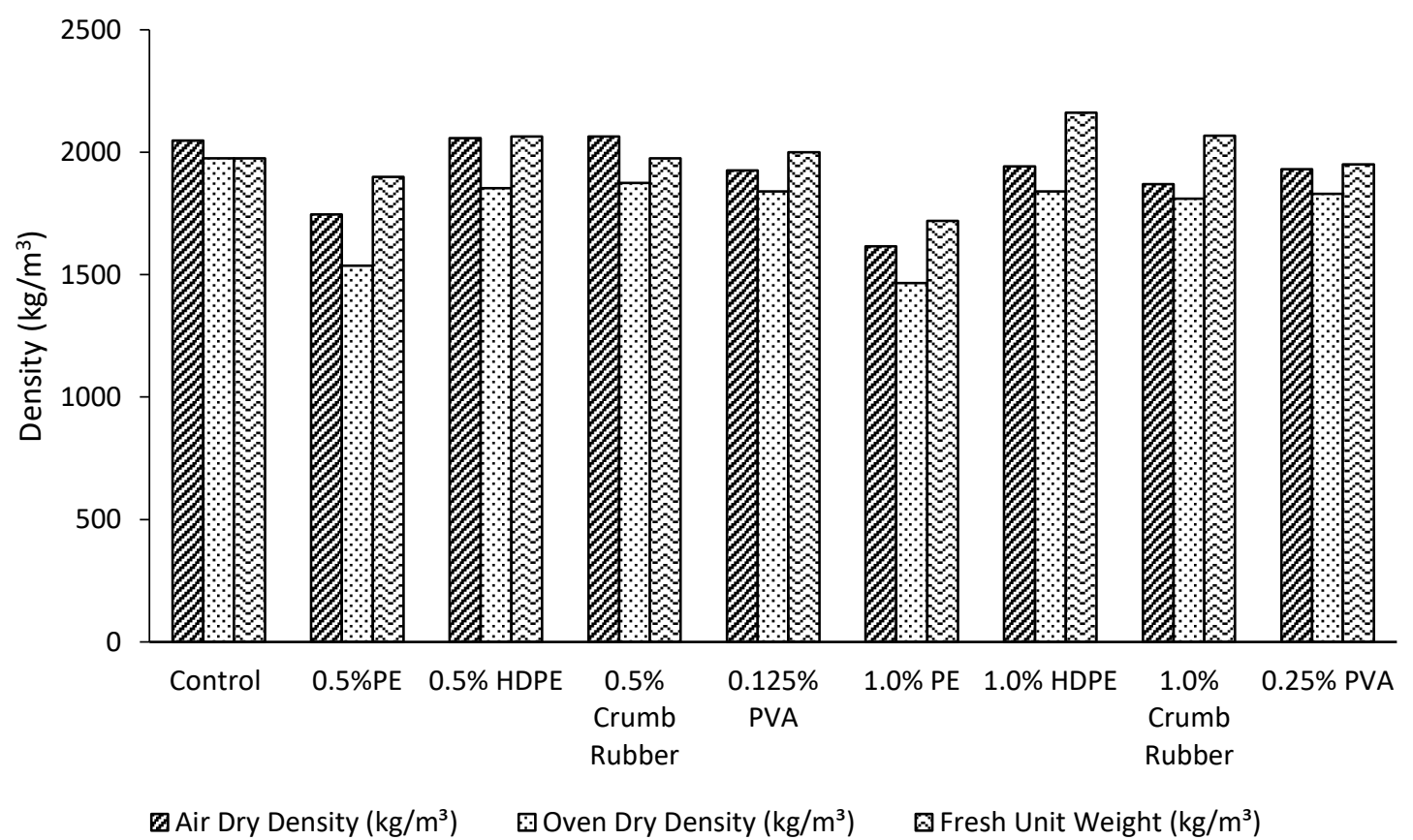

Figure 4.1: Densities of Concrete Mixtures 


\subsubsection{Slump flow}

From previous research results, it was concluded by many researchers that the slump flow of the concrete mixture would decrease with the increase in fiber content. The results of slump flow of concrete mixtures obtained are compared in Figure 4.2. It can be seen that between the control mix and the $0.5 \%$ PE fiber mix the slump flow did in fact decrease. This shows that the fibers did decrease the workability of the mixture. Although this statement is not true for $0.5 \%$ HDPE mix, where the mixture had a slump flow of $650 \mathrm{~mm}$, which was higher than the control mix. One reason for the higher value could be due to the adjustments made to the different components of the concrete mix, such as the increase in water. The visual stability index (VSI) was recorded in Table 4.2 using Table 3.3 as a guideline. For all the concrete batches the VSI was a value 1, which means there was no segregation between the aggregate and the paste and the mix was stable according to ASTM C1611/ C1611M (2014).

Table 4.2: VSI of Specimens

\begin{tabular}{cc}
\hline Specimen Type & VSI \\
\hline Control & 1 (Stable) \\
\hline $0.5 \%$ PE Fibers & 1 (Stable) \\
\hline $0.5 \%$ HDPE Fibers & 1 (Stable) \\
\hline $0.5 \%$ Crumb Rubber & 1 (Stable) \\
\hline $0.125 \%$ PVA & 1 (Stable) \\
\hline $1.0 \%$ PE & 1 (Stable) \\
\hline $1.0 \%$ HDPE & 1 (Stable) \\
\hline $1.0 \%$ Crumb Rubber & 1 (Stable) \\
\hline $0.25 \%$ PVA & 1 (Stable) \\
\hline
\end{tabular}

The increase in fiber content in the concrete mixture exhibited decreased slump flow, which resulted in decreased workability. Another factor that caused the decrease in workability was the higher absorption capacity of LWA compared with normal aggregate. The purpose of LWSCC is to flow easily into the crevices without mechanical vibration, therefore with the addition of the 
fibers in the mixture overall decreases the workability, but most of the specimens meet the slump flow criteria of $550 \mathrm{~mm}$ to $850 \mathrm{~mm}$. The lower slump flow value is in $1.0 \%$ HDPE of $450 \mathrm{~mm}$. This is because during the mixing process of the mixture, the fibers had a tendency to clump together instead of mixing uniformly with the concrete paste. Therefore, the workability of the mixture decreased. The highest slump flow was recorded in the $1.0 \%$ Crumb rubber specimen. $0.5 \%$ and $1.0 \%$ Crumb Rubber mixtures revealed more bleeding around the edges in the slump flow test. This is due to the plastic nature of the crumb rubber where the absorption capacity of the fibers is much lower. In conclusion, 0.5\% HDPE, $0.5 \%$ and 1.0\% Crumb Rubber specimens exhibited better slump flow performance compared with the control specimen, therefore this can be an advantage from a self-consolidating point of view. A visual representation of slump flow for $0.5 \%$ PE, 0.25\% PVA, 1\% Crumb Rubber and 1\% HDPE is shown in Figures 4.3, 4.4, 4.5 and 4.6, respectively.

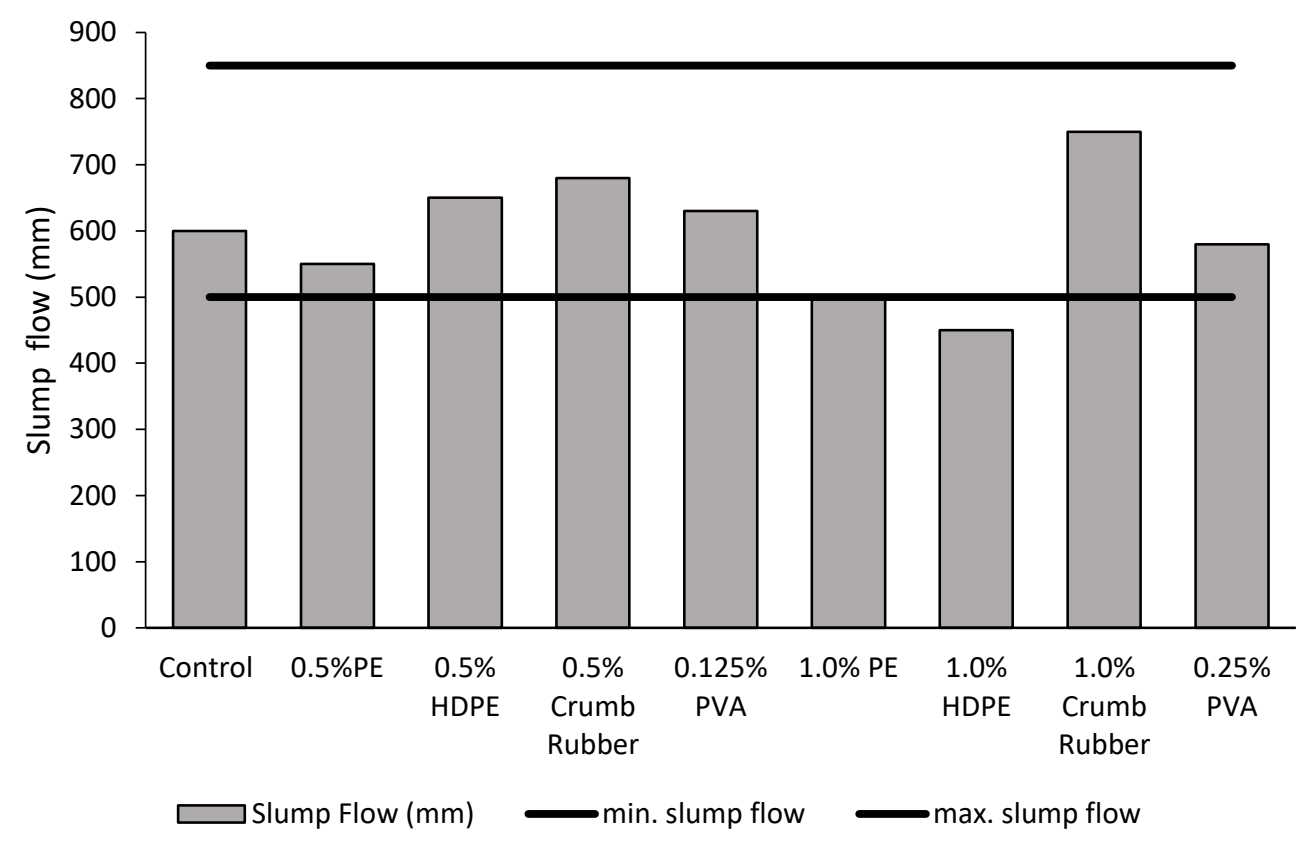

Figure 4.2: Slump Flow of Specimens 


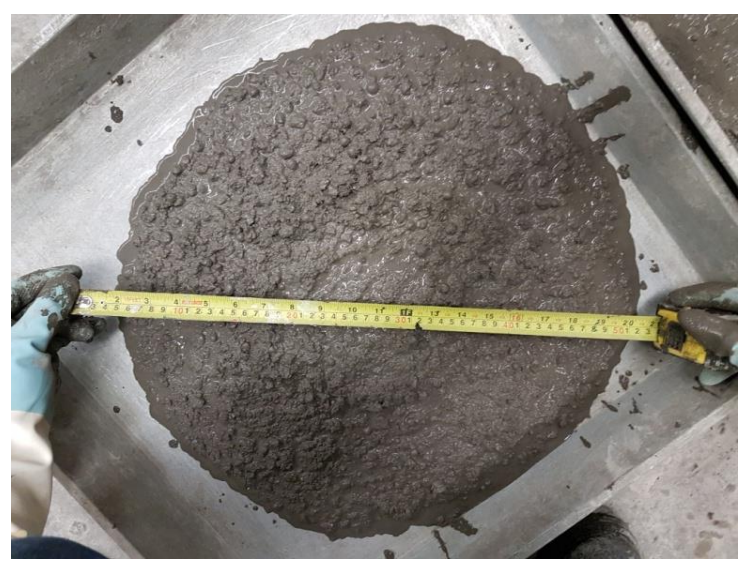

Figure 4.3: Slump Flow for 0.5\% PE Concrete Mixture

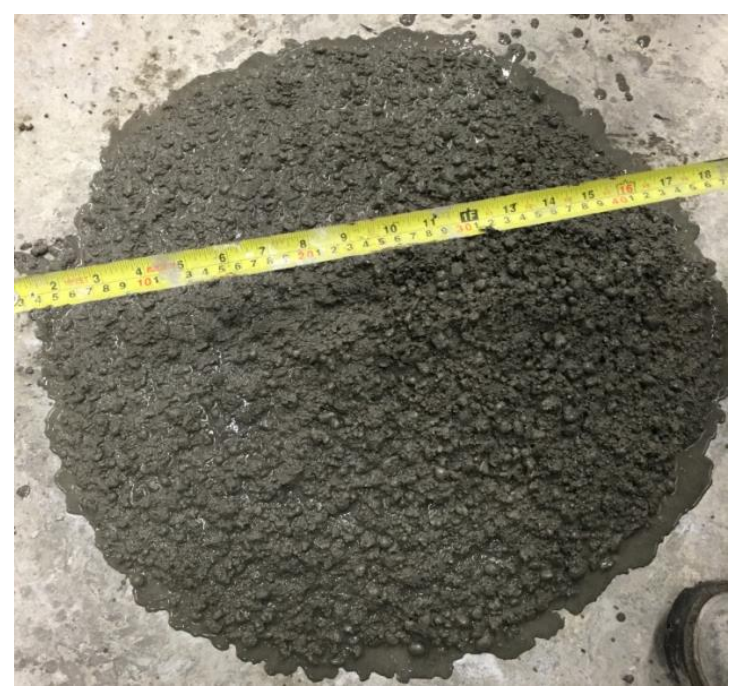

Figure 4.4: Slump Flow for 0.25\% PVA Concrete Mixture

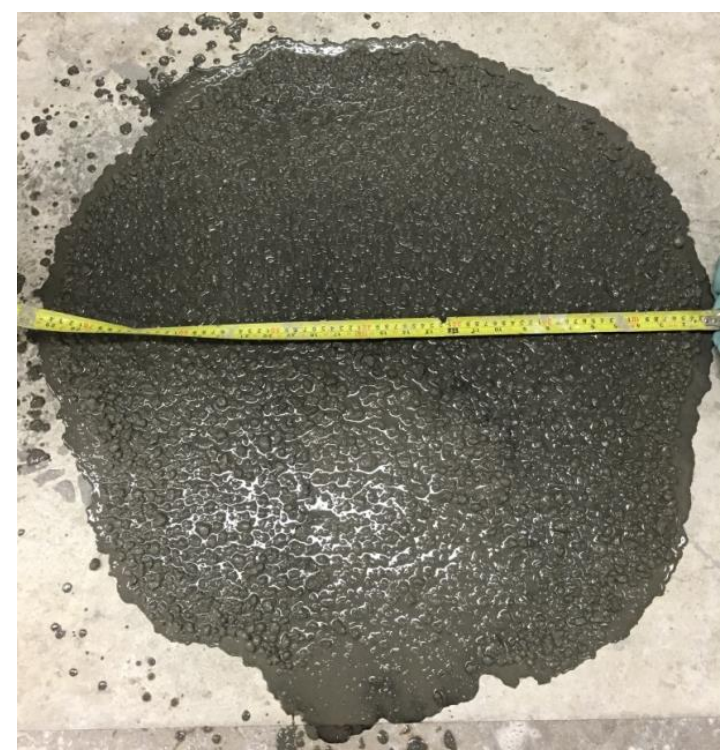

Figure 4.5: Slump Flow for 1.0\% Crumb Rubber Concrete Mixture 


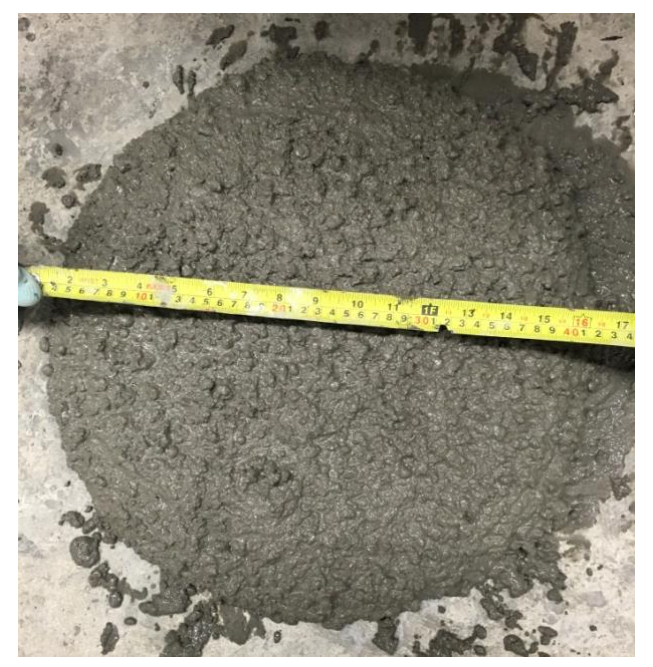

Figure 4.6: Slump Flow for 1.0\% HDPE Concrete Mixture

\subsection{Mechanical Properties}

Table 4.3 shows the cross sections of all the specimens made from different concrete mixtures after twenty-eight days of curing. Mixture 1 and Mixture 2 in the table define the $0.5 \%$ and $1.0 \%$ fiber content in the concrete mixtures, respectively. The exception to this is for the PVA mixture, where Mixture 1 and Mixture 2 represent $0.125 \%$ and $0.25 \%$ fiber content, respectively. These cross-sections reveal a uniform distribution of various component of concrete mixture in the cast concrete specimens. 
Table 4.3: Cross Sections of All Specimens

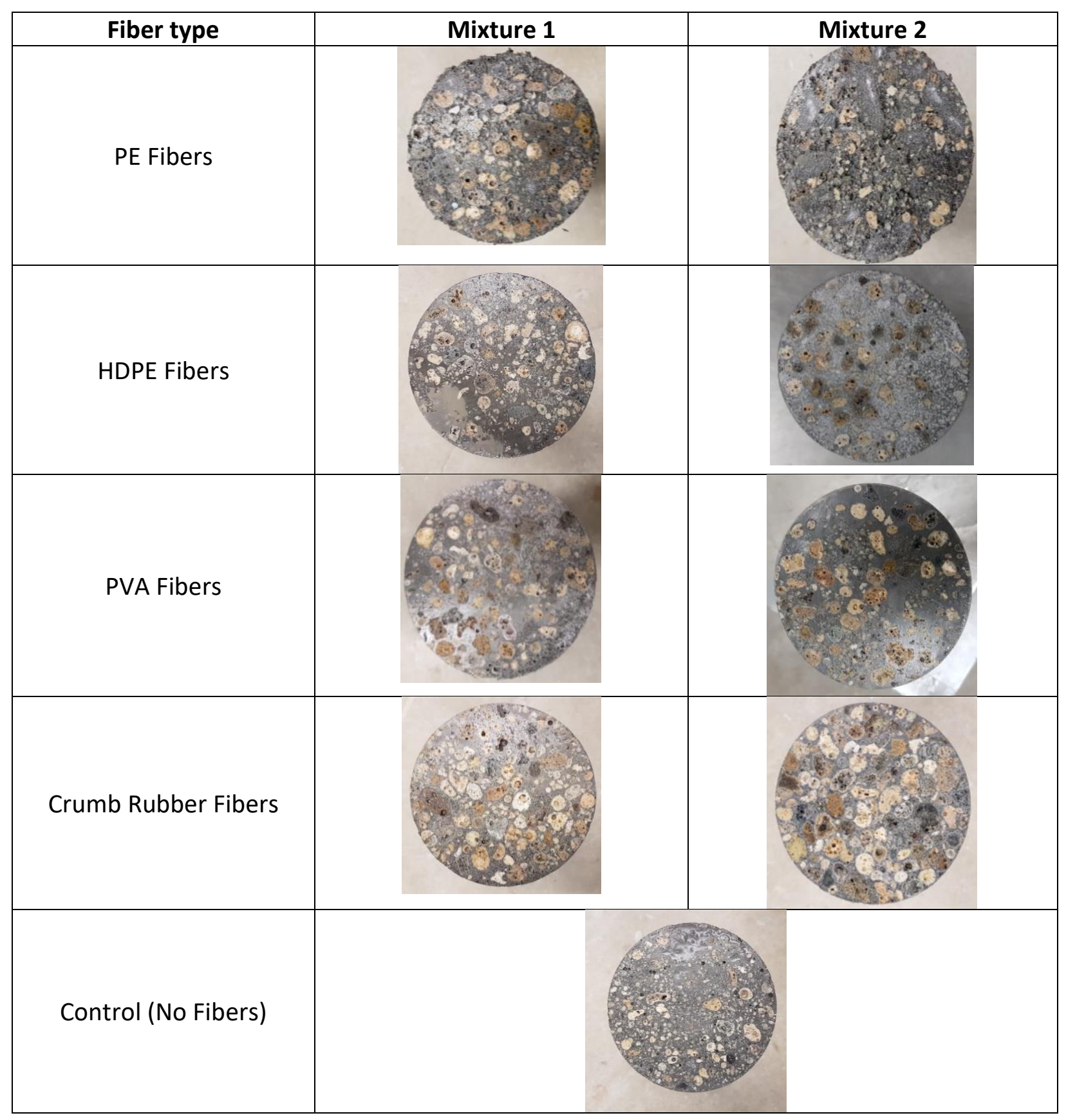

\subsubsection{Compressive Strength}

Table 4.4 and 4.5 , summarizes the maximum load at which the specimen failed and the corresponding compressive strength for 7 and 28-days testing. As per $\mathrm{ACl} 318$ (2014), to qualify as structural LWSCC, the 28-day compressive strength should be at least 17.2 MPa. Figure 4.7 
compares the 7 and 28 days compressive strength of concrete mixtures showing the line of compressive strength to qualify for structural concrete.

PE Mixtures: The PE specimens were able to develop strength from seven to twenty-eight days but from the comparison into the effects of increasing PE fiber content, the $0.5 \%$ PE increase had caused the compressive strength to decrease. This decrease is due to the clumping that was formed during the mixing stages of the concrete. When there isn't a proper dispersion of fibers, certain areas of the concrete are not as strong as the areas where there are more fibers, hence creating weak spots. Thus, these weak spots caused the specimen to gain more strength. Furthermore, when clumping of the fibers occurs, more paste is absorbed into these clumps, which can negatively affect the mechanical properties of concrete. Since both the $0.5 \%$ and $1.0 \%$ PE specimens did not reach the target compressive strength of $17.2 \mathrm{MPa}$, these specimens cannot be classified as structural LWSCC. Therefore, no further analysis has been conducted on the remaining PE specimens.

HDPE Mixtures: Comparing the seven-day compressive strength, 0.5\% HDPE specimen gained strength of 17.8 MPa, while 1.0\% HDPE gained 23.18 MPa. This reveals that the increase of HDPE fibers increased the early development of seven-day compressive strength. At twenty-eight day, there was not a significant difference between the two mixes. This same observation was recorded in another experiment, where the increase in HDPE fibers from $0.2 \%$ to $0.6 \%$, had a compressive strength of approximately $32 \mathrm{MPa}$ and $35 \mathrm{MPa}$, respectively (Bhavi et al. 2012). Due to the shorter length of the HDPE fibers compared to PE fibers, this allowed the fibers to fill in the air voids and create a denser matrix. Thus, the decreased air voids allowed the specimen to be more resistant to compressive loading (Bhavi et al. 2012).

Crumb Rubber Mixtures: The $0.5 \%$ crumb rubber specimen recorded a compressive strength of 41.74 MPa which showed that early strength development occurred. It was not expected for the seven-day compressive strength to be that high. However, the strength development was not continued with age which caused the twenty-eight-day compressive strength to decrease approximately $12 \mathrm{MPa}$. One reason for the decrease of compressive strength can be due to the material behavior between the rubber and the paste. Since rubber is plastic, water is repelled, 
therefore the bonding between the fibers and cement paste is weak, which as a result can cause lower compressive strength. Therefore, the poor cohesion between the fibers and the paste can cause a lower compressive strength. The $1.0 \%$ Crumb Rubber specimen showed an increase of compressive strength from 27.5 $\mathrm{MPa}$ to $36.9 \mathrm{MPa}$ at seven and twenty-eight days, respectively. This same outcome has been found in previous research studies with crumb rubber. The compressive strength of self-consolidating rubberized concrete was decreased from $35.6 \mathrm{MPa}$ to 21.1 MPa with the increase in crumb rubber content from $10 \%$ to $30 \%$ (Karahan et al. 2012). A similar outcome where a concrete specimen with a $0.4 \mathrm{w} / \mathrm{cm}$ ratio had twenty-eight-day compressive strength of $42 \mathrm{MPa}$ and decreased to approximately $9 \mathrm{MPa}$ when the crumb rubber content increased to 25\% (Gesoglu \& Guneyisi, 2007).

PVA Mixtures: The increase in PVA fibers created a similar outcome as with the other fibers in this experiment, where the compressive strength decreased. Both $0.125 \%$ and $0.25 \%$ exhibited a small development in compressive strength from seven to twenty-eight days. 0.125\% PVA specimen had an increase in compressive strength of approximately $3 \mathrm{MPa}$, while $0.25 \%$ PVA specimen gained $6 \mathrm{MPa}$ to $26.2 \mathrm{MPa}$. Similar twenty - eight day compressive strength value of $38 \mathrm{MPa}$ was found for a SCC mixture with the same amount of PVA fiber content of $0.125 \%$, while the compressive strength increased to $40 \mathrm{MPa}$ for 0.3\% PVA (Hossain et al. 2013). One major factor that affected the compressive strength was workability of mixes. The increase in PVA fibers caused workability to decrease significantly due to the clumping of fibers that occurred as the concrete was being mixed. Due to the clumping of the fibers, the specimen had weak spots which caused some areas not to have enough fibers to resist the compressive loading and cracking.

The decrease in the development of compressive strength from seven to twenty-eight days has also been noticed in other research with different fibers such as steel fibers and polypropylene fibers (PP). Although not significant, a decrease of $1 \mathrm{MPa}$ in twenty-eight-day compressive strength for LWSCC was noted in one research study with the increase of steel fibers from $30 \%$ to $60 \%$ fiber content (Doukakis, 2013). Reason for the slight decrease can be due to the nature of the steel where it can resist more load and cracking, therefore increasing the compressive strength of the concrete. Compared to normal aggregate, LWA has more porous structure, allowing more absorption of water which causes the aggregate to be weaker under loading. Thus, 
research studies under compressive loading; found that the use of steel fibers increased the compressive strength of the specimens. However, researchers concluded that the compressive strength increased for specimens with PP fibers ranging from $3 \mathrm{~kg} / \mathrm{m}^{3}$ to $12 \mathrm{~kg} / \mathrm{m}^{3}$ (Gencel, 2011). There are many factors that can affect the compressive strength of concrete and it should be noted that it can be an advantage for fibers that are weaker in nature tend to clump more. Previous literature has revealed that the subtle increase in silica fumes can allow for a better bonding of the paste and the fibers, which creates a denser mixture, therefore enhancing the compressive strength (Gesoglu \& Guneyisi, 2007). Also, the increase in water content in the mixture can negatively affect the compressive strength, while an increase $\mathrm{w} / \mathrm{b}$ ratio can improve the compressive strength (Gencel, 2011). Overall, it can be seen from Figure 4.7 that the use of fibers does not enhance the compressive strength of the concrete and the increase in fiber content further reduces the compressive strength as noted in PVA, PE, HDPE and Crumb Rubber specimens.

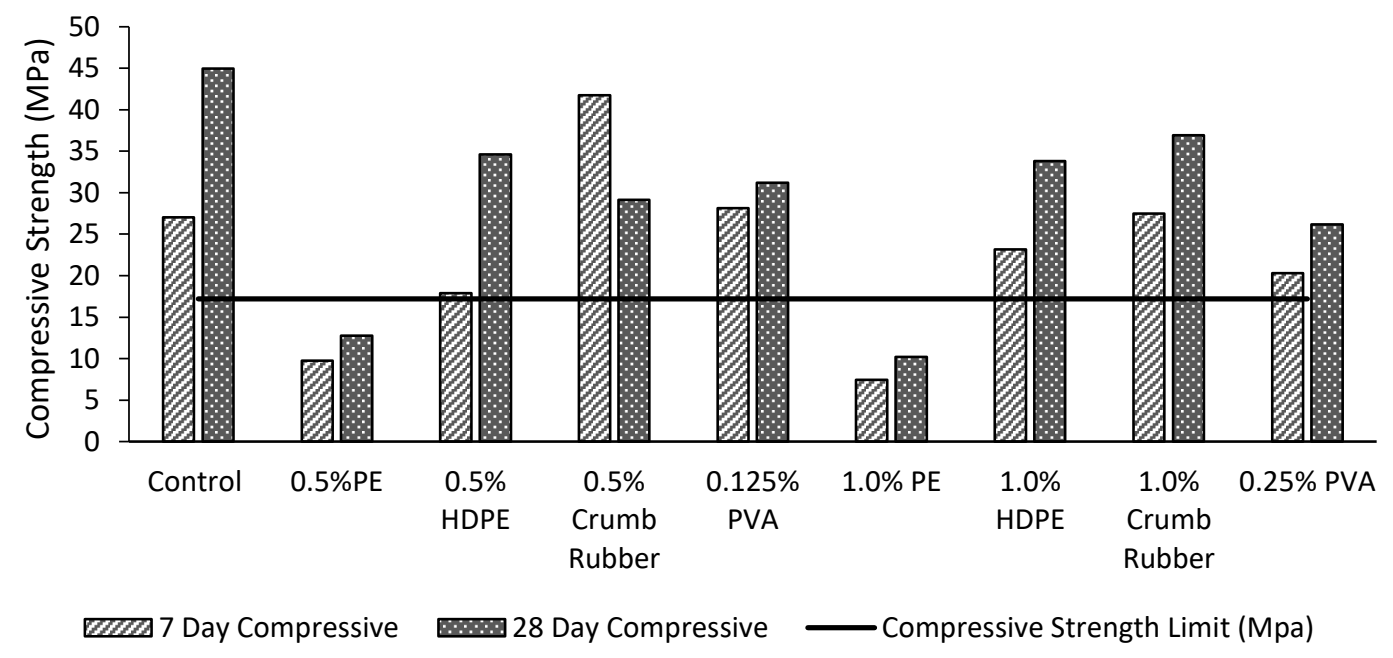

Figure 4.7: Seven and Twenty - Eight Day Compressive Strength of Specimens 
Table 4.4: Failure Loading and Corresponding Compressive Strength at Seven Days

\begin{tabular}{ccccccc}
\hline \multirow{2}{*}{ Specimen } & \multicolumn{3}{c}{ Failure Load (kN) } & \multicolumn{3}{c}{ Compressive Strength at 7 days } \\
& (MPa) & \\
\cline { 2 - 7 } & Test \#1 & Test \#2 & Average & Test \#1 & Test \#2 & Average \\
\hline Control & 215.85 & 208.66 & 212.255 & 27.483 & 26.566 & 27.0245 \\
\hline $0.5 \%$ PE & 75.33 & 78.21 & 76.77 & 9.59 & 9.96 & 9.775 \\
\hline $0.5 \%$ HDPE & 122.91 & 157.7 & 140.305 & 15.651 & 20.078 & 17.8645 \\
\hline $0.5 \%$ Crumb Rubber & 326.12 & 329.44 & 327.78 & 41.52 & 41.95 & 41.735 \\
\hline $0.125 \%$ PVA & 243.24 & 198.44 & 220.84 & 30.97 & 25.27 & 28.12 \\
\hline $1.0 \%$ PE & 58.46 & 58.43 & 58.445 & 7.45 & 7.43 & 7.44 \\
\hline $1.0 \%$ HDPE & 181.45 & 182.65 & 182.05 & 23.104 & 23.256 & 23.18 \\
\hline $1.0 \%$ Crumb & 148.01 & 283.69 & 215.85 & 18.843 & 36.122 & 27.4825 \\
\hline $0.25 \%$ PVA & 159.82 & 159.33 & 159.575 & 20.347 & 20.285 & 20.316 \\
\hline
\end{tabular}

Table 4.5: Failure Loading and Corresponding Compressive Strength at Twenty - Eight Days

\begin{tabular}{ccccccc}
\hline \multirow{2}{*}{ Specimen } & \multicolumn{3}{c}{ Failure Load @ 28 days (kN) } & \multicolumn{3}{c}{$\begin{array}{c}\text { Compressive Strength at 28 } \\
\text { days (MPa) }\end{array}$} \\
\cline { 2 - 7 } & Test \#1 & Test \#2 & Average & Test \#1 & Test \#2 & Average \\
\hline Control & 334.69 & 371.42 & 353.055 & 42.617 & 47.291 & 44.954 \\
\hline $0.5 \%$ PE & 88.54 & 112.3 & 100.42 & 11.27 & 14.3 & 12.785 \\
\hline $0.5 \%$ HDPE & 315.28 & 228.72 & 272 & 40.142 & 29.124 & 34.633 \\
\hline $\begin{array}{c}0.5 \% \text { Crumb } \\
\text { Rubber }\end{array}$ & 205.93 & 252.15 & 229.04 & 26.221 & 32.102 & 29.1615 \\
\hline $0.125 \%$ PVA & 226.76 & 263.41 & 245.085 & 28.875 & 33.54 & 31.2075 \\
\hline $1.0 \%$ PE & 77.95 & 82.16 & 80.055 & 9.929 & 10.459 & 10.194 \\
\hline $1.0 \%$ HDPE & 262.4 & 268.6 & 265.5 & 33.412 & 34.198 & 33.805 \\
\hline $1.0 \%$ Crumb & 338.56 & 241.24 & 289.9 & 43.186 & 30.716 & 36.951 \\
\hline $0.25 \%$ PVA & 206.68 & 204.7 & 205.69 & 26.311 & 26.062 & 26.1865 \\
\hline
\end{tabular}


Table 4.6: Crack Pattern for Each Specimen at Twenty - Eight Days

\begin{tabular}{cc}
\hline Specimen Type & Crack Pattern \\
\hline Control & Type 4 \\
\hline $0.5 \%$ PE & Type 3 \\
\hline $0.5 \%$ HDPE & Type 3 \\
\hline $0.5 \%$ Crumb Rubber & Type 3 \\
\hline $0.125 \%$ PVA & Type 2 \\
\hline $1.0 \%$ PE & Type 5 \\
\hline $1.0 \%$ HDPE & Type 4 \\
\hline $1.0 \%$ Crumb Rubber & Type 3 \\
\hline $0.25 \%$ PVA & Type 3
\end{tabular}

Table 4.6 summarizes the types of crack pattern for each specimen as per ASTM C39 (2016) and using Figure 3.6. Table 4.7 visually summarizes the crack pattern of twenty-eight-day specimens at failure. From Table 4.7 it can be concluded that the crack patterns for almost all the specimens display vertical cracks. Mixture 1 and Mixture 2 represent the $0.5 \%$ and $1.0 \%$ fiber content, respectively, while for PVA fiber specimens it represents $0.125 \%$ and $0.25 \%$ fiber contents. From the inspection of these specimens, PE fibers showed less scaling. This is due to the smaller length of fibers compared to the other fibers used in this study. The shorter fiber length allowed for a better interlocking of the cement, therefore keeping the specimen intact than the rest of the specimens. The Crumb Rubber specimens revealed more peeling of concrete pieces when the specimen failed. One reason for this type of failure can be due to bonding failure because of the low bonding behavior between the rubber fibers and the paste. Compared to the control specimen's scaling on the bottom portion of the specimen, most of the fiber specimens showed less scaling and fewer deformations. Lastly, the compressive failures for each specimen, it can be concluded that due to the porous nature of the lightweight aggregate; PE, PVA, control and HDPE specimens failed also due to aggregate failure while crumb rubber specimen failed from bonding failure because of the bonding behavior between the cement paste and the rubber particles. Referring to Table 4.7, aggregate failure can be seen in the control and HDPE specimens because of the splitting of the aggregates. The PE and PVA specimens do show cracking but the specimen is still intact. Closer inspection of the PE and specimens showed no pull out of fibers, therefore 
the fibers ruptured under compressive loading. Furthermore, HDPE specimens showed some fibers sticking out of the concrete in the areas where cracking occurred, which means that there was fiber pull out when the specimen failed.

Table 4.7: Failure of Specimens under Maximum Compressive Loading

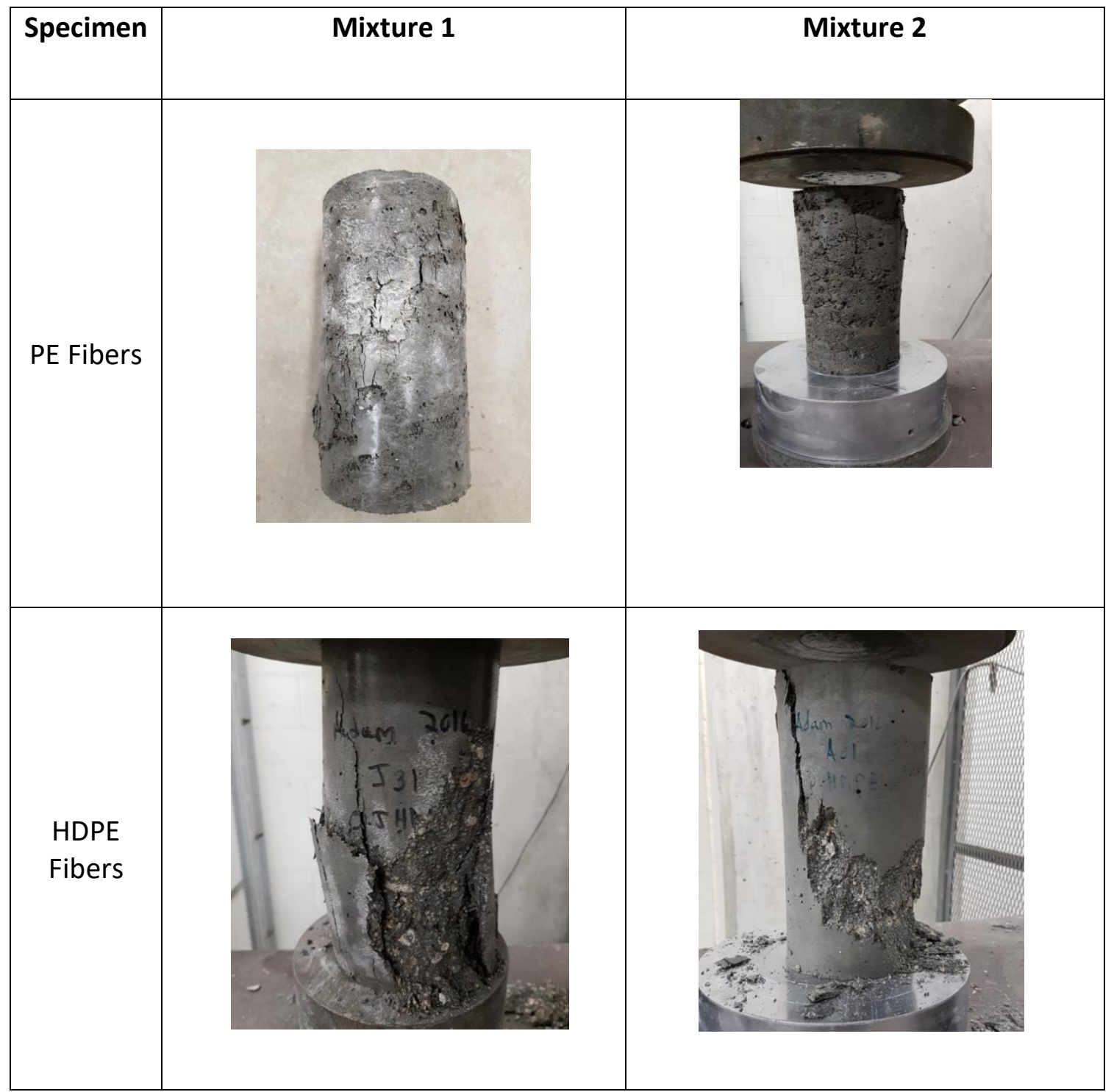




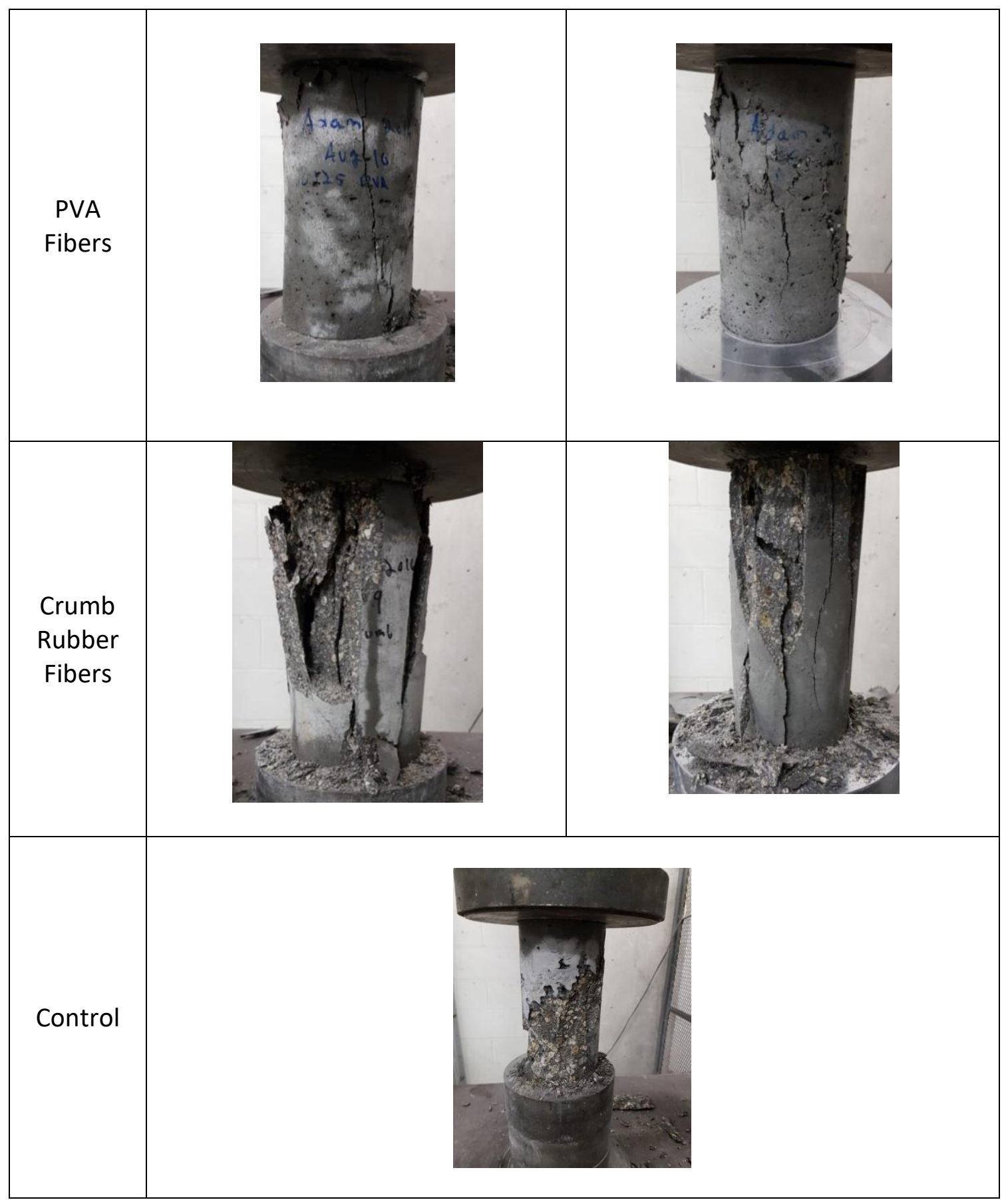




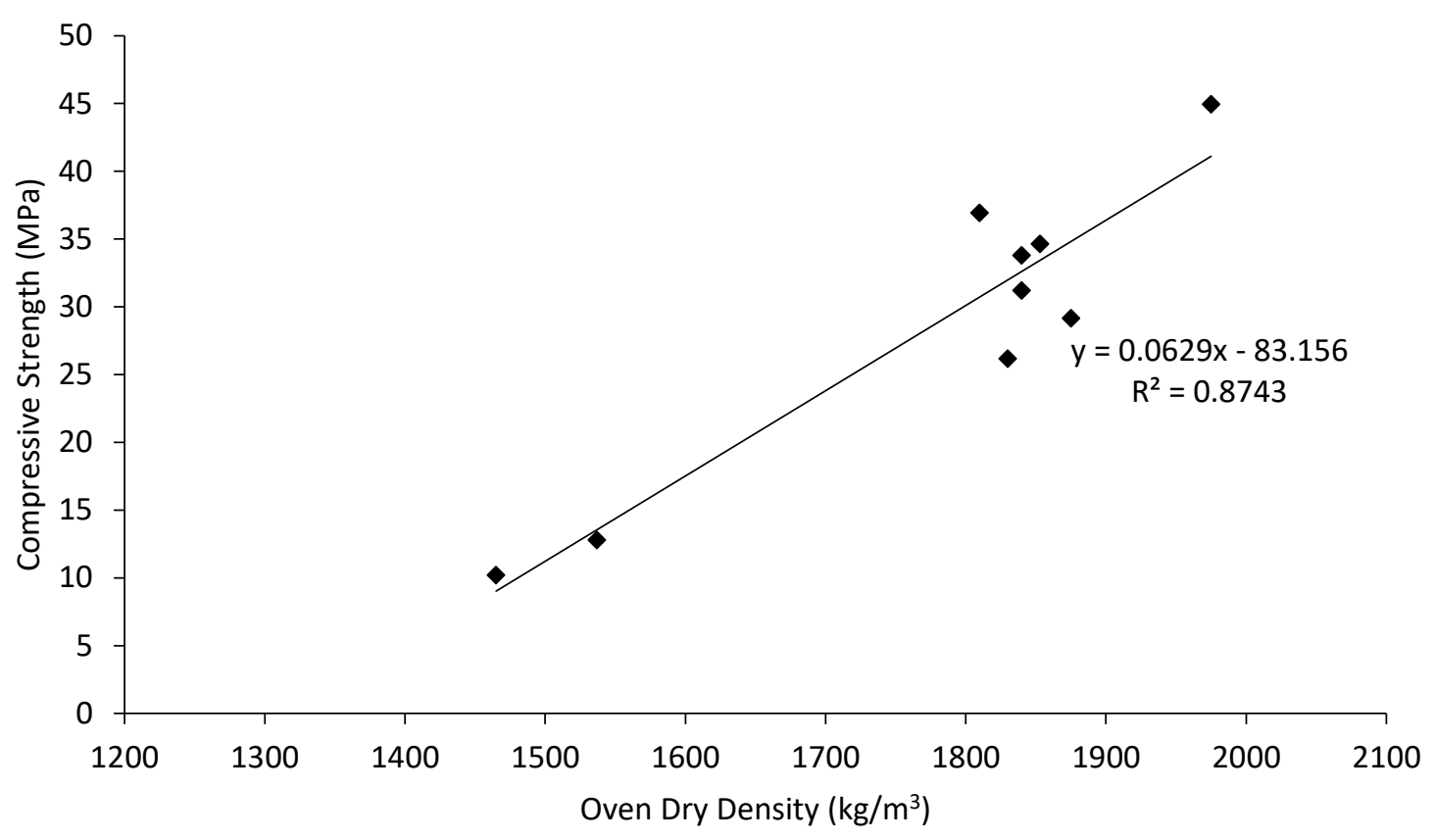

Figure 4.8: Relationship between Compressive Strength and Density

A good correlation between density and the compressive strength of LWSCFRC mixtures is found and shown in Figure 4.8. From this figure, it can be concluded that the compressive strength increases with the increase of density. The increase in density provides a denser concrete matrix due to the addition of fibers that can provide a higher load resistance, therefore improving the compressive strength.

\subsubsection{Flexural Strength}

Flexural load-deflection responses of beam specimens obtained from four-point loading tests are compared in Figure 4.9. It should be noted that only up to the peak load has been plotted since there was drastic drop in post-peak loading. Since the two beams from each concrete showed very similar results, the average was taken for the net deflection and peak load. Cracking of concrete beam specimens after loading to failure is shown in Figure 4.10 to 4.16 . It should be noted that all specimens have been split into two after testing. Table 4.8 presents the number of cracks and the range of crack widths (measured by using a crack scope) formed in beam specimens at failure. A summary of experimental results is provided in Table 4.9. From this data, the modulus of rupture was calculated as per ASTM C1609/C1609M-12 (2012). A percentage 
increase or decrease in modulus of rupture and toughness were presented for each of the specimens with a comparison to the control specimen. The toughness was calculated based on the area under the load-deflection curve as summarized in Table 4.10.

HDPE Mixtures: The first peak load and the modulus of rupture were found to be very similar between concretes with $0.5 \%$ and $1.0 \%$ HDPE fiber content. The displacement of $0.5 \%$ HDPE specimen was $0.28 \mathrm{~mm}$ while the $1.0 \%$ specimen was $0.36 \mathrm{~mm}$. Compared to the control concrete (without fiber) specimen, $0.5 \%$ HDPE fiber specimen exhibited $0.9 \%$ increase in the modulus of rupture while the 1.0\% HDPE specimen exhibited no increase in modulus of rupture. Both these specimens exhibited one crack in the center span of the beam with a crack width range of 50 150 microns for $0.5 \%$ HDPE and $120-220$ microns for 1.0\% HDPE. From all the crack width ranges that were recorded, the $0.5 \%$ HDPE specimen had the lowest crack width. This can be due to the short length of the fibers that provided better bonding to keep the paste together after the first crack. However, the calculated toughness is shown to be roughly $0.1 \mathrm{~J}$ more in the $1.0 \% \mathrm{HDPE}$ specimen. This increase in toughness can be due to the close bonding between the fibers and the paste, creating a denser mixture. Compared with the control specimen, the $0.5 \%$ HDPE specimen exhibited a decrease in toughness by $3 \%$ while the 1.0\% HDPE specimen had an increase of toughness by $28 \%$. From previous research, it was found that the increase in HDPE fibers from $0.2 \%$ to $0.6 \%$ exhibited an increase in flexural strength from 6.13 MPa to 7.1 MPa, but a further increase of fibers to $1 \%$ had shown a decrease in flexural strength (Bhavi et al. 2012). Therefore, the increase in HDPE fibers from $0.5 \%$ to $1.0 \%$ had not provided any improvement in flexural strength although it had provided more toughness to the specimen.

Crumb Rubber Mixtures: The increase in crumb rubber fibers from $0.5 \%$ to $1.0 \%$ has shown to increase the modulus of rupture from $0.85 \mathrm{MPa}$ to $1.14 \mathrm{MPa}$, which is a $5.5 \%$ increase compared to the control specimen. The increased fiber content has provided an increased resistance to crack propagation. Therefore, the specimen was able to resist more loading. The range of crack width for $0.5 \%$ Crumb Rubber specimens ranged from 130 to 190 microns, while the $1.0 \%$ Crumb Rubbers specimens had a range from 80 to 160 microns. The toughness of the crumb rubber specimens was decreased compared to the control specimen by a maximum of $14 \%$. The significant decrease in toughness was found in the $0.5 \%$ crumb rubber specimen, while the $1.0 \%$ 
crumb rubber specimen had a smaller decrease of toughness (about 8.3\%). This can be due to the low bonding behavior between the rubber and the cement, since rubber is a plastic material it will repel water and therefore decrease the bonding between the fibers and the paste. A similar conclusion was drawn from other resarch studeis, where it was concluded that the increase in crumb rubber content to $30 \%$ exhibited a decrease in flexural strength by $36 \%$, where the main contributing factors were the weak bond between the fibers and the paste, increased porosity and higher deformability of the rubber fibers (Karahan et al. 2012). Therefore, the increase in crumb rubber fibers provided a very little improvement in flexural strength and a decrease in toughness.

PVA Mixtures: An increase in the modulus of rupture was noted with the increase in PVA fibers, but the 0.5\% PVA and 1.0\% PVA specimens performed poorly under flexural loading compared with the control specimens. The 0.5\% PVA and 1.0\% PVA specimens failed at $2.37 \mathrm{kN}$ and $2.62 \mathrm{kN}$ loading and exhibited a higher net displacement. Even though the specimens failed under a lower load, the higher displacement can be due to the clumping of fibers that occurred during mixing of the concrete batch and also by multi-cracking due to fiber bridging. The non-uniform dispersal of the fibers can be the cause of unexpected failure in the specimens. Furthermore, the increase in PVA fibers can cause a denser concrete matrix which, therefore, can reduce the ductility of the specimen causing earlier cracking. The toughness was found to decrease with the increase in PVA fibers from $0.5 \%$ to $1.0 \%$. Although, the toughness decreased, the $0.5 \%$ PVA specimen had a $27.8 \%$ increase in toughness compared with the control specimen. This may be due to strain hardening behavior of PVA concrete and fiber bridging as it happens with the presence of PVA fiber. Two cracks were formed on each of the PVA specimens. The crack widths ranged from 70 to 250 microns for $0.25 \%$ PVA and 250 to 350 microns for $0.125 \%$ PVA. Compared to the rest of the specimens, $0.125 \%$ PVA had a higher crack width range. This could be due to rupturing of fibers or fiber pull out failure. 


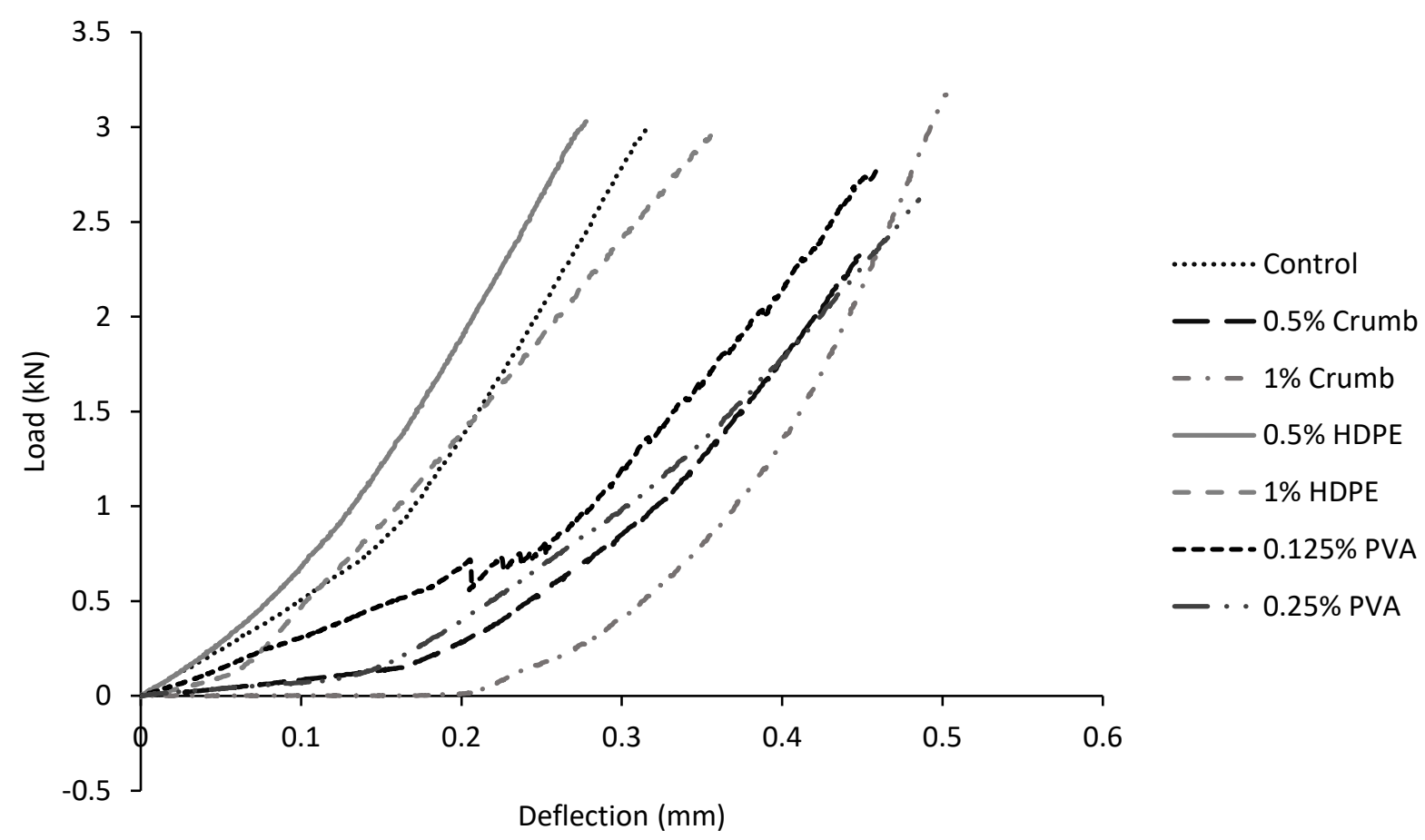

Figure 4.9: Load Deflection Curve

From previous literature, it was found that steel fibers, which has an increase tensile strength, provided better flexural strength performance and crack control because it was able to resist more loading and resist micro-cracking (Yehia et al. 2014). This statement, however, is not the same for HDPE and PVA fibers, since the modulus of rupture was lower compared to the control specimen. The reason for this can be due to the fact the shorter fibers are not long enough to resist the micro-cracks. Also, the increase in steel fibers in LWC was found to increase the flexural toughness of the samples because the fibers were able to resist the formation of micro-cracks (Wang \& Wang, 2013). Besides steel fibers, polypropylene fibers were also tested, where the increase in PP fibers from approximately $1.2 \mathrm{~kg} / \mathrm{m}^{3}$ to $2.4 \mathrm{~kg} / \mathrm{m}^{3}$ decreased the modulus of rupture from 0.98 MPa to 0.95 MPa (Doukakis, 2013). In addition to the steel and PP fibers, glass fibers which have a tensile strength of approximately $1700 \mathrm{MPa}$, did not affect the flexural strength of concrete (Manjunatha et al. 2015). This similar behavior can be noted in PVA and HDPE specimens where the modulus of rupture was either the same or lower than those of the control specimens. In summary, the use of HDPE and PVA fibers did not reveal an improvement in the flexural strength of concrete. However, an increase in these two fibers exhibited a higher 
flexural toughness. The increase in crumb rubber fibers showed an increase of modulus of rupture compared with the control specimen.

Table 4.8: Number of Cracks and Range of Crack Widths

\begin{tabular}{ccccc}
\hline & \multicolumn{2}{c}{ Specimen 1 } & \multicolumn{2}{c}{ Specimen 2 } \\
\cline { 2 - 5 } Specimen Type & \# of Cracks & $\begin{array}{c}\text { Crack Width } \\
\text { Range (microns) }\end{array}$ & \# of Cracks & $\begin{array}{c}\text { Crack Width Range } \\
\text { (microns) }\end{array}$ \\
\hline Control & 2 & $\begin{array}{c}190-210 \\
80-90\end{array}$ & 1 & $\begin{array}{c}200-220 \\
80-100\end{array}$ \\
\hline $0.5 \%$ HDPE & 1 & $50-100$ & 1 & $100-150$ \\
\hline $\begin{array}{c}0.5 \% \text { Crumb } \\
\text { Rubber }\end{array}$ & 1 & $130-150$ & 1 & $160-190$ \\
\hline $\begin{array}{c}0.125 \% \text { PVA } \\
\text { (1.0\% HDPE }\end{array}$ & 3 & $\begin{array}{c}150-300 \\
90-100 \\
70-90\end{array}$ & 3 & $330-350$ \\
\hline $\begin{array}{c}\text { Rubber } \\
\text { 0.25\% PVA }\end{array}$ & 1 & $120-150$ & 1 & $110-140$ \\
\hline
\end{tabular}

Table 4.9: Peak Load, Displacement and Modulus of Rupture

\begin{tabular}{ccccc}
\hline Specimen Type & $\begin{array}{c}\text { First Peak Load } \\
(\mathbf{k N})\end{array}$ & $\begin{array}{c}\text { Displacement } \\
(\mathbf{m m})\end{array}$ & $\begin{array}{c}\text { Modulus of } \\
\text { Rupture (MPa) }\end{array}$ & $\begin{array}{c}\text { \% difference in } \\
\text { Modulus of } \\
\text { Rupture }\end{array}$ \\
\hline Control & 2.99 & 0.317 & 1.08 & - \\
\hline $0.5 \%$ HDPE & 3.03 & 0.278 & 1.09 & +0.9 \\
\hline $\begin{array}{c}0.5 \% \text { Crumb } \\
\text { Rubber }\end{array}$ & 2.37 & 0.454 & 0.85 & -21.3 \\
\hline $0.125 \%$ PVA & 2.78 & 0.46 & 1.00 & -7.4 \\
\hline $\begin{array}{c}1.0 \% \text { HDPE } \\
1.0 \% \text { Crumb } \\
\text { Rubber }\end{array}$ & 3.00 & 0.361 & 1.08 & 0 \\
\hline $0.25 \%$ PVA & 3.17 & 0.502 & 1.14 & +5.5 \\
\hline
\end{tabular}

$+:$ increase $-:$ decrease 
Table 4.10: Toughness of Specimens

\begin{tabular}{ccc}
\hline Specimen Type & $\begin{array}{c}\text { Toughness } \\
(\mathrm{J})\end{array}$ & $\begin{array}{c}\text { \% Difference in } \\
\text { Toughness }\end{array}$ \\
\hline Control & 0.36 & - \\
\hline $0.5 \%$ HDPE & 0.35 & -3.0 \\
\hline $0.5 \%$ Crumb Rubber & 0.31 & -14.0 \\
\hline $0.125 \%$ PVA & 0.46 & +27.8 \\
\hline $1.0 \%$ HDPE & 0.46 & +27.8 \\
\hline $1.0 \%$ Crumb Rubber & 0.33 & -8.3 \\
\hline $0.25 \%$ PVA & 0.41 & +13.9 \\
\hline
\end{tabular}

+ : increase - : decrease

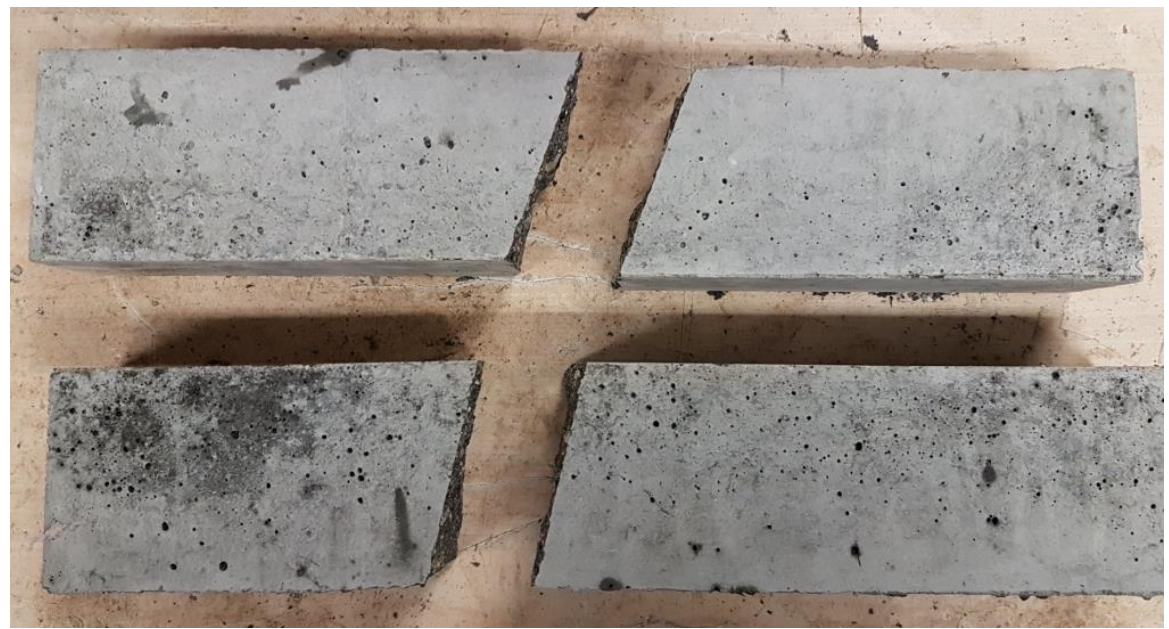

Figure 4.10: Flexural Crack Due to Maximum Load for Control Specimens

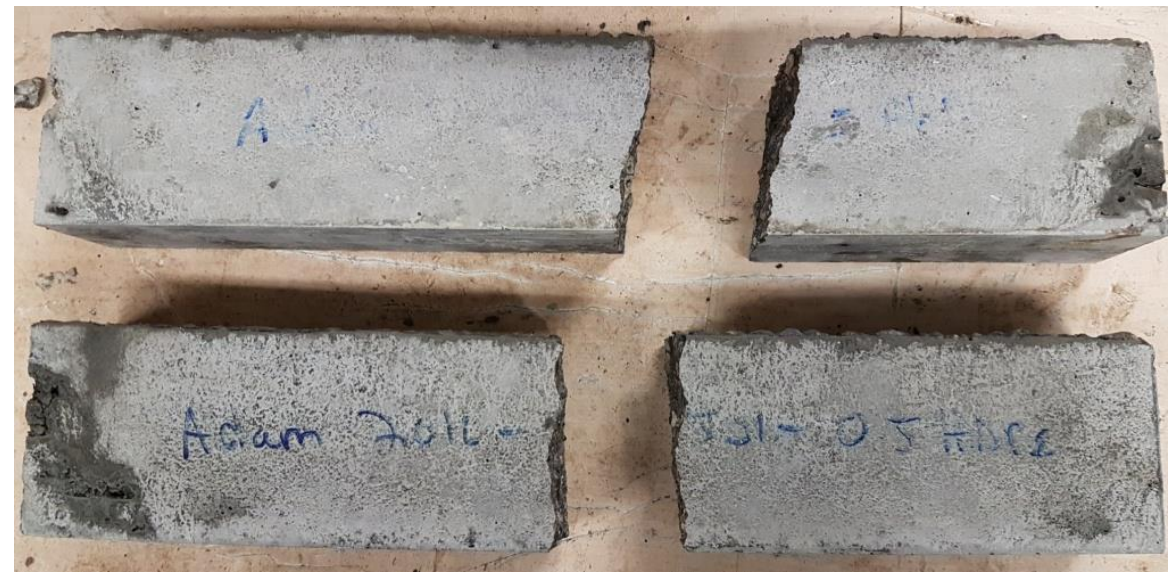

Figure 4.11: Flexural Crack Due to Maximum Load for 0.5\% HDPE Specimens 


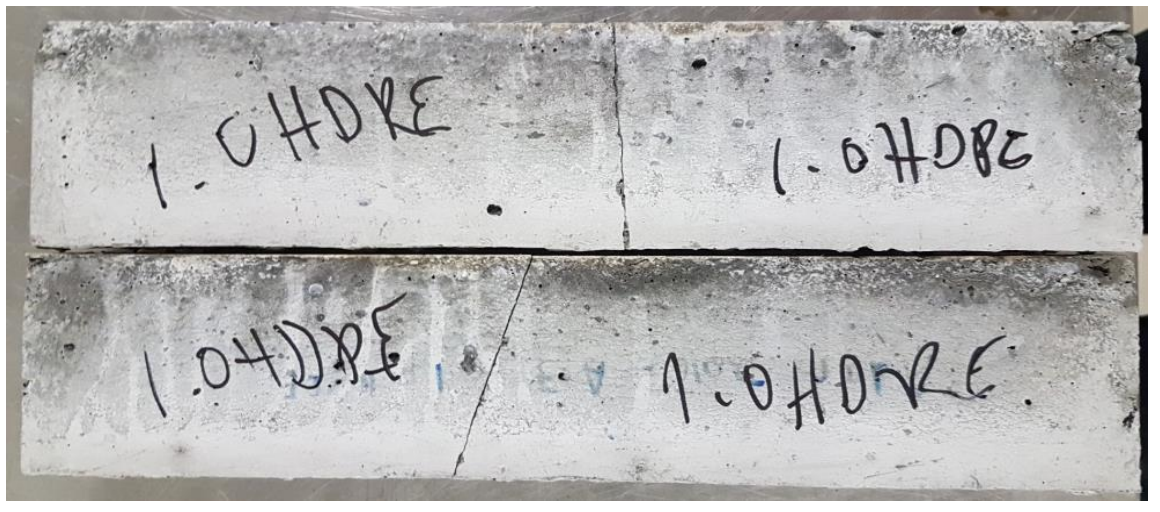

Figure 4.12: Flexural Crack due to Maximum Load for 1.0\% HDPE Specimens

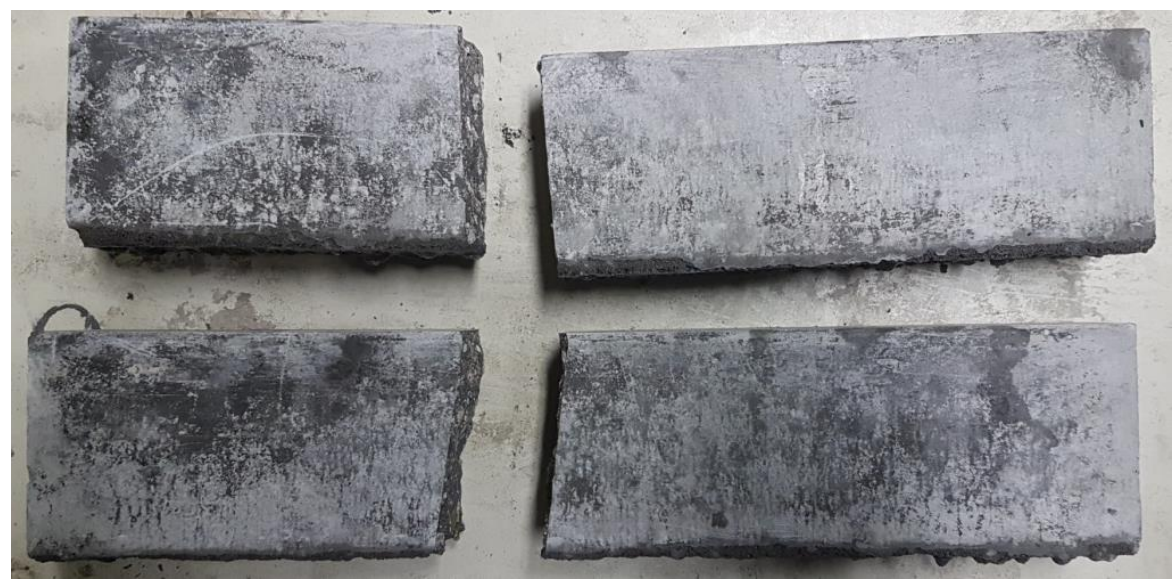

Figure 4.13: Flexural Crack due to Maximum Load for 0.5\% Crumb Rubber Specimens

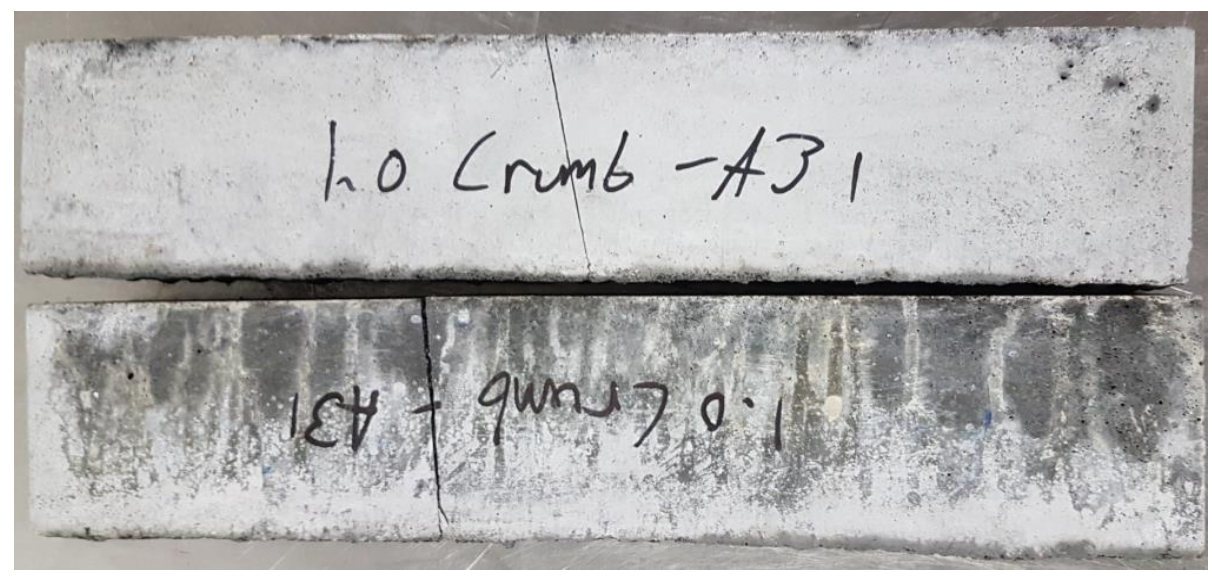

Figure 4.14: Flexural Crack due to Maximum Load for 1.0\% Crumb Rubber Specimens 


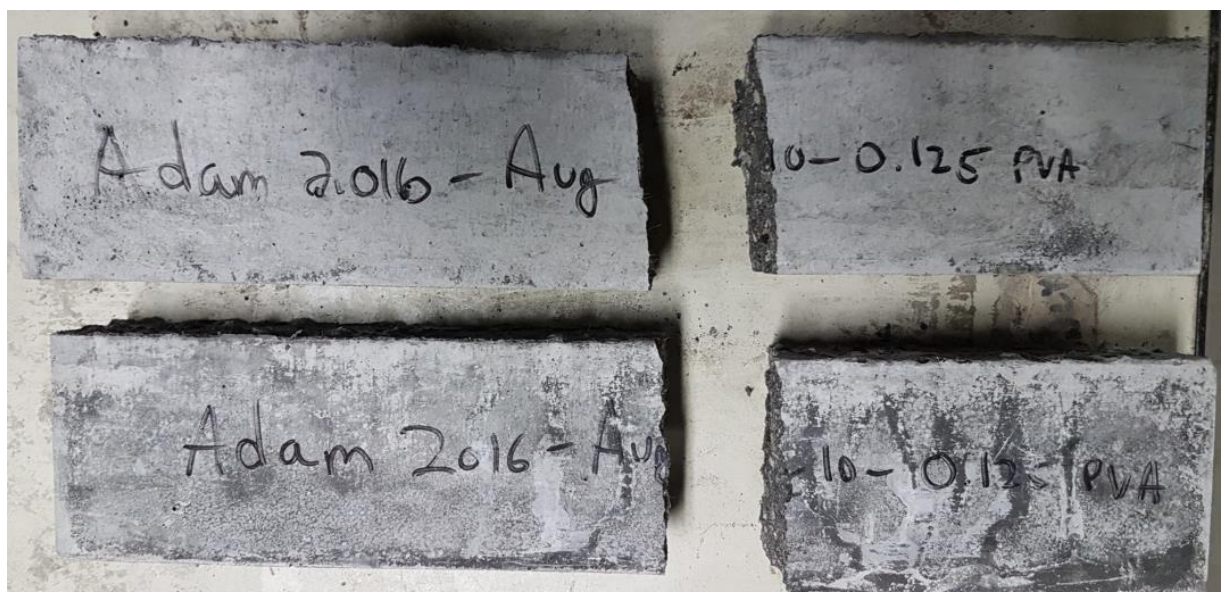

Figure 4.15: Flexural Crack due to Maximum Load for 0.125\% PVA Specimens

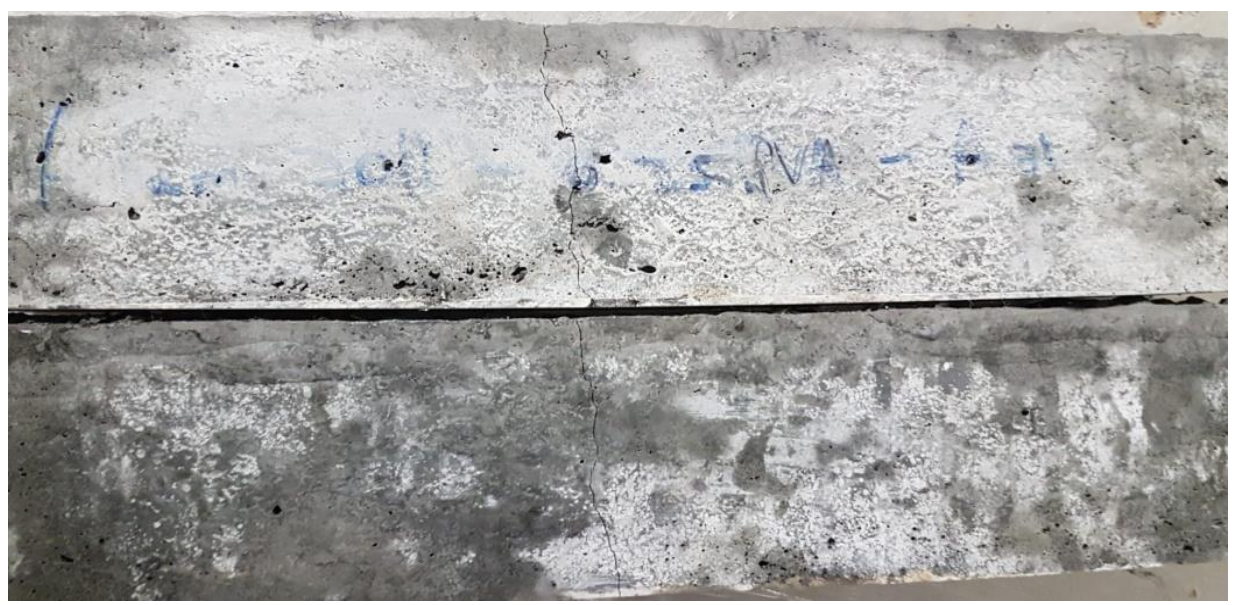

Figure 4.16: Flexural Crack due to Maximum Load for 0.25\% PVA Specimens

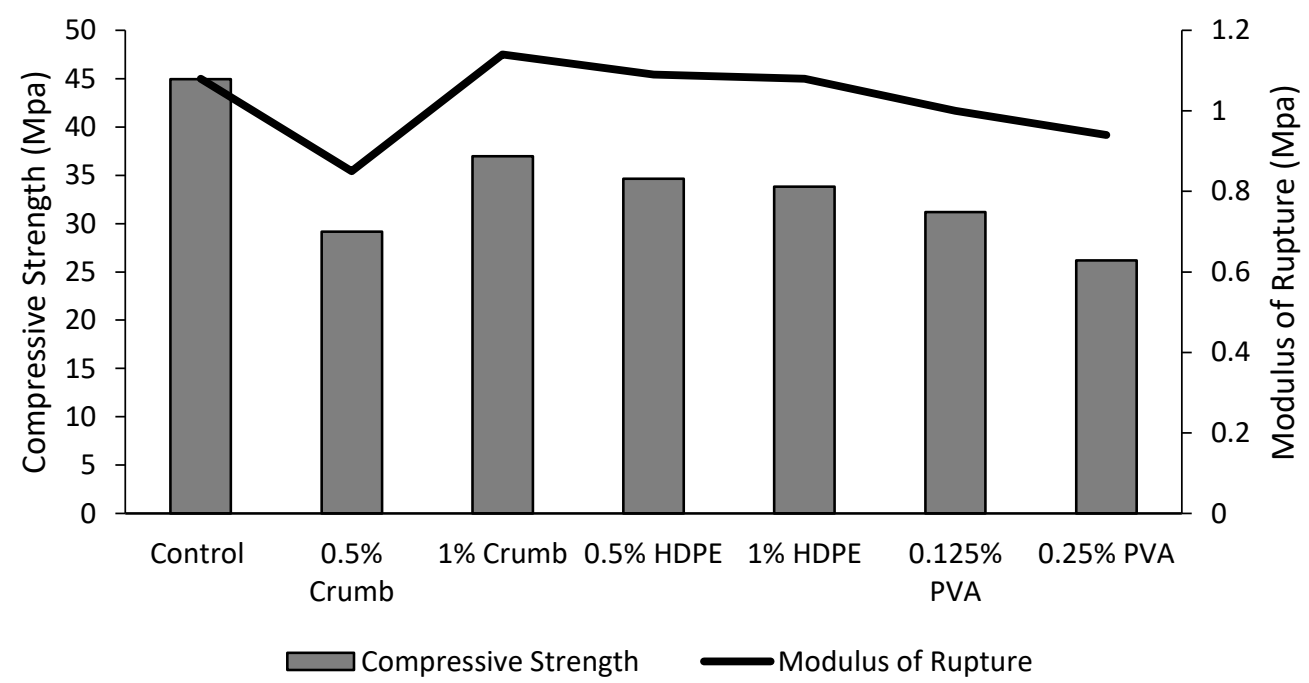

Figure 4.17: Comparison of Modulus of Rupture and Compressive Strength at Twenty - Eight Days 
A correlation can be made between the compressive strength and modulus of rupture of LWSCFRC specimens as shown in Figure 4.17. The overall relationship reveals that the compressive strength decreases with the decrease of the modulus of rupture. Therefore, the doubling of fiber content in HDPE and PVA LWSCFRC mixtures decreases the compressive strength as well as modulus of rupture. However, for crumb rubber LWSCFRCs, the increase in fiber content increased both compressive strength and modulus of rupture.

\subsection{Durability Properties}

The objective was to study the influence of fibers on the durability properties of LWSCFRCs based on rapid chloride permeability (RCP), freeze-thaw resistance and resistance to chloride and acid attack. Furthermore, performance 28-days cured specimens (made of LWSCFRCs) subjected to chloride and acid environments for different durations will be judged based on the change in mass and strength properties.

\subsubsection{Rapid Chloride Permeability (RCP) Properties}

The data that was obtained from this test revealed how the specimens with different fiber types and contents affected the RCP of LWSCFRC specimens. The lower the charges that passed through the specimen the higher the resistance of the specimen to chloride ion penetration. Table 4.11 summarizes the RCP of all LWSCFRC specimens. Typically, an increase in fiber content increased coulombs that passed through the specimens. An exception to this is for Crumb Rubber and PVA specimens where there was no change in the RCP was observed. According to the previous research, the specimens with crumb rubber displayed the same resistance to chloride ions with a rating of 'low' (Karahan et al. 2012). Furthermore, other researchers concluded that the increase in crumb rubber content increased the chloride ion penetration depth (Gesoglu \& Guneyisi, 2007). 
Table 4.11: Chloride Ion Penetrability of Specimens

\begin{tabular}{ccc}
\hline Specimen & Charge Passed (Coulombs) & Chloride lon Penetrability \\
\hline Control & 1070.00 & Low \\
\hline $0.5 \%$ PE & 3024.00 & Moderate \\
\hline $0.5 \%$ HDPE & 581.33 & Very Low \\
\hline $0.5 \%$ Crumb Rubber & 1668.33 & Low \\
\hline $0.125 \%$ PVA & 1094.00 & Low \\
\hline $1.0 \%$ PE & 5650.00 & High \\
\hline $1.0 \%$ HDPE & 2096.33 & Moderate \\
\hline $1.0 \%$ Crumb Rubber & 1398.33 & Low \\
\hline $0.25 \%$ PVA & 1429.33 & Low \\
\hline
\end{tabular}

Compared to the control specimen, specimens with fibers exhibited more charge passing through as can be seen from Figure 4.18. It should be noted that the PE specimens showed higher coulombs. This can be due to the nature of the concrete mixture, because the increased air voids that were created due to the shorter fiber lengths could decrease the concrete's resistance to chloride ions penetration. Furthermore, 0.5\% HDPE specimen had the lowest chloride ion permeability. This can be the results of a denser ITZ that allowed for an increased resistance to chloride ion penetration. This was also noted by another research studies which concluded that LWC made with light weight porous aggregate had a better ITZ than NWC (Chia \& Zhang, 2002).

Another factor that affected the ability for the increase in chloride ion penetration is the $\mathrm{w} / \mathrm{c}$ ratio. The increase in water content in the mixture can negatively affect the durability behavior. The addition of cementitious material such as silica fume and a lower w/c ratio has shown to increase the resistance to chloride ions from approximately from 2843 to 316 coulombs (Chia \& Zhang, 2002). To ensure that the resistance to chloride ions were accurately interpreted across all specimens the $\mathrm{w} / \mathrm{c}$ ratio was kept more or less the same. In comparison to the data that has been obtained by other researchers (Yehia et al. 2016), fiber reinforced self-consolidating concrete made of a combination of fibers (steel and synthetic) with a w/c ratio of 0.35 performed similarly to LWSCFRC with $0.5 \%$ HDPE. Overall, the increase in fiber content negatively affected the concrete's resistance to chloride ion penetration, with PE fibers providing the worst behavior. 
The ideal concrete mixture that can provide the optimal durability against chloride ion penetration (very low) is a concrete mixture with $0.5 \%$ HDPE.

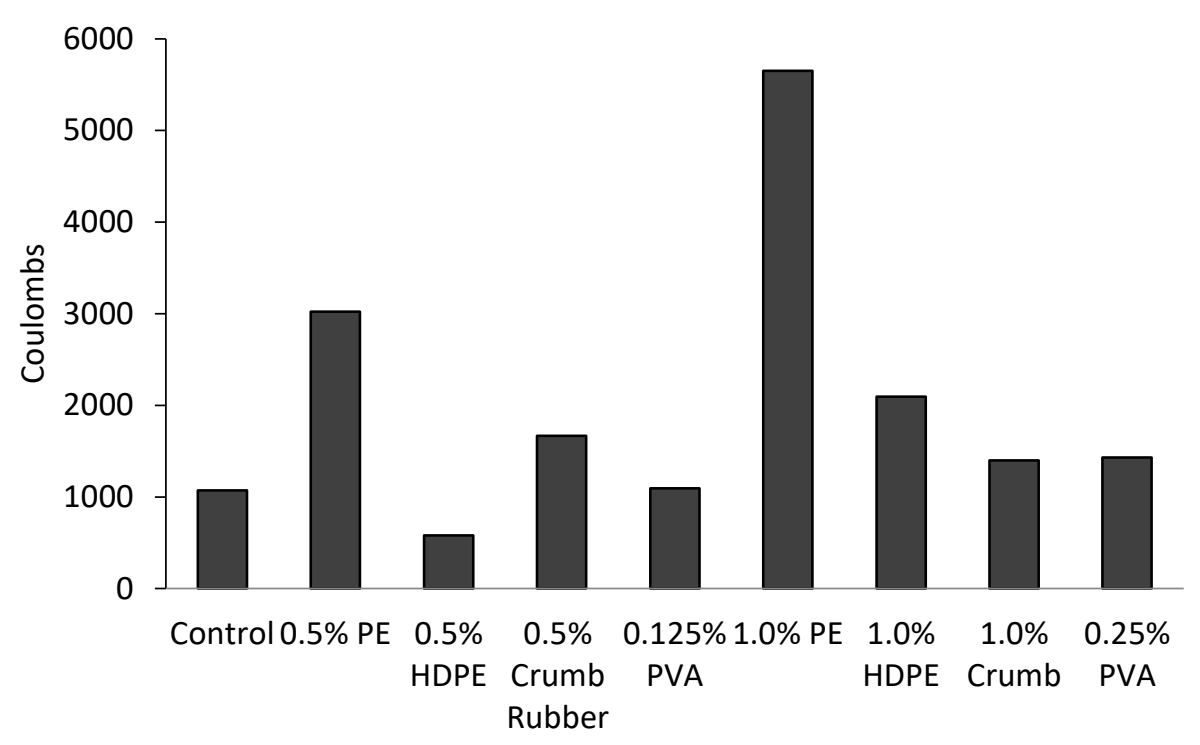

Figure 4.18: Coulombs Passed Through Specimens

\subsubsection{Resistance to Acid $\left(\mathrm{H}_{2} \mathrm{SO}_{4}\right)$ and Chloride ( $\left.\mathrm{NaCl}\right)$ Attack}

There are many types of acids that can be detrimental to the physical characteristics and performance of concrete. Creating a concrete mixture with porous material, poses extra challenges to ensure that acid attack is properly controlled and diminished. It has been found that the addition of silica fume and fly ash enhanced concrete resistance against $1 \%$ sulfuric acid solution because it would decrease the amount of calcium hydroxide $\left(\mathrm{Ca}(\mathrm{OH})_{2}\right)($ Lotfy et al. 2016). The addition of silica fume and fly ash in the specimens reduce the damage associated with the acid attack in concrete. The performance of specimens in $5 \%$ sulfuric acid solution and $5 \%$ sodium chloride solution were compared against the same specimens placed in water based on change in weight/mass and compressive strength. Throughout the 56 days duration of acid/chloride immersion, mass change of the specimens was recorded. It was noticed at the end of 56 days of immersion, specimens in $5 \%$ sodium chloride solution did not exhibit any mass loss. Therefore, these specimens were placed back in the $5 \% \mathrm{NaCl}$ solution to allow for longer exposure to the solution and to cause more deterioration. 
Figure 4.19 to 4.22 shows the deterioration of HDPE, Crumb Rubber, PVA and Control specimens after eight weeks of immersion in the $5 \% \mathrm{H}_{2} \mathrm{SO}_{4}$ solution. Inspections between the two specimens for each fiber type reveals more spalling and cement paste deterioration in the specimens with more fiber content. Due to cement paste deteriorating, fibers are more visible on the surface of the specimens; this is more prominent in $0.25 \%$ PVA. Specimens with the lower fiber content had a similar deterioration as the control specimen.
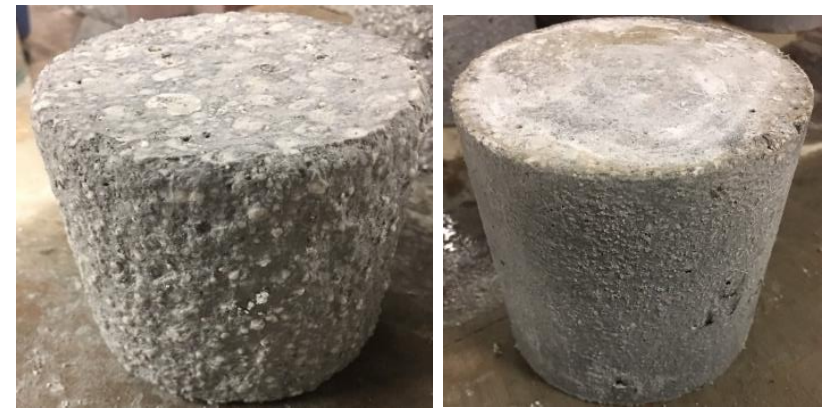

Figure 4.19: Deterioration of 1.0\% HDPE (Left) and 0.5\% HDPE (Right) after 56 Days in 5\% $\mathrm{H}_{2} \mathrm{SO}_{4}$

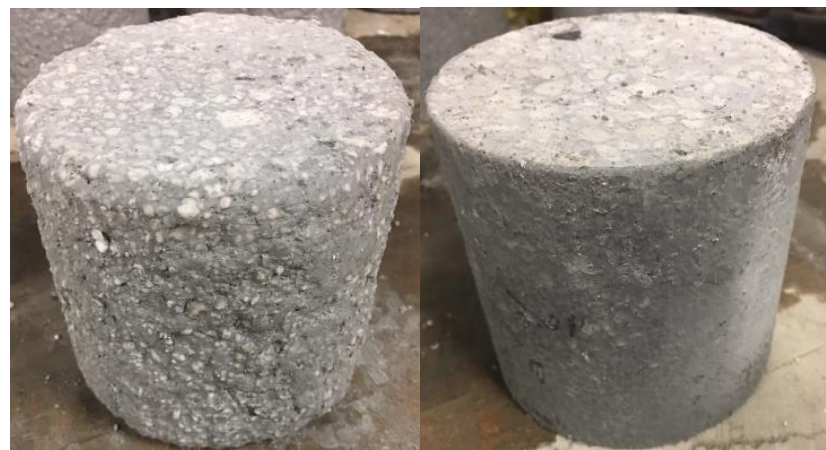

Figure 4.20: Deterioration of 1.0\% Crumb Rubber (Left) and 0.5\% Crumb Rubber (Right) after 56 Days in 5\% $\mathrm{H}_{2} \mathrm{SO}_{4}$
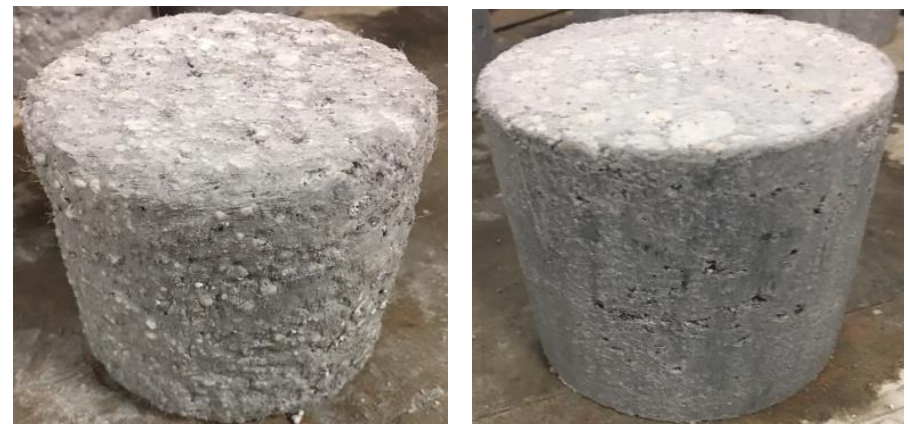

Figure 4.21: Deterioration of 0.25\% PVA (Left) and 0.125\% PVA (Right) after 56 Days in 5\% $\mathrm{H}_{2} \mathrm{SO}_{4}$ 


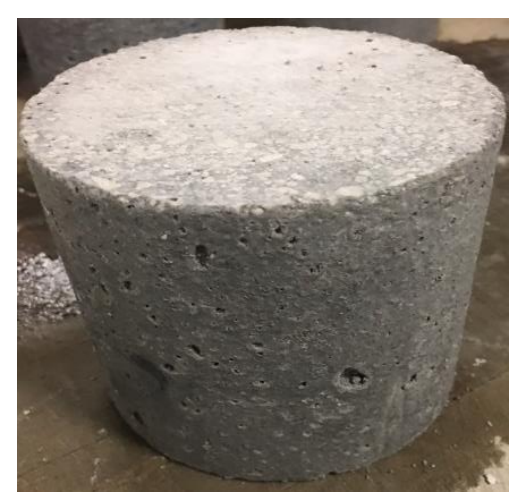

Figure 4.22: Deterioration of Control Specimen after 56 Days in $\mathrm{H}_{2} \mathrm{SO}_{4}$

At the end of 56 days, the crushing of the specimens for determination of compressive strength of specimens immersed in $5 \%$ sulfuric acid solution and water was performed. Failures of crushed specimens are presented in Figure 4.22 and Figure 4.23. Comparing the specimens immerged in $\mathrm{H}_{2} \mathrm{SO}_{4}$ solution and water, $0.25 \%$ PVA specimens developed more cracks but few concrete pieces that fell off at failure under compression loading. This can be due to the shorter length of the PVA fibers, which could mitigate the cracks and kept integrity of the matrix through fiber bridging. 


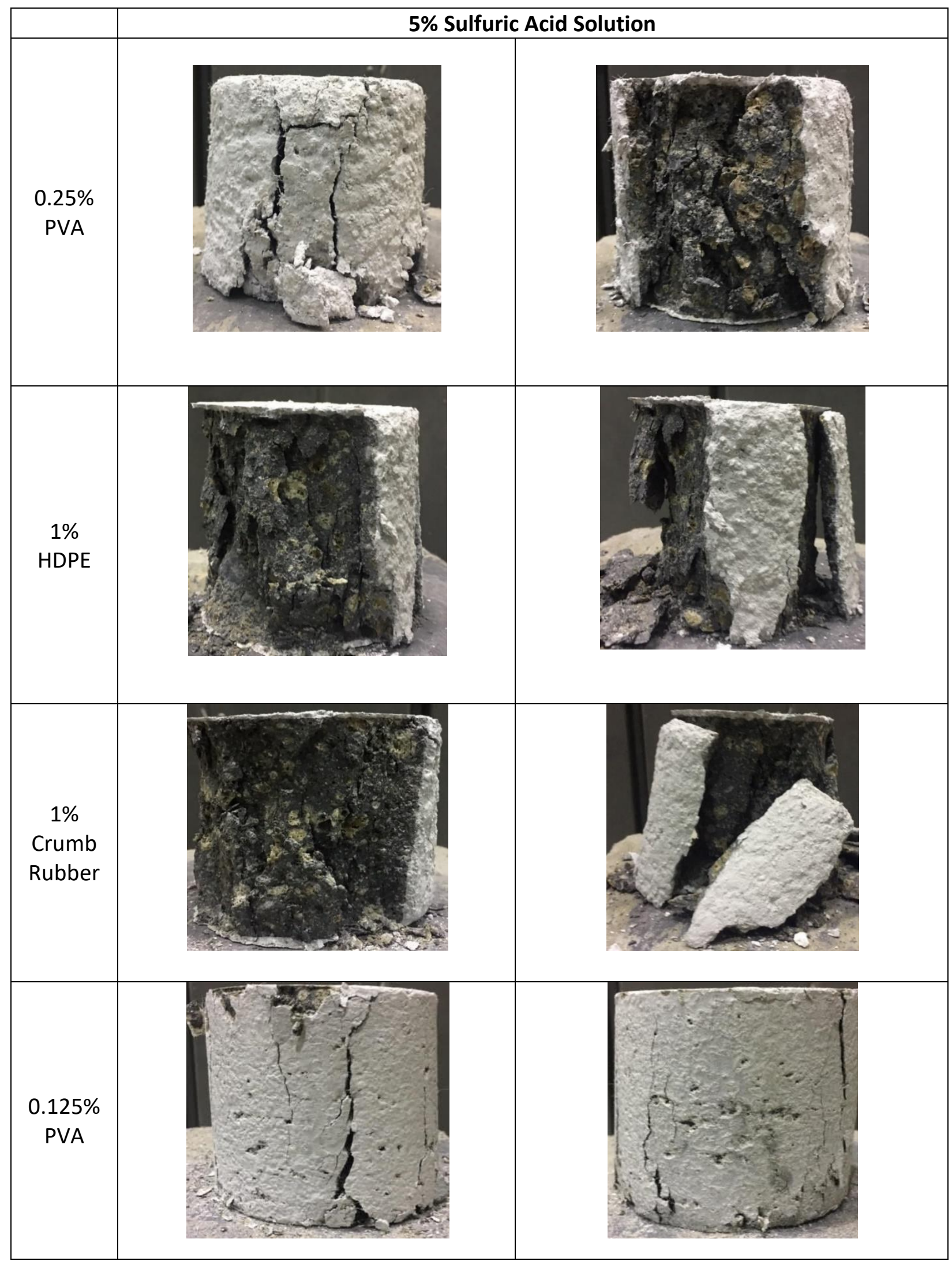




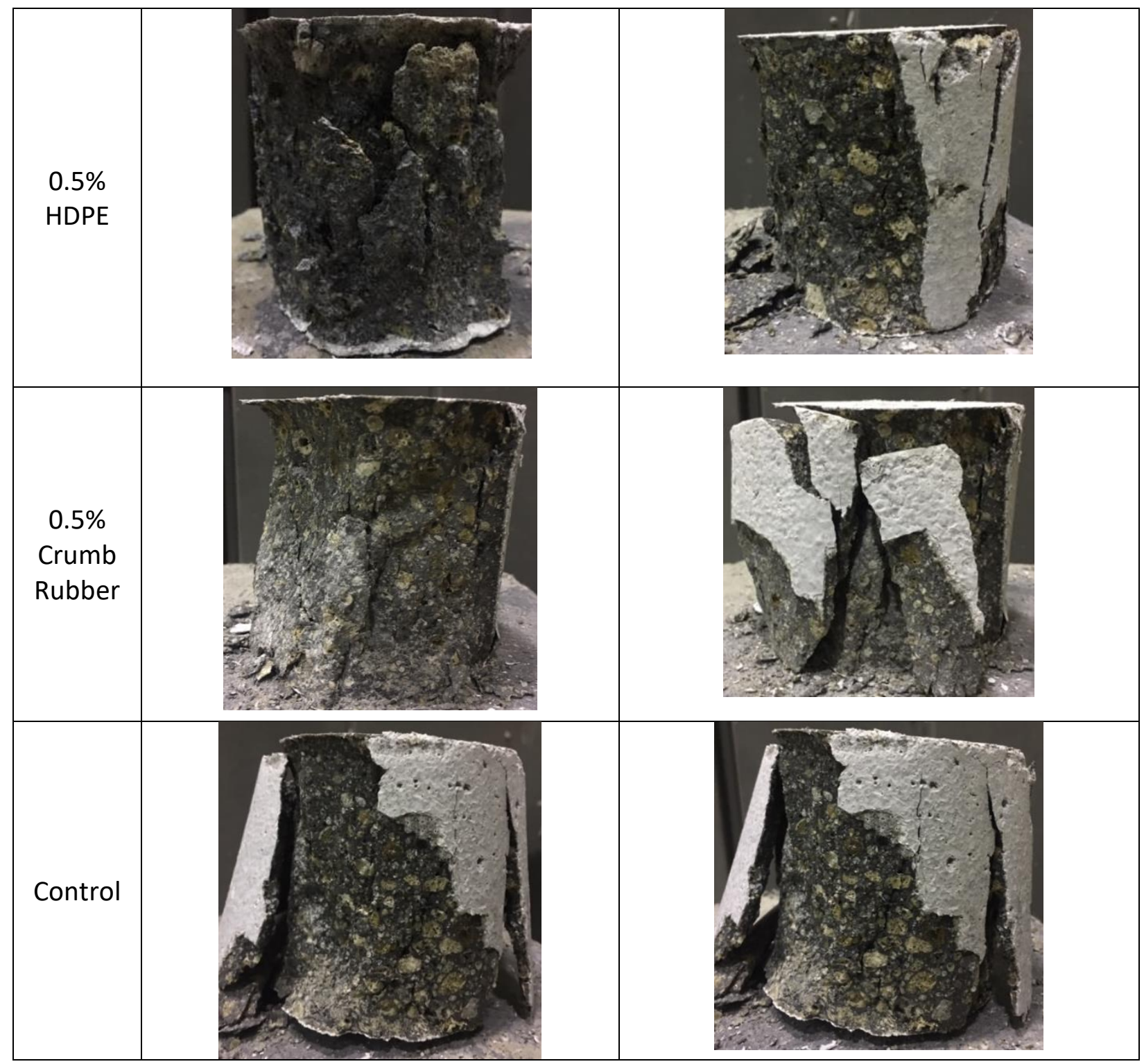

Figure 4.23: Failure of Specimens under Compression after Exposure to 5\% Sulfuric Acid Solution 


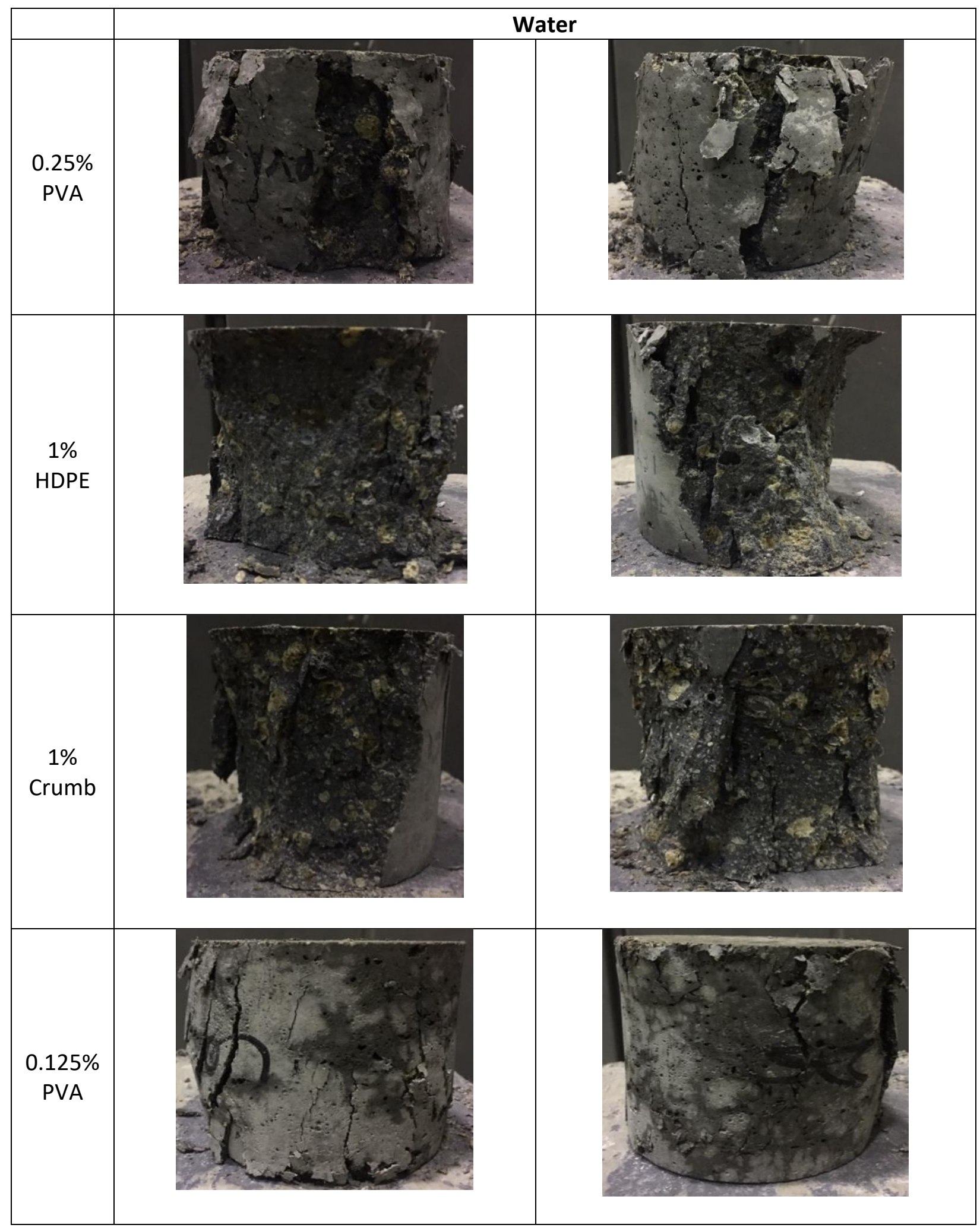




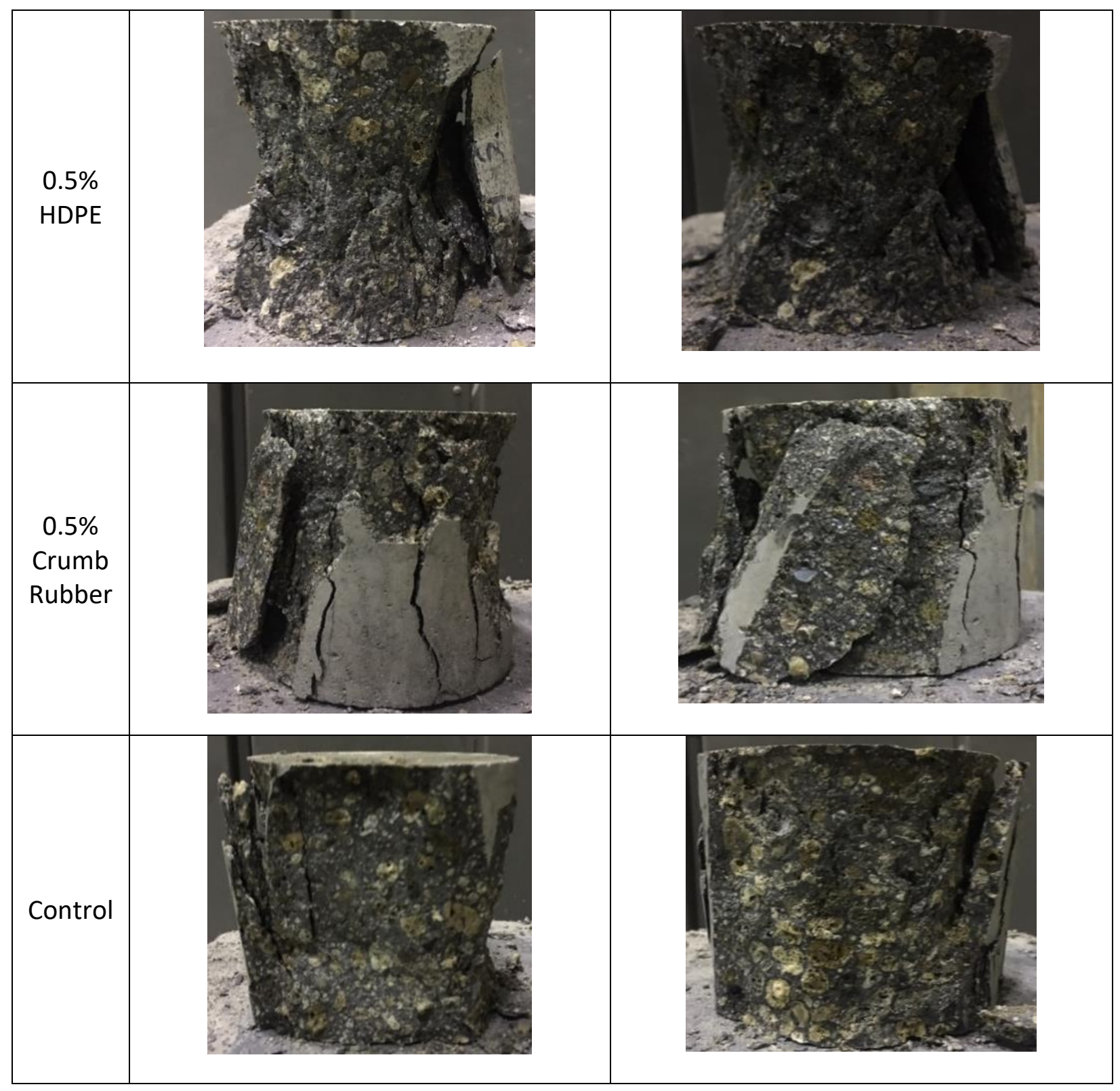

Figure 4.24: Failure of Specimens under Compression after Exposure to Water Immersion 


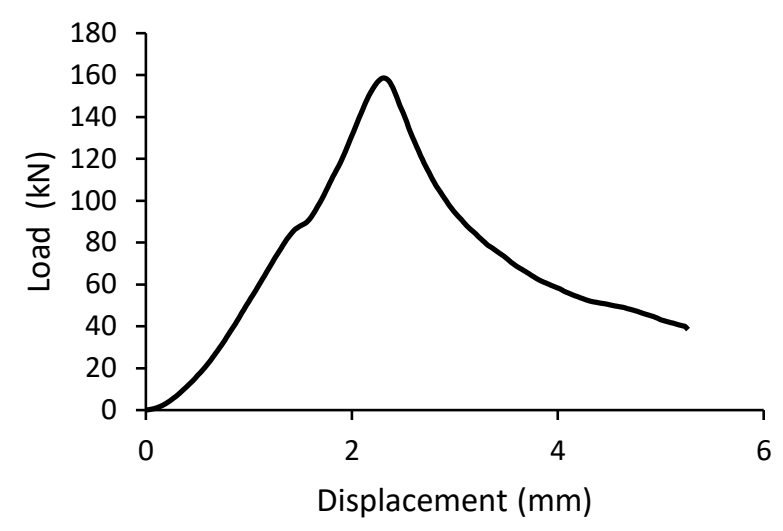

Figure 4.25: Load Deformation Curve for 0.25\% PVA Specimen in Water
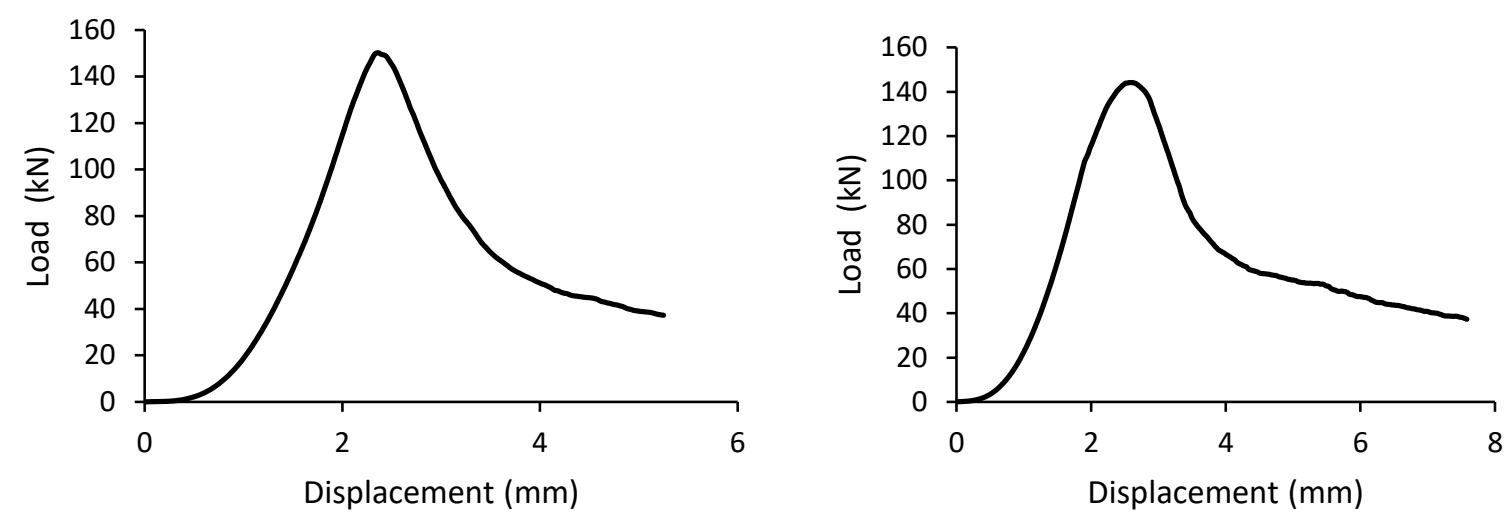

Figure 4.26: Load Deformation Curve for 0.25\% PVA Specimens in 5\% Sulfuric Acid Solution Left: Test 1. Right: Test 2

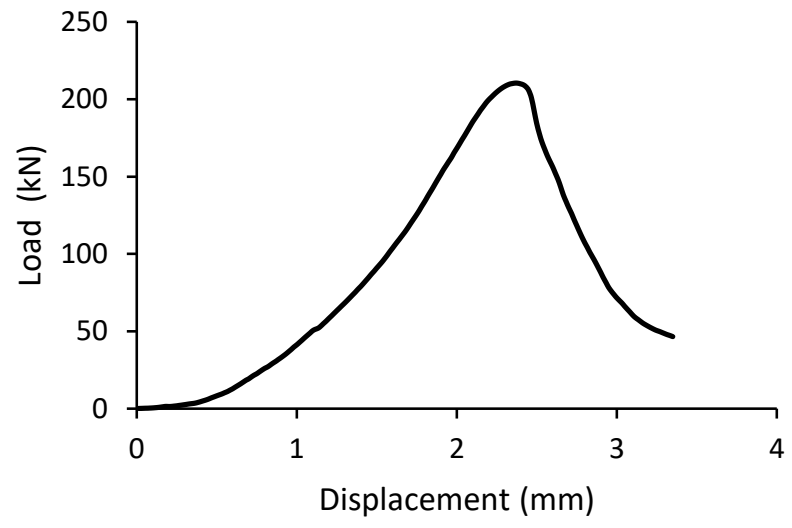

Figure 4.27: Load Deformation Curve for 1.0\% HDPE Specimen in Water 

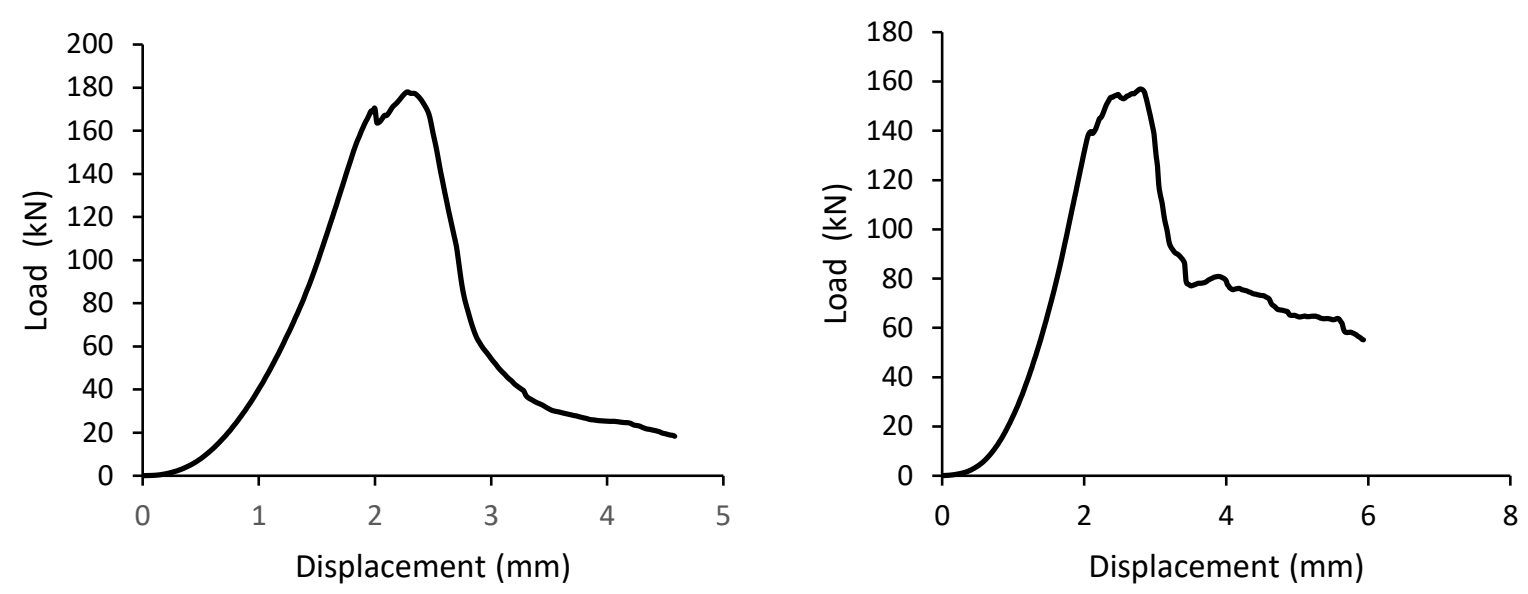

Figure 4.28: Load Deformation Curve for 1.0\% HDPE Specimens in 5\% Sulfuric Acid Solution Left: Test 1. Right: Test 2

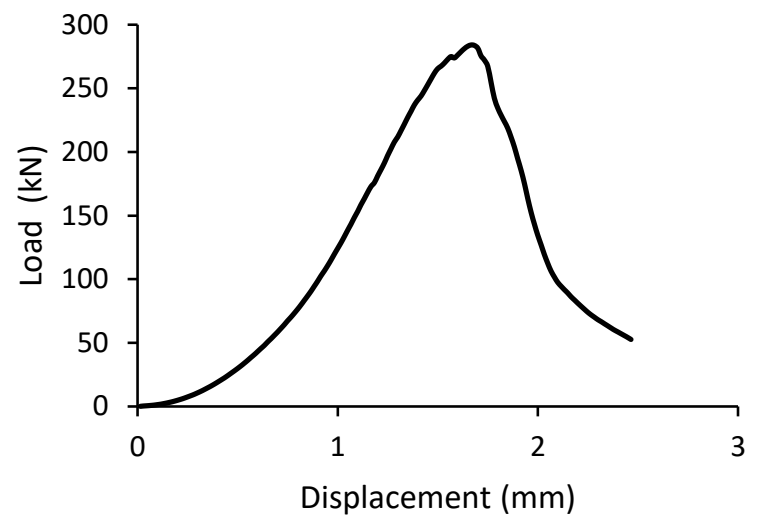

Figure 4.29: Load Deformation Curve for 1.0\% Crumb Rubber Specimen in Water
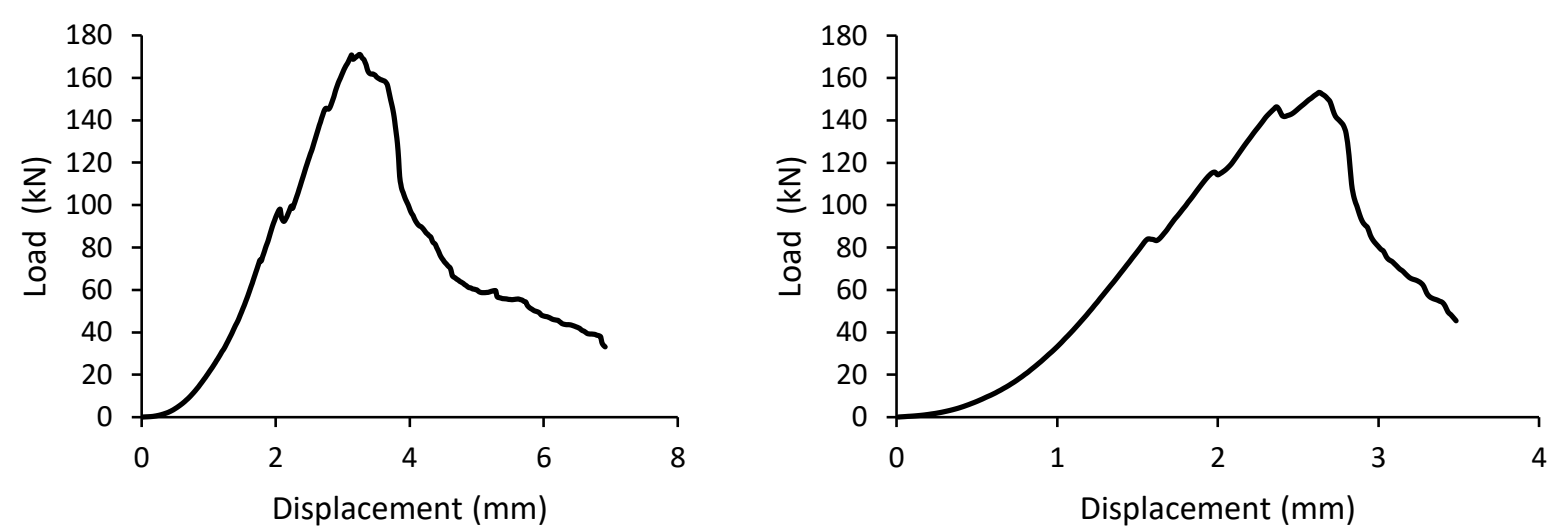

Figure 4.30: Load Deformation Curve for 1.0\% Crumb Rubber Specimens in 5\% Sulfuric Acid Solution Left: Test 1. Right: Test 2 

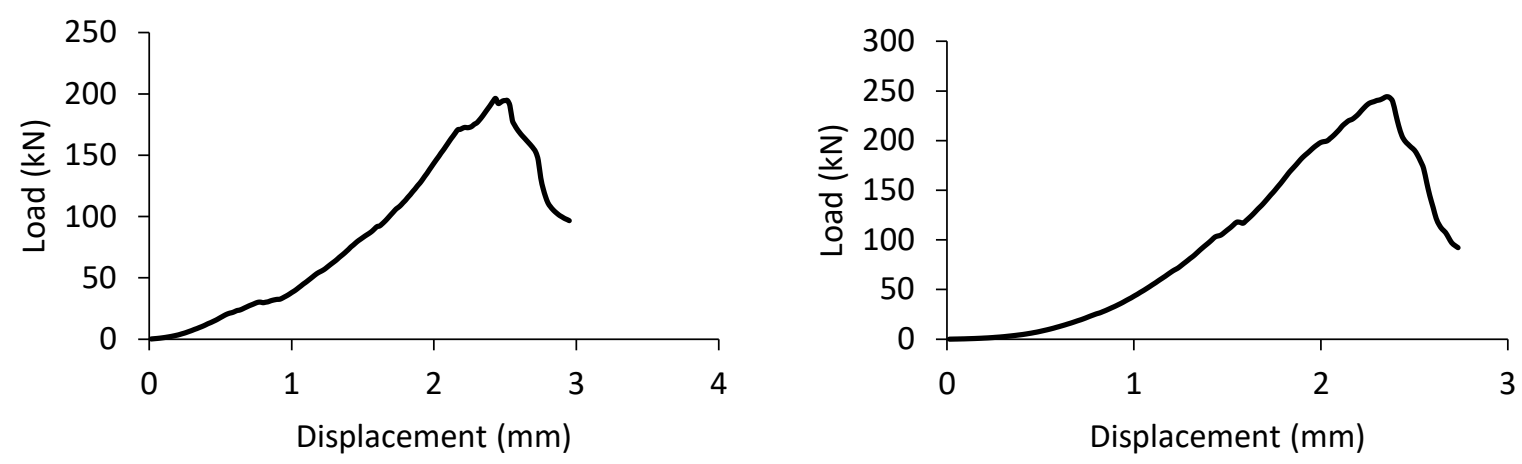

Figure 4.31: Load Deformation Curve for Control Specimen Left: Water. Right: 5\% Sulfuric Acid Solution
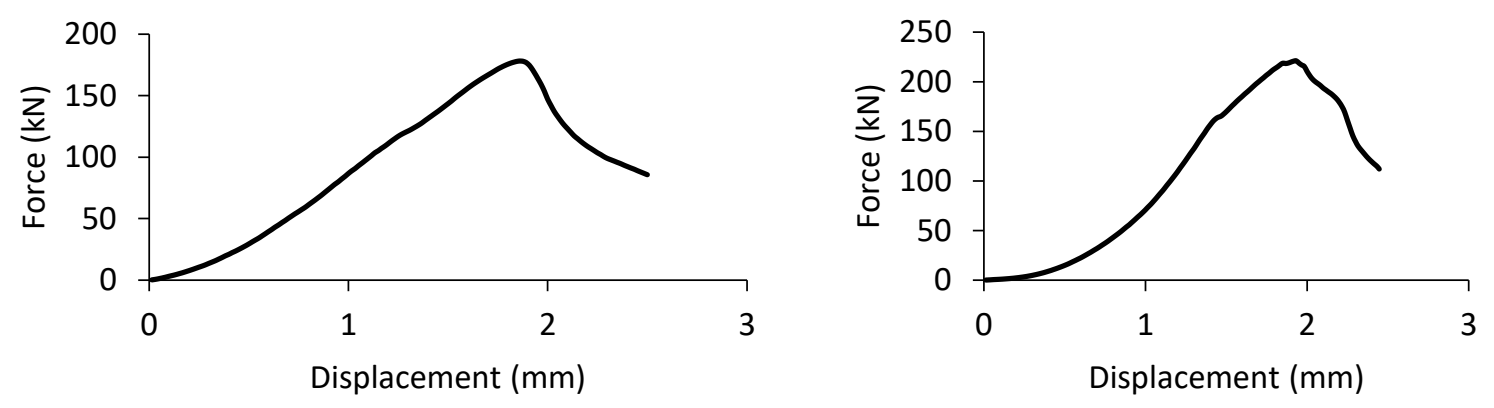

Figure 4.32: Load Deformation Curve for 0.125\% PVA Specimen Left: Water. Right: 5\% Sulfuric Acid Solution
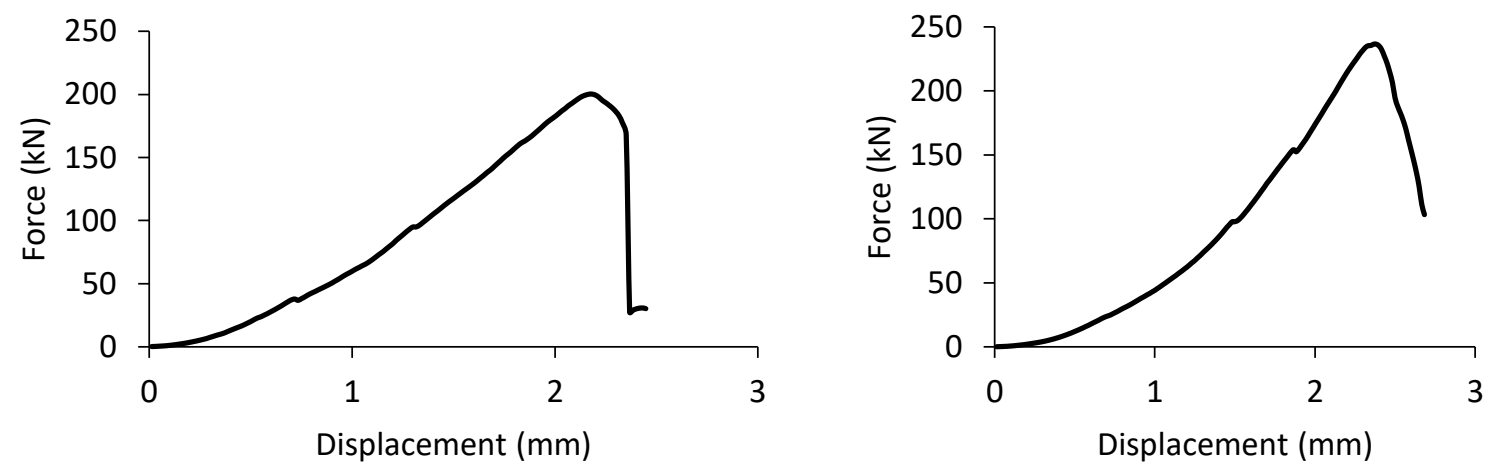

Figure 4.33: Load Deformation Curve for 0.5\% HDPE Specimen Left: Water. Right: 5\% Sulfuric Acid Solution 

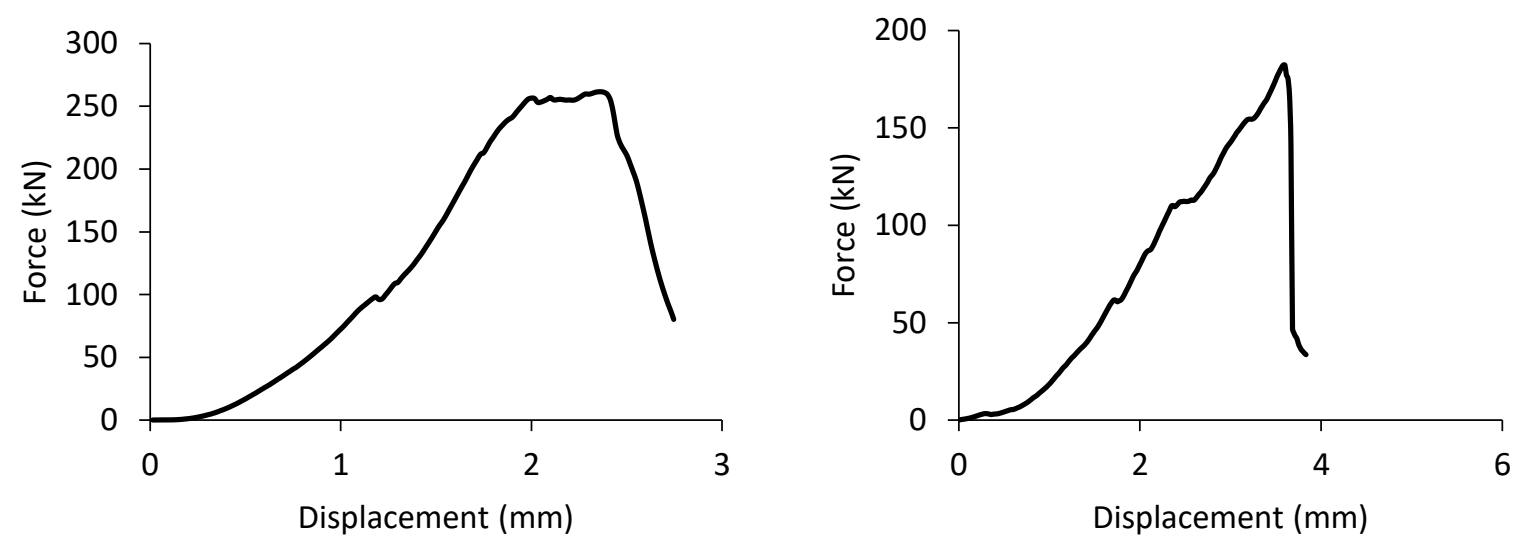

Figure 4.34: Load Deformation Curve for 0.5\% Crumb Rubber Specimen Left: Water. Right: 5\% Sulfuric Acid Solution

From the compressive strength test of water/acid exposed specimens, load-displacement data was obtained until the specimen failed. The other specimens in the water stayed for the same duration as the sodium chloride specimens so that the change in mass can be accurately recorded and subsequently compressive strength can be obtained. The load-displacement curves for all the specimens are displayed in Figures 4.25 - 4.34. Comparison between the specimens in sulfuric acid and water shows that the specimens in water could withstand higher load before failure compared to their $\mathrm{H}_{2} \mathrm{SO}_{4}$ counterparts which exhibited higher deterioration due to $\mathrm{H}_{2} \mathrm{SO}_{4}$ environment. Due to the sulfuric acid attack, failure of the specimens occurred at a lower loading due to external spalling of concrete. Peak failure load occurred at much later deformation in $1 \%$ Crumb Rubber specimen, compared to $1 \%$ HDPE and $0.25 \%$ PVA specimens, which is due to increased toughness and the ability of the specimen to absorb more energy. Furthermore, the decrease of fiber content displays increased strength by failing at a higher load compared to their counter parts with higher fiber content. Table 4.12 summarizes the toughness of each specimen submerged in both the sulfuric acid solution and water. The toughness was calculated from the load - deflection curve up to the point of failure and the value represents the specimen's ability to absorb energy before failure. The toughness for specimens submerged in the sulfuric acid solution was found to be higher than the specimens in water except for $0.25 \%$ PVA and $0.5 \%$ Crumb Rubber which showed the opposite. 
Table 4.12: Toughness of Specimens

\begin{tabular}{ccc}
\hline Specimen & $\begin{array}{c}\text { Toughness for Specimen in } \mathbf{5} \mathbf{~ H}_{\mathbf{2}} \mathbf{S O}_{4} \\
(\mathrm{~J})\end{array}$ & $\begin{array}{c}\text { Toughness for Specimen in Water } \\
(\mathrm{J})\end{array}$ \\
\hline $0.25 \%$ PVA & 132.25 & 155.18 \\
\hline $1 \%$ HDPE & 184.16 & 179.81 \\
\hline $1 \%$ Crumb & 202.96 & 184.35 \\
\hline Control & 200.27 & 188.80 \\
\hline $0.125 \%$ PVA & 169.54 & 134.61 \\
\hline $0.5 \%$ HDPE & 190.38 & 157.78 \\
\hline $0.5 \%$ Crumb & 261.02 & 263.00 \\
\hline
\end{tabular}

For the eight-week (56 day) duration of acid attack on the specimens, the mass was recorded every two weeks to monitor the change in mass. Eq. 4.1 was used to calculate the change in mass. Where $W_{\text {initial }}$ is the initial weight before immersion and $W_{\text {final }}$ is the final weight for the particular week during the eight week duration.

$$
\text { Mass Change }(\%)=\frac{W_{\text {final }}-W_{\text {inital }}}{W_{\text {final }}} * 100
$$

The change in mass for $1 \%$ Crumb Rubber, $0.25 \%$ PVA and 1\% HDPE specimens during eight-week duration of immersion in water, $\mathrm{NaCl}$ and $\mathrm{H}_{2} \mathrm{SO}_{4}$ is presented in Figures 4.34 to 4.36 , respectively. Specimens in water and $5 \% \mathrm{NaCl}$ solution exhibited an increase in mass (up to 1.5\%) throughout the eight-week duration possibly due to the absorption of liquid by the porous lightweight aggregates with high absorption capacity. According to Bagherzadeh et al. (2012), these specimens with fibers showed an increased water absorption capacity due to air entrapment and creation of air voids that allow for water to easily enter into the matrix. Since 1\% HDPE fibers are longer in length compared to PVA and Crumb Rubber, the mass gain in this specimen is higher during the first two weeks due to the increased amount of air voids in the concrete matrix. Furthermore, the $1 \%$ Crumb Rubber specimen exhibited lower mass gain which can be due to shorter fibers that resulted in a denser concrete matrix and decreased the permeability of the specimen.

The comparison of mass change between lower and higher fiber content for water reveals that lower fiber content has a similar mass gain, while $0.125 \%$ PVA exhibited the highest mass gain at 
the end of the 56 day duration. Furthermore, specimens with lower fiber content exhibited mass gain throughout the duration of the experiment. The increase in mass is due to higher absorption of the aggregate as well as more voids in the concrete matrix which was able to hold in more water. It can be concluded that specimens with lower fiber content are able to resist acid attack longer.

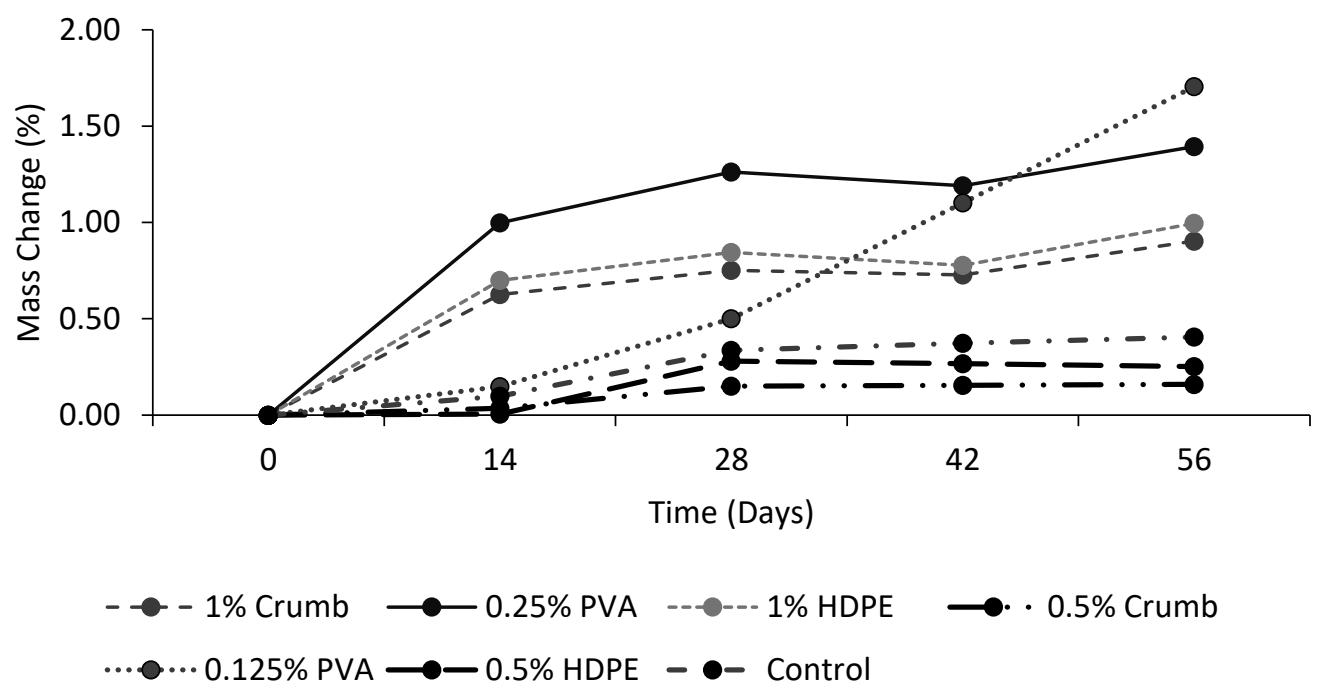

Figure 4.35: Mass Change of Specimens Submerged in Water

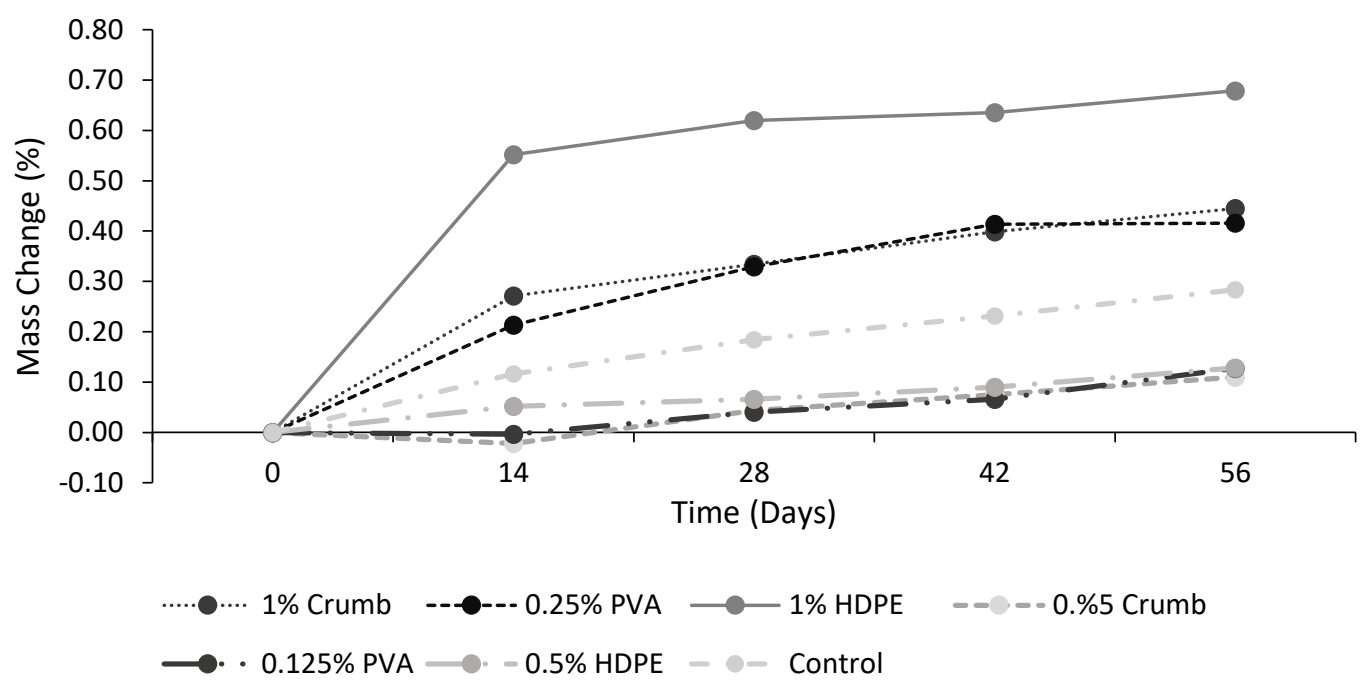

Figure 4.36: Mass Change of Specimens Submerged in 5\% NaCl Solution 


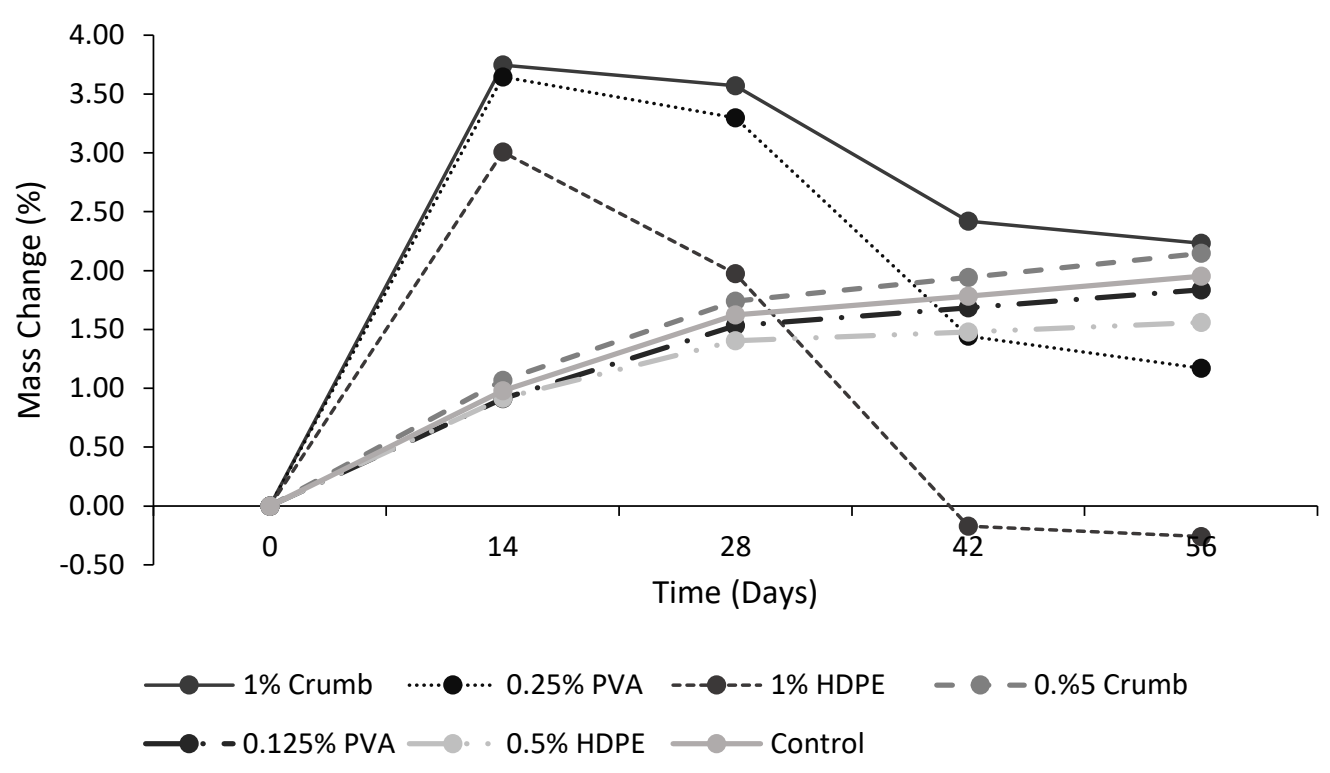

Figure 4.37: Mass Change of Specimens Submerged in $5 \% \mathrm{H}_{2} \mathrm{SO}_{4}$ Solution

Table 4.13: Total Absorption at 56 Days

\begin{tabular}{|c|c|c|c|}
\hline Specimen & Water (\%) & $\mathbf{5 \% ~ N a C l ~ ( \% ) ~}$ & $\mathbf{5 \%} \mathbf{~ H}_{\mathbf{2}} \mathbf{S O}_{\mathbf{4}} \mathbf{( \% )}$ \\
\hline 1\% Crumb Rubber & +0.9 & +0.44 & +2.23 \\
\hline $1 \%$ HDPE & +0.99 & +0.68 & -0.26 \\
\hline $0.25 \%$ PVA & +1.39 & +0.42 & +1.17 \\
\hline Control & +0.41 & +0.28 & +1.95 \\
\hline $0.5 \%$ Crumb Rubber & +0.16 & +0.11 & +2.14 \\
\hline $0.5 \%$ HDPE & +0.25 & +0.13 & +1.56 \\
\hline $0.125 \%$ PVA & +1.71 & +0.13 & +1.84 \\
\hline
\end{tabular}

+ : increase - : decrease

A similar trend in mass gain (maximum up to $0.70 \%$ ) was found for specimens immersed in $5 \%$ $\mathrm{NaCl}$ solution, where 1\% HDPE specimen had a higher mass in the first two weeks than the rest of the specimens. These specimens were placed back in the solution to allow for the solution to cause deterioration and provide mass loss. Therefore, it could have affected the compressive strength significantly. Total absorption that occurred at end of the 56-day duration is summarized in Table 4.13. A positive result depicts mass was absorbed wile a negative result as shown in 1.0\% HDPE shows no solution was absorbed due to deterioration. In addition, 0.25\% PVA specimen has a lower mass loss compared to the other specimens because of the denser concrete matrix due to the shorter fibers that had better interlocking of the aggregate and cement in the ITZ. Another reason for no mass loss in these specimens can be due to the advantages of silica 
fume and fly ash. In a previous research, it was found that the use of silica fume and fly ash increased the resistance to salt scaling (Lotfy et al. 2016). Specimens with lower fiber content exhibited lower absorption submerged in water and $5 \% \mathrm{NaCl}$ solution at the end of the experiment compared with specimens with higher fiber content, while those submerged in $5 \%$ sulfuric acid solution had more mass gain.

The specimens in the sulfuric acid solution started show a decrease in mass as in Figure 4.33, where 1\% HDPE had mass loss at 6 weeks. This trend is consistent with the other specimens and it can be said that with a longer duration of submergence in the solution the higher the mass loss due to aggressive attack of the sulfuric acid solution.

Figure 4.37 compares the compressive strength of LWSCFRC specimens immersed in water and sulfuric acid solution for 56 days while Table 4.14 shows mass loss due to the change in compressive strength. A correlation can be seen between the change in compressive strength and change in mass. Since there was only mass gain for the specimens in water, the compressive strength increased, which can be attributed to no physical deterioration and increase in load capacity. Furthermore, 0.25\% PVA, 1.0\% HDPE, 1.0\% Crumb Rubber and 0.5\% Crumb Rubber specimens in the sulfuric acid solution revealed a loss of compressive strength which was due to the spalling of the concrete resulting in lower load capacity. 1\% Crumb Rubber solution exhibited a higher loss in compressive strength between water and sulfuric acid solution, with a loss of approximately $43 \%$. The plastic nature of the crumb rubber fibers has poor bonding behavior between the aggregate, cement and fibers, therefore causing more sulfuric acid solution to attack the specimen. All fiber specimens exhibited lower compressive strength compared to the control specimen, where $0.25 \%$ PVA exhibited the lowest loss in compressive strength of $7.32 \%$ due to cement paste deterioration and the exposure of PVA fibers. In addition, the lower fiber content revealed an increase in the change of compressive strength except for $0.5 \%$ Crumb Rubber, which is due to poor bonding performance of the fibers and paste. Overall, 0.5\% HDPE had similar compressive strength with respect to the control specimen. 


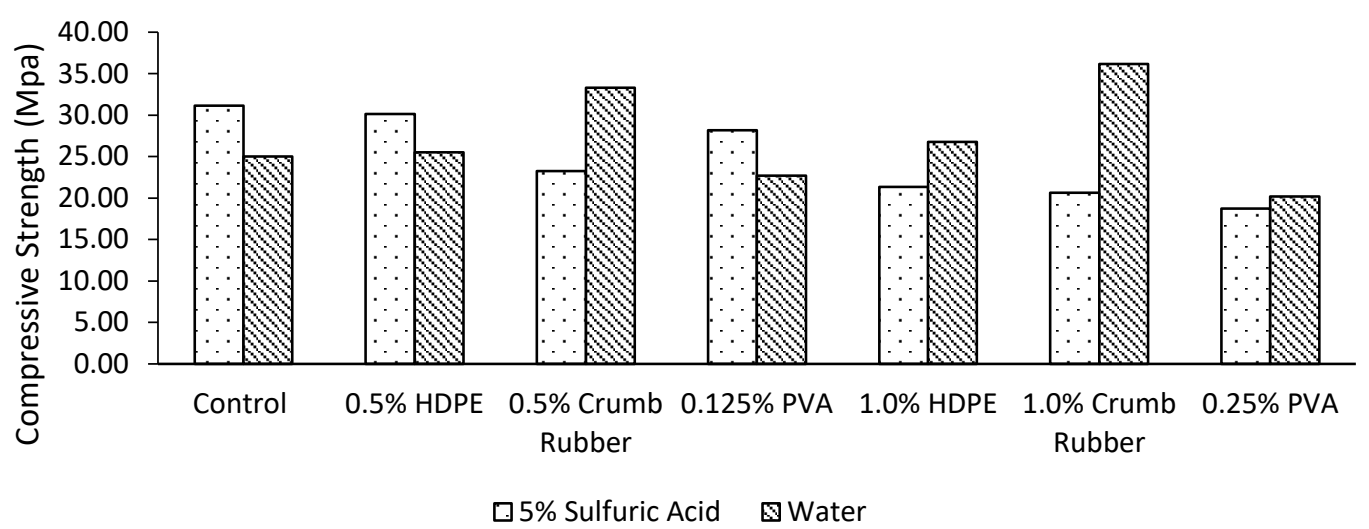

Figure 4.38: Comparison of Compressive Strength between 5\% Sulfuric Acid Solution and Water Table 4.14: Percentage Change in Compressive Strength

\begin{tabular}{cc}
\hline Specimen & Change in Compressive Strength \\
\hline $0.25 \%$ PVA & $-7.23 \%$ \\
\hline $1 \%$ HDPE & $-20.38 \%$ \\
\hline Crumb Rubber & $-42.87 \%$ \\
\hline Control & $+24.55 \%$ \\
\hline $0.125 \%$ PVA & $+24.12 \%$ \\
\hline $0.5 \%$ HDPE & $+18.24 \%$ \\
\hline $0.5 \%$ Crumb Rubber & $-30.26 \%$ \\
\hline
\end{tabular}

+: increase -: decrease

The eight-week duration for specimens submerged in the sulfuric acid solution revealed the start of deterioration which significantly affected the compressive strength. The loss in compressive strength can be attributed to the porous nature of the aggregates. The increased permeability and absorption capacity of the aggregate caused more acid to be penetrated into the specimen causing more deterioration and loss in strength. However, the addition of silica fume which creates an external layer of protection by forming Calcium Silicate Hydrate (C-S-H), has helped to lower the amount of deterioration and lower mass loss in the concrete specimens submerged in sulfuric acid solution as found in the case 0.25\%PVA (Lotfy et al. 2016). 


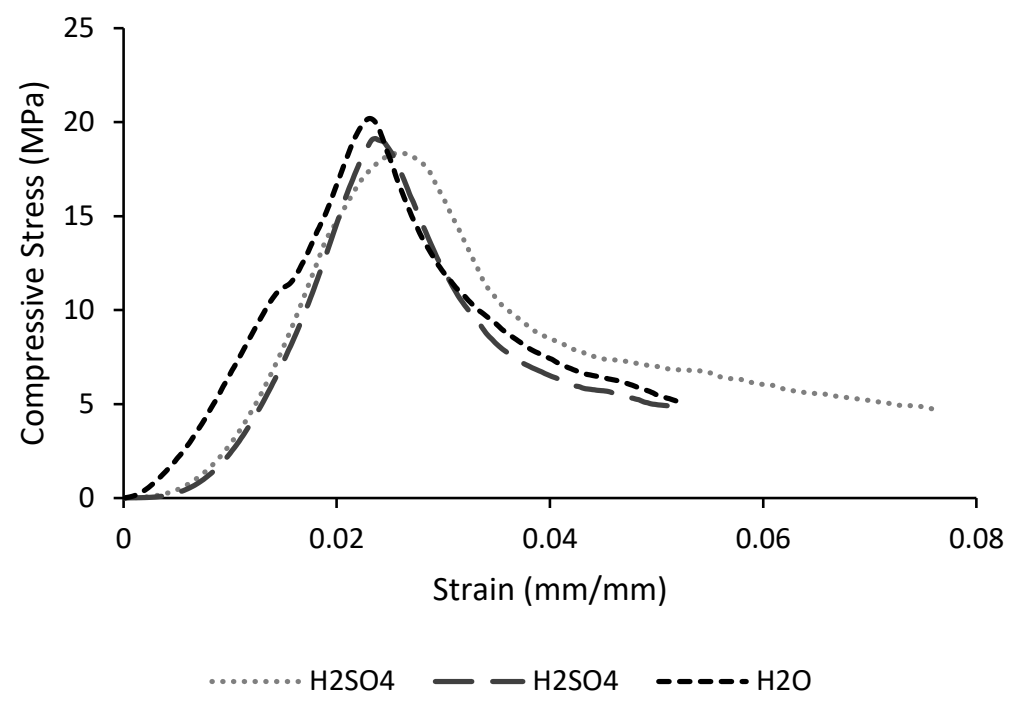

Figure 4.39: Stress - Strain Curve for 0.25\% PVA

The stress verses strain curve for all the specimens in each solution has been found by using the load deflection curve obtained from the compressive test and the original cross sectional area and height of the specimens. Figures $4.38-4.44$ display the stress - strain curve for all specimens. The curves for $0.25 \%$ PVA and 1\% HDPE display similar trends between the specimens in $5 \%$ sulfuric acid solution and water. The specimens in water exhibited a higher stress compared to the specimens in the sulfuric acid solution which is due to water being non-detrimental; therefore, the specimen was able to absorb more energy before failing.

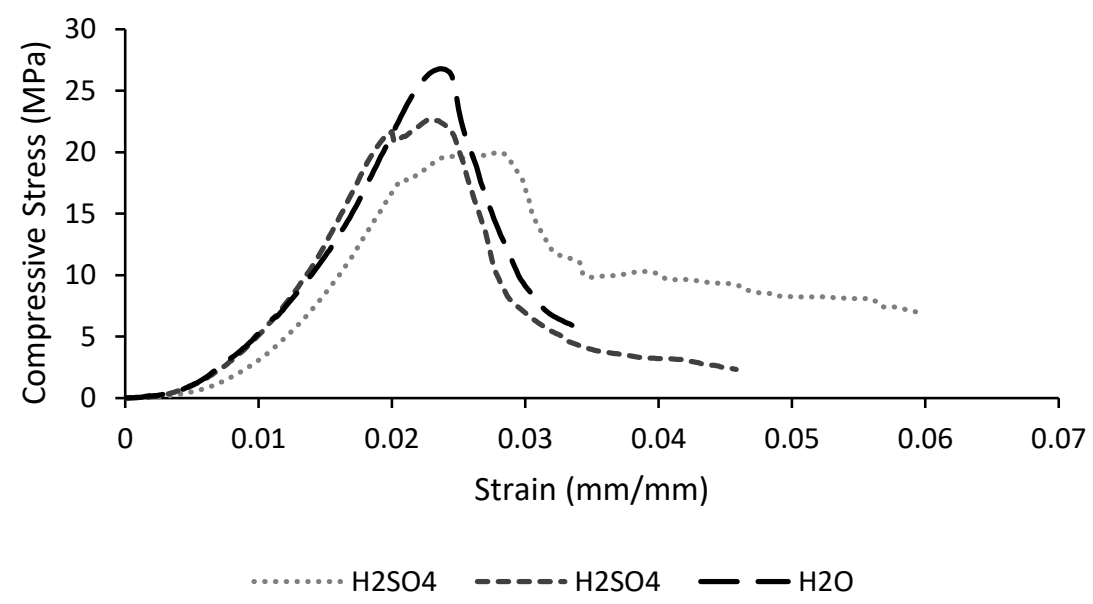

Figure 4.40: Stress - Strain Curve for 1.0\% HDPE 


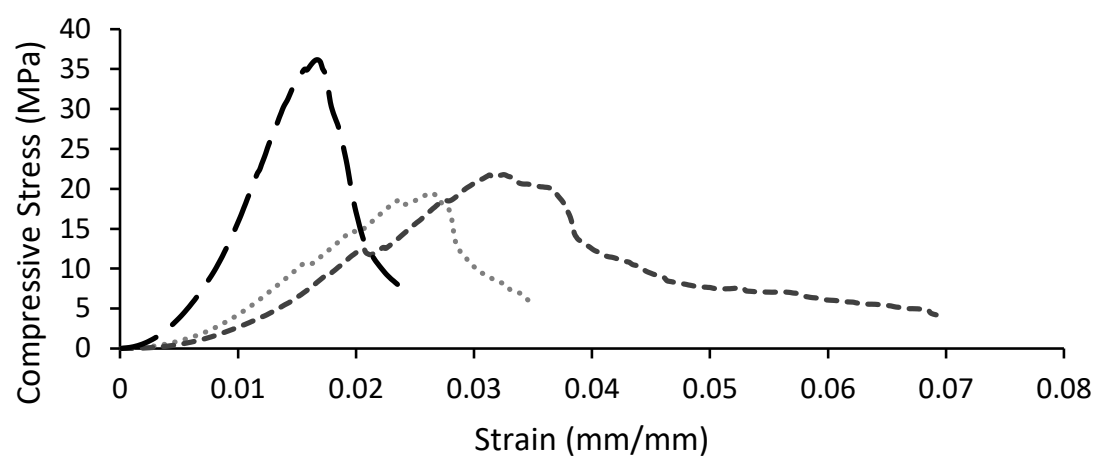

$\mathrm{H} 2 \mathrm{SO} 4----\cdot \mathrm{H} 2 \mathrm{SO} 4--\mathrm{H} 2 \mathrm{O}$

Figure 4.41: Stress - Strain Curve for 1.0\% Crumb Rubber

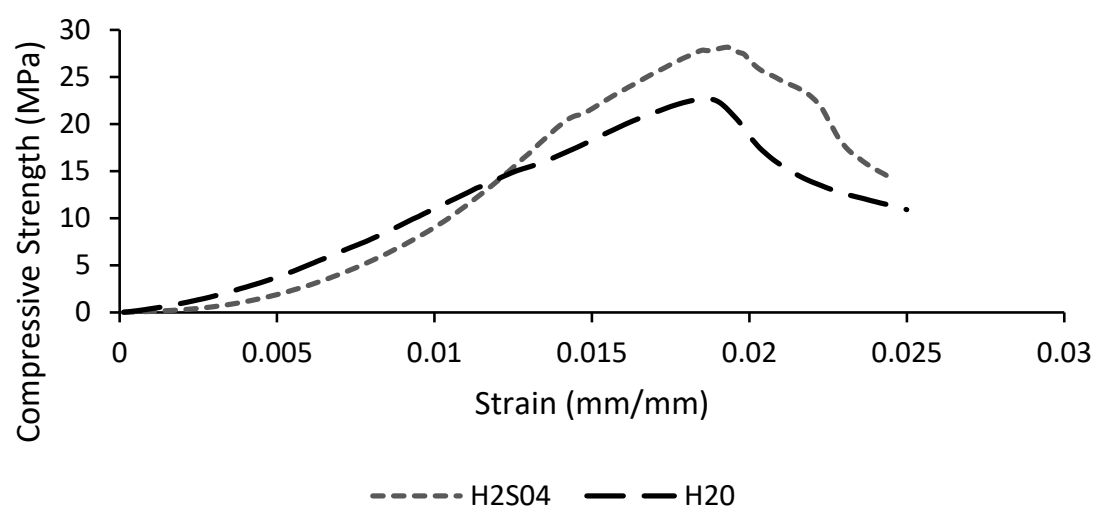

Figure 4.42: Stress - Strain Curve for 0.125\% PVA

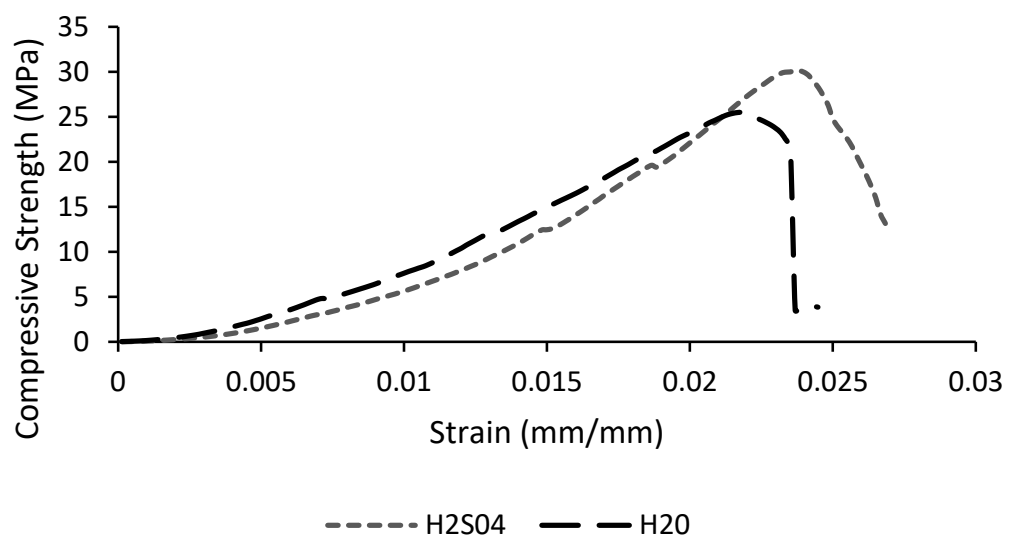

Figure 4.43: Stress - Strain Curve for 0.5\% HDPE 


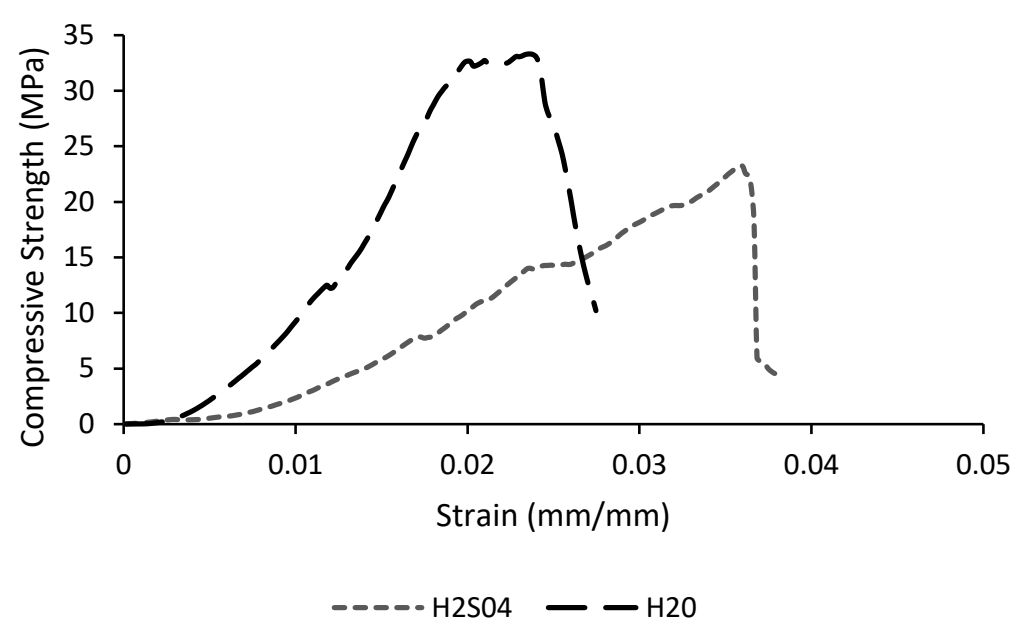

Figure 4.44: Stress - Strain Curve for 0.5\% Crumb Rubber

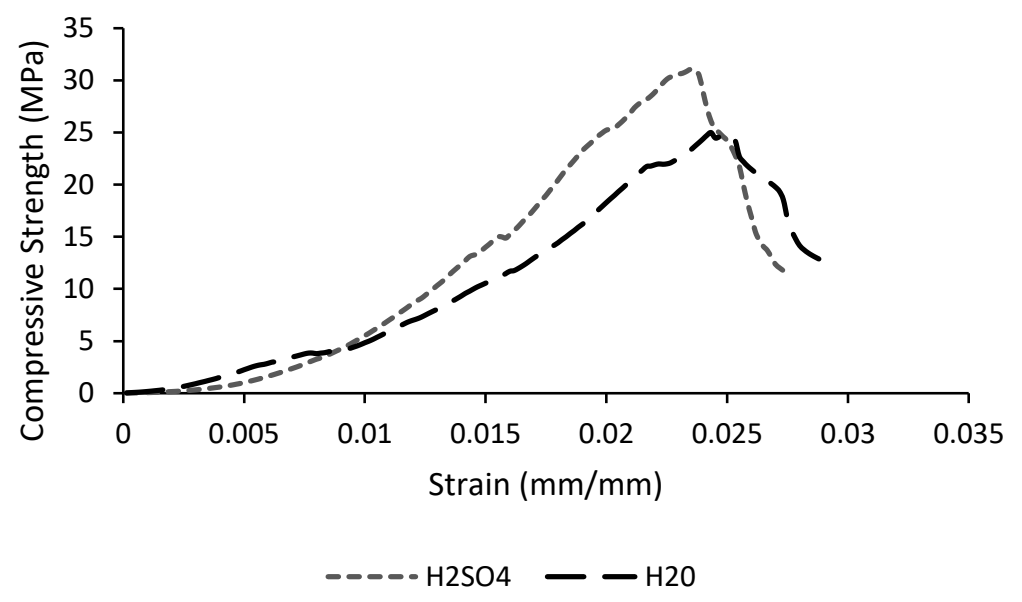

Figure 4.45: Stress - Strain Curve for Control

The stress verses strain curve for $1 \%$ Crumb Rubber exhibits a difference in the curve between the specimen in the sulfuric acid solution and the specimen in water. The specimens in sulfuric acid solution displayed a lower ratio between stress and the corresponding strain, which is due to deterioration of the specimens causing a lower absorption of energy, therefore the specimens failed under lower stress. For all the curves, the range leading up to the rupture point reveals that the specimens are brittle because there are no signs of slowing of the deformation before the failure point. 


\section{Chapter 5: Conclusion and Recommendations for Future Research}

Studies

\subsection{Conclusions}

Lightweight self-consolidating fiber reinforced concrete (LWSCFRC) is a new technology. This research has investigated the influence of different types and contents of fibers on fresh state (slump flow and density), mechanical (compressive and flexural strength) and durability (rapid chloride permeability " $\mathrm{RCP}$ ", freeze-thaw resistance and resistance to $\mathrm{H}_{2} \mathrm{SO}_{4}$ and $\mathrm{NaCl}$ attack) properties of LWSCFRC. Eight LWSCFRC mixtures in addition to one control concrete (without fiber) made of four different types of fibers (polyethylene 'PE', high density polyethylene 'HDPE', Crumb Rubber and polyvinyl alcohol 'PVA') and varying fiber content from $0.25 \%$ to $1.0 \%$ were used in this investigation. The addition of fibers decreased the workability of the concrete mixes as fibers tend to form more clumps, absorb water and make the mix dry. Therefore, concrete mixtures were adjusted accordingly to be able to offset the poor workability caused by the addition of fibers. Fresh state properties of the mixtures were observed by slump flow and density, while the mechanical properties were investigated by 7 and 28-days compressive strength and 28-days flexural strength. The durability properties were evaluated by rapid chloride penetration test and acid attack using $5 \%$ sulfuric acid solution and $5 \%$ sodium chloride solution. The following conclusions are drawn from the study:

- The increase in fiber content decreased the workability due to clumping that occurred in the mixing phase. Furthermore, due to the use of slag lightweight aggregate (LWA), more water was absorbed because of the increased porosity, which increased the fresh density of the mixtures. The oven dry densities were significantly lower than the fresh density because more water was evaporated. The top three mixtures that provided a higher slump flow were made of $1.0 \%$ Crumb Rubber, $0.5 \%$ Crumb Rubber and $0.5 \%$ HDPE with slump flow values of 750,680 and $650 \mathrm{~mm}$, respectively.

- Similar to previous research studies, the analysis of mechanical properties of the LWSCFRC specimens revealed that there was not much improvement to the compressive and flexural strengths by the addition of fibers. The 28-day compressive strength of all 
LWSCFRC specimens was found to be lower than the control specimen (without fiber). The top three LWSCFRC mixes that had the highest compressive strength were made of 1.0\% Crumb Rubber, 0.5\% HDPE and 1.0\% HDPE with 37, 35 and $34 \mathrm{MPa}$, respectively. The top three LWSCFRC mixes with the highest flexural strength were made of $1.0 \%$ Crumb Rubber, 0.5\% HDPE, and 1.0\% HDPE with 1.14, 1.09 and $1.08 \mathrm{MPa}$, respectively. The fibers were able to propagate cracks better and therefore resulted in lower crack widths. This decrease was a result of some clumping of fibers that resulted in insufficient crack propagation. A good correlation between the oven dry density and the 28-days compressive strength revealed that the increase in density also increased the compressive strength of the specimens. This was attributed to the denser concrete matrix and better bonding between the fibers and the paste in the ITZ. Most of the concrete mixtures satisfied the criteria for structural LWSCFRC based on slump flow, density and compressive strength.

- The durability performance of the specimens revealed both positive and negative effects of using fibers in LWSCFRC. Due to the denser concrete matrix in specimens with fibers, the chloride ion penetration resistance was found to have a rating of 'low' or 'very low', except for LWSCFRC with 1\% PE which had a 'high' chloride ion permeability. The better interlocking of fibers with the aggregate and paste in the ITZ showed significant benefits in improving chloride ion penetration resistance.

- It was concluded that there was no mass loss of specimens submerged in water and sodium chloride solution but the specimens in sulfuric solution displayed a decreasing trend of mass loss starting at the second week. Specimens that had longer fibers such as HDPE exhibited higher mass gain due to the creation of more voids which allowed more liquids to be stored in the specimen. 1\% HDPE LWSCFRC specimens submerged in sulfuric acid solution for eight-week duration exhibited mass loss at the six-week mark. Specimens with lower fiber content exhibited a higher resistance to acid attack than those with higher fiber content. A correlation between mass loss and compressive strength revealed that as the mass loss increased, the compressive strength decreased. The compressive strength of specimens in sulfuric acid significantly decreased. The highest loss of 
compressive strength (about 43\%) was noted for $1 \%$ Crumb Rubber LWSCFRC specimens. This significant decrease can be due to the plastic nature of the crumb rubber and the poor bonding between the fiber and the paste. In addition, the toughness of the specimens submerged in the sulfuric acid solution was lower compared to those in water. Overall, fiber specimens revealed no improvement in resisting acid attack compared to the control specimen.

- Compared to the control concrete specimens, 1.0\% Crumb Rubber specimen performed better in mechanical properties, while those with $0.5 \%$ and $1.0 \%$ PE fibers performed worst in both fresh state and mechanical properties. Furthermore, 1.0\% Crumb Rubber specimen provided a higher compressive strength compared to the other specimens submerged in sulfuric acid.

\subsection{Recommendations for Future Research}

The following recommendations are made for future research studies:

- Continue the durability tests under chloride and acid environment for extended duration and analyze the change in compressive strength.

- Similar investigations should be conducted on LWSCFRC with other types of fibers and comparisons should be made with current analysis.

- Conducting research on developing LWSCFRC mixtures with optimal fiber content and combination of fibers for improvement of mechanical and durability properties.

- Creating of structural members using the concrete mixtures in this report to understand loading behaviour under structural applications.

- Lastly research should be summarized, and an implementation method should be discussed on how specific standards and codes be improved to incorporate LWSCFRC in construction. 


\section{References}

ACl Committee 213. (2014). A213R-14 Guide for Structural Lightweight-Aggregate Concrete. Farmington Hills: American Concrete Institute, USA.

ACl Committee 237. (2007). ACl 237R - 07 Self-Consolidating Concrete. Farmington Hills: American Concrete Institute, USA.

ACl Committee 318. (2014). 318-14 Building Code Requirments for Structural Concrete and Commentary. Farmington Hills: American Concrete Institute, USA.

ACl Committee 544. (2001 ). ACI 544.1R - 96 State-of-the-Art Report on Fiber Reinforced Concrete . American Concrete Institute, USA.

Afroughsabet, V., \& Ozbakkaloglu, T. (2015). Mechanical and Durability Properties of HighStrength Concrete Containing Steel and Polypropylene Fibers. Construction and Building Materials, 94, 73-82.

Ali, A., Iqbal, S., Holschemacher, K., \& Bier, T. A. (2016). Effect of Fibers on Bond Performance of Lightweight Reinforced Concrete. Periodica Polytechnica, 60(1), 97-102.

Arisoy, B., \& Wu, H.-C. (2008). Material Characteristics of High Performance Lightweight Concrete Reinforced with PVA. Construction and Building Materials, 22(4), 635-645.

ASTM C1202 (2012). Standard Test Method for Electical Indication of Concrete's Ability to Resist Chloride Ion Penetration. West Conshohocken: ASTM International .

ASTM C469/C469M (2014). Standard Test Method for Static Modulus of Elasticity and Poisson's Ratio of Concrete in Compression. West Conshohocken : ASTM International .

ASTM C1609/C1609M (2012). Standard Test Method for Flexural Performance of Fiber-Reinforced Concrete (Using Beam with Third-Point Loading). West Conshohocken: ASTM International.

ASTM C1611/C1611M (2014). Standard Test Method for Slump Flow of Self-Consolidating Concrete. West Conshohocken: ASTM International. 
ASTM C567/C567M (2014). Standard Test Method for Determining Density of Structural Lightweight Concrete. West Conshohocken: ASTM International.

ASTM C666/C666M (2015). Standard Test Method for Resistance of Concrete to Rapid Freezing and Thawing. West Conshohocken: ASTM International.

ASTM C192/C192M (2016). Standard Practice for Making and Curing Concrete Test Specimens in the Laboratory. West Conshohocken: ASTM International.

ASTM C39/C39M (2016). Standard Test Method for Compressive Strength for Cylindrical Concrete Specimens. West Conshohocken: ASTM International.

ASTM C330/C330M (2014). Standard Specification for Lightweight Aggregates for Structural Concrete. West Conshohocken: ASTM International.

Bagherzadeh, R., Pakravan, H. R., Sadeghi, A.-H., Latifi, M., \& Merati, A. A. (2012). An Investigation on Adding Polypropylene Fibers to Reinforce Lightweight Cement Composites (LWC). Journal of Engineered Fibers and Fabrics, 7(4).

BASF. (2015). MasterGlenium 7700 High Range Water - Reducing Admixture. BASF Corporation, Canada.

BASF. (2016). MasterLife SF 100 Densified Silica Fume Mineral Admixture. BASF Corporation, Canada.

Bhavi, B. K., Reddy, V. V., \& Ullagaddi, P. (2012). Effect of Different Percentages of Waste High Density Polyethylene (HDPE) Fibres on the Properties of Fibre Reinforced Concrete. Nature Environment and Pollution Technology, 11(3), 461-468.

Chia, K. S., \& Zhang, M.-H. (2002). Water Permeability and Chloride Penetrability of High Strength Lightweight Aggregate Concrete. Cement and Concrete Research, 32(4), 639 645.

Choi, Y. W., Kim, Y. J., Shin, H. C., \& Moon, H. Y. (2006). An Experimental Research on the Fluidity and Mechanical Properties of High Strength Lightweight Self Compacting Concrete. Cement and Concrete Research, 36(9), 1595-1602. 
Corinaldesi, V., \& Moriconi, G. (2015). Use of Synthetic Fibers in Self-Compacting Lightweight Aggregate Concretes. Journal of Building Engineering, 4, 247-254.

Doukakis, J. P. (2013). Lightweight Self Consolidating Fiber Reinforced Concrete. Ann Arbor: ProQuest.

Foti, D. (2013). Use of Recycled Waste Pet Bottles Fibers for The Reinforcement of Concrete. Composite Structures, 96, 396-404.

Gencel, O., Ozel, C., Brostow, W., \& Martinez-Barrera, G. (2011). Mechanical Properties of SelfCompacting Concrete Reinforced with Polypropylene Fibers. Material Research Innovations, 15(3), 216-225.

Gesoglu, M., \& Guneyisi, E. (2007). Strength Development and Chloride Penetration in Rubberized Concretes with and without Silica Fume. Materials and Structures, 40(9), 953964.

Gonen, T. (2015). Mechanical and Fresh Properties of Fiber Reinforced Self-Compacting Lightweight Concrete. Scientia Iranica, 22(2), 313-318.

Gupta, K., \& Singla, S. (2014). Improving Mechanical Properties of Self Compacting Light Weight Concrete on Mixture (SCLWC) with Fiberglass. International Journal of Civil Engineering, 1(1), 1-2.

Hossain, K. M. (2004). Properties of Volcanic Pumice Based Cement and Lightweight Concrete. Cement and Concrete Research, 34(2), 283-291.

Hossain, K. M., Ahmed, S., \& Lachemi, M. (2011). Lightweight Concrete Incorporating Pumice Based Blended Cement and Aggregate: Mechanical and Durability Characteristics. Construction and Building Materials, 25(3), 1186-1195.

Hossain, K. M., Lachemi, M., Sammour, M., \& Sonebi, M. (2013). Strength and Fracture Energy Characteristics of Self-Consolidating Concrete Incorporating Polyvinyl Alcohol, Steel and Hybrid Fibres. Construction and Building Materials, 45, 20 - 29. 
Iqbal, S., Ali, A., Holschemacher, K., \& Bier, T. A. (2015). Mechanical Propoerties of Steel Fiber Reinforced High Strength Lghtweight Self-Compacting Concrete (SHLSCC). Construction and Building Materials, 98, 325-333.

Karahan, O., Ozbay, E., Hossain, K. M., Lachemi, M., \& Atis, C. D. (2012, July/August). Fresh, Mechanical, Transport and Durability Properties of Self-Consolidation Rubberized Concrete. ACI Materials Journal, 109(4), 413-420.

Kayali, O., Haque, M. N., \& Zhu, B. (2003). Some Characteristics of High Strength Fiber Reinforced Lightweight Aggregate Concrete. Cement \& Concrete Composites, 25(2), 207-213.

Kim, Y. J., Choi, Y. W., \& Lachemi, M. (2010). Characteristics of Self-Consolidating Concrete Using Two Types of Lightweight Coarse Aggregates. Construction and Building Materials, 24(1), 11-16.

Lo, T. Y., \& Cui, H. Z. (2004). Effect of Porous Lightweight Aggregate on Strength of Concrete. Materials Letters, 58(6), 916-919.

Lotfy, A. (2012). Lightweight Self-Consolidating Concrete: Statistical Modelling, Mixture Design and Performance Evaluation. Toronto: Ryerson University. PhD Thesis.

Lotfy, A., Hossain, K. M., \& Lachemi, M. (2016). Durability Properties of Lightweight SelfConsolidating Concrete Developed with Three Types of Aggregates. Construction and Building Materials, 106, 43-54.

Manjunatha, J., Sanjith, J., Ashwini, B., \& Ranjith, A. (2015). Fibre Reinforced Self Compacting Concrete - A Review. International Journal of Science, Technology \& Management, 4(2), $120-124$.

Mazaheripour, H., Ghanbarpour, S., Mirmoradi, S. H., \& Hosseinpour, I. (2011). The Effect of Polypropylene Fibers on the Properties of Fresh and Hardened Lightweight SelfCompacting Concrete. Construction and Building Materials, 25(1), 351-358.

MiniFibers INC. (2016). Retrieved from MiniFibers INC.: http://www.minifibers.com/

Nycon. (2013). Nycon-PVA RECS15. Retrieved from Nycon: http://nycon.com/nycon-pva-recs15/ 
Park, Y.-D., Ferrara, L., \& Shah, S. P. (2007). A Method For Mix-Design of Fiber-Reinforced SelfCompacting Concrete. Cement and Concrete Research, 37(6), 957-971.

Perez-Pena, M., \& Mobasher, B. (1994). Mechanical Properties of Fiber Reinforced Lightweight Concrete Composites. Cement and Concrete Research, 24(6), 1121-1132.

Suprenant, B. A., \& Malisch, W. R. (1999). The Fiber Factor. The Aberdeen Group. Retrieved from The Fiber Factor.

Topcu, I. B., \& Uygunoglu, T. (2010). Effect of Aggregate Type of Properties of Hardened Self Consolidating Lightweight Concrete (SCLC). Construction and Building Materials, 24(7), 1286-1295.

Wang, H. T., \& Wang, L. C. (2013). Experimental Study on Static and Dynamic Mechanical Properties of Steel Fiber Reinforced Lightweight Aggregate Concrete. Construction and Building Materials, 38, 1146-1151.

Weiss, J. (2016 ). Research Interests. Retrieved from Purdue University : https://engineering.purdue.edu/ concrete/weiss/Researchlnt/RCP.html

Yehia, S., AlHamaydeh, M., \& Farrag, S. (2014). High-Strength Lightweight SCC Matrix with Partial Normal-Weight Coarse-Aggregate Replacement: Strength and Durability Evaluations. Journal of Material Civil Engineering, 26(11).

Yehia, S., Douba, A., Abdullahi, O., \& Farrag, S. (2016). Mechanical and Durability Evaluation of Fiber-Reinforced Self-Compacting Concrete. Construction and Building Materials, 121, 120-133. 